\title{
Die Untersuchung der paläolithischen Freilandstation von Salzgitter-Lebenstedt
}

Ein Vorbericht von A. Tode, F. Preul, K. Richter, W. Selle, K. Pf a f $f$ en berg, A. Kleinschmidt, E. Guenther; mit einem Anhang von A. Müller \&W. Schwartz.

\section{Einleitung}

(A. Tode). Mit 3 Abb.

Es mußte rasch gehandelt werden, als Anfang 1952 beim Bau der neuen Kläranlage nördlich von Salzgitter-Lebenstedt an der Straße nach Broistedt (Abb. 1: Ausschnitt aus dem Meßtischblatt 3827 Lesse) in der Baugrube des Pumpenhauses $5 \mathrm{~m}$ tief, - d. h. $4 \mathrm{~m}$ unter dem normalen Grundwasserspiegel - Dutzende von $\mathrm{Knochen}$ eiszeitlicher Tiere gefunden waren und der Verdacht bestand, daß mehrere auf dem Abraum neben der Grube gefundene F e u e r s t e in a r t e f a k t e paläolithischen Gepräges (Finder: Dr. ing. Kummer, Salzgitter) aus derselben Fundschicht stammen könnten.

Es ist das nicht hoch genug anzurechnende Verdienst des Heimatpflegers und Heimatforschers von Salzgitter, Stadtschulrat ZoBel, sofort telefonisch dem Braunschweigischen Landesmuseum als der amtlichen Stelle für die urgeschichtliche Bodendenkmalpflege im Niedersächsischen Verwaltungsbezirk Braunschweig Nachricht von dem Funde gegeben zu haben. Mancher Heimatfreund hätte vielleicht im Interesse einer vermeintlichen „Sicherung“ der Funde für das eigene Museum mit dem Finder der Artefakte nur ein Bodenprofil genommen und alle erreichbaren Funde aus der Schicht geborgen, bis der Platz einige Tage später nach Abschluß des Fundamentbaues für die Wissenschaft verloren gewesen wäre.

Von wie wenigen paläolithischen Fundplätzen haben wir aber neben einem gesicherten geologischen Bodenprofil einen ausreichenden archäologischen Fundbestand a us einer durch Fachgrabung gesicherten Lagerung! Das sollte bei diesem Platz einmal anders sein! Nachdem eine zweitägige Probeuntersuchung eine primäre Lagerung der Knochen und Artefakte bestätigt hatte, entschloß sich daher der Verfasser, im Interesse der Quartärforschung hier mit aller Kraft und mit allem Optimismus zuzupacken.

Eine gleich zu Anfang aufgestellte Grabungsplanung mit etwa DM 20000.Kosten, die zwar von Fachkollegen als viel zu großzügig angegriffen wurde, konnte in vollem Umfange zur Durchführung gebracht werden. Der Stadt Salzgitter, die sofort Mittel bereitstellte, damit die Grundwasserabsenkung im Gange bleiben konnte, der Deutschen Forschungsgemeinschaft und dem Herrn Niedersächsischen Kultusminister, die sodann weitere Forschungszuschüsse leisteten, sowie den zahlreichen Werken, Firmen und Privatspendern, die insgesamt unsere fast viermonatige Grabung mit den so reichen Ergebnissen ermöglicht haben, sei schon in diesem ersten Bericht herzlicher Dank gesagt!

Durch die sofortige Heranziehung sämtlicher Disziplinen der Quartärforschung hat sich der Verfasser als Leiter der Grabung bemüht, alle nur irgend möglichen Spezialerkenntnisse aus dem Fundplatz zu gewinnen, mußte doch bei 


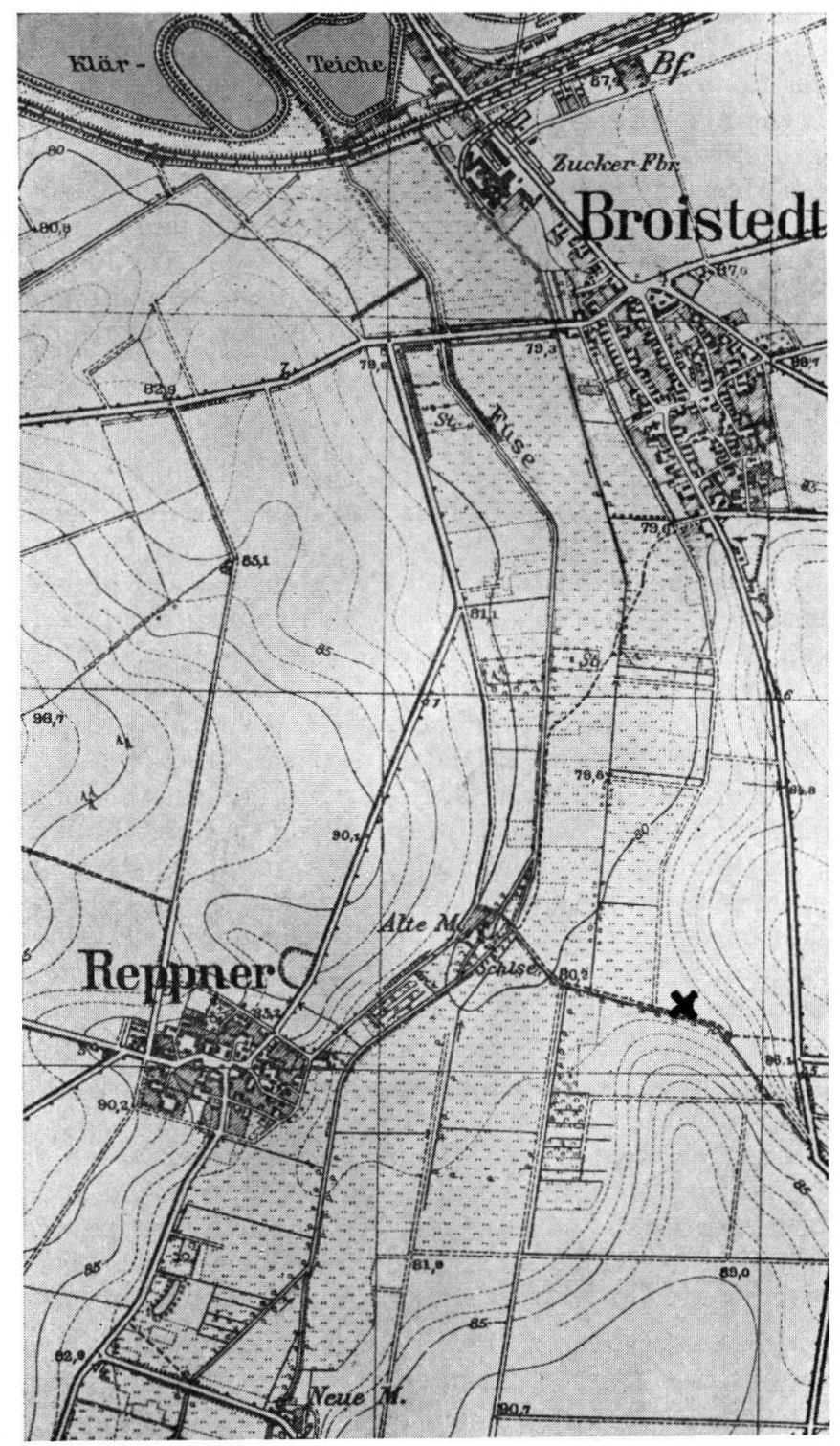

Abb. 1. Die Lage des Fundplatzes an der Gemarkungsgrenze Salzgitter-Lebenstedt/ Broistedt. Ausschnitt aus der Top. Karte 1: 25000 Blatt 3827 Lesse. Mit Genehmigung des Niedersächsischen Landesvermessungsamts vom 20. 4. 1953 - Kart. 1080 B.

genügend reichem Forschungsmaterial die so ermöglichte gegenseitige Ergänzung und Kontrolle der einzelnen Fächer den Gesamterfolg des Forschungsvorhabens erheblich vergrößern. Einige hauptbeteiligte Forscher kommen bereits in den folgenden vorläufigen Berichten zu Worte. Andere werden darüber hinaus im Rahmen der vom Amt für Bodenforschung, Hannover, geplanten Monographie über die paläolithische Station von Salzgitter-Lebenstedt ihren Beitrag veröffentlichen. 
Einen ganz besonderen Dank möchte ich den Herren Geologen vom Amt für Bodenforschung in Hannover sagen, die in voller Erkenntnis der Bedeutung des Fundplatzes für die Quartärgeologie trotz anderweitiger drängender Arbeiten einen wochenlangen Einsatz in Salzgitter ermöglichten und das geologische Ergebnis über die Frage der Datierung der Fundschichten hinaus erheblich verbreiterten. Dem Herausgeber dieses Jahrbuches, Prof. Dr. Woldstedt, der unsere Grabung mehrfach besuchte, und der mit seinem anspornenden Interesse auch die Vorberichte der einzelnen Mitarbeiter auf der Tagung in Krefeld veranlaßte, sei herzlichst gedankt für die Raum- und Abbildungsmöglichkeiten, die er dem Problem der paläolithischen Station von Salzgitter-Lebenstedt in dieser Zeitschrift einräumt!

Der Ausgangspunkt der Grabung war ein sauber abgestochenes, im Lackabzug gesichertes g o ologisches B odenprofil an der Nordwand der ziemlich steil ausgehobenen Baugrube des Pumpenhauses. Unter Verbreiterung der Baugrubensohle - Zurücklegung der Profilwand um etwa $1 \mathrm{~m}$ nach Norden hin - konnte ein unberührter, etwa $1,5 \mathrm{~m}$ breiter, West-Ost verlaufender Streifen als erster Versuch s chnit t (Fläche I) in mehreren Schichten untersucht werden. Durch die Verlängerung des Versuchsschnittes am Pumpenhaus entlang nach Osten (Fläche II/III) wurde dann ein Streifen von insgesamt $10 \mathrm{~m}$ Länge bis über $5 \mathrm{~m}$ Tiefe zur Untersuchung gebracht, vor allem, um Art und Ausdehnung der Fundschichten zu ermitteln. Der Reichtum an zoologischem Material und an Feuerstein-Artefakten (mehrere auf jedem Quadratmeter!) wurde schon in diesem ersten Schnitt klar. Später ist der Versuchsschnitt auch nach Westen hin noch um fast $5 \mathrm{~m}$ verlängert worden (Fläche 0 ), so daß insgesamt ein Profileinblick West-Ost durch die Fundschichten von fast $15 \mathrm{~m}$ Länge möglich geworden ist.

Wegen der für unsere Grabung noch nicht tief genug reichenden Grundwasserabsenkung konnte im Versuchsschnitt die Untersuchung zunächst nur bis etwas über 5,0 m Tiefe geführt werden, so daß also das Liegende der Fundschichten noch nicht erreicht wurde. (Diese untersten Schichten sind später im Zusammenhang mit der Hauptfläche untersucht worden.) Um aber den Umfang des Gesamtvorhabens schon am Anfang besser abschätzen zu können, wurde durch kleine, die Fundschichten möglichst schonende Versuchslöcher und Handbohrungen versucht, die Gesamtmächtigkeit der Fundschichten zu bestimmen.

Als die Bewilligung größerer Mittel gesichert war, entschloß sich der Verfasser, eine Hauptfläche von $10 \times 12 \mathrm{~m}$ nördlich des Pumpenhauses für die Untersuchung freizulegen. Erst aus einer solchen Fläche war ein ausreichendes wissenschaftliches Ergebnis zu erhoffen. Dadurch daß diese Fläche nach Norden hin, also in Richtung auf den natürlichen Hang des Tales genommen wurde, konnte dabei Aussicht bestehen, die Grenzen der besonders stark knochenführenden humosen Schichten und damit die eigentlichen menschlichen Lagerplätze am Talhang zu erreichen.

Die Hauptfläche (Fläche IV) ist nach Abdeckung der oberen fundleeren Schichten mit dem Greifbagger und nach Erweiterung des Pumpsystems um zwei weitere, $8 \mathrm{~m}$ tiefe Brunnen mit etwa $20 \mathrm{~m}$ Leitungen in den Monaten April und Mai 1952 in aller Gründlichkeit bis zum Liegenden der Fundschichten untersucht worden (Abb.2). Durch die Hilfe der Bundesgrenzschutzabteilung in Braunschweig und durch die erwähnten hochherzigen Spenden braunschwei- 


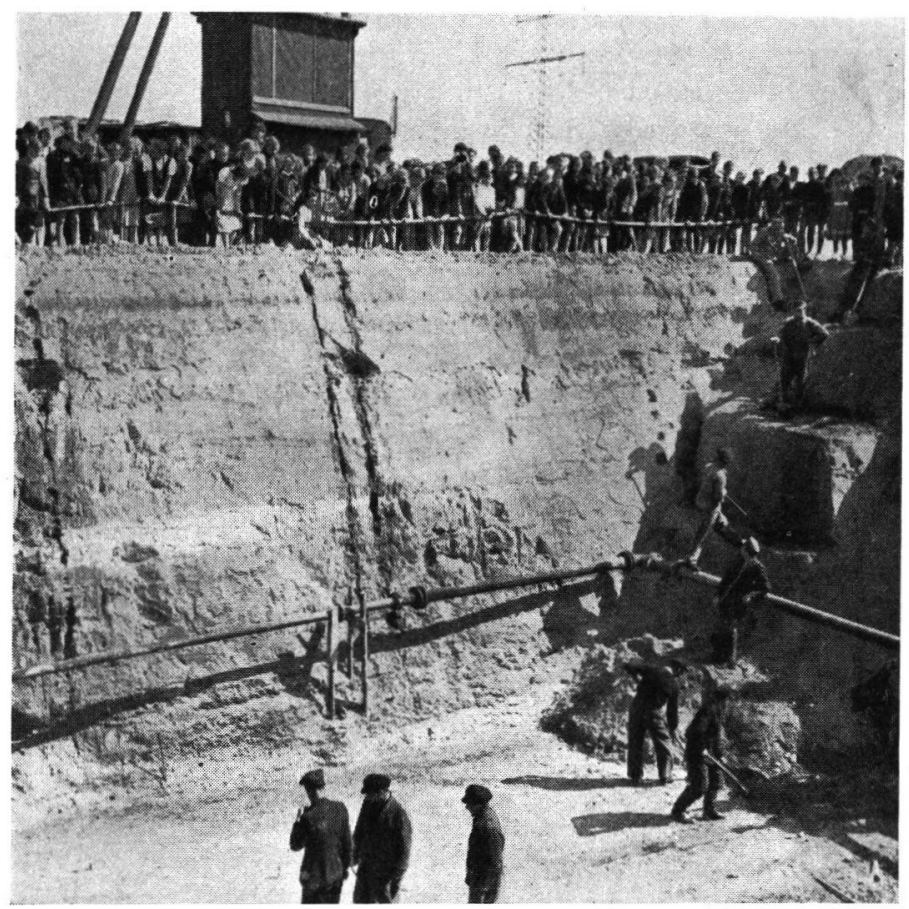

Abb. 2. Die Hauptgrube während der Ausgrabung.

gisch-hannoverscher Werke und Unternehmen wurde es möglich, die Hauptfläche IV nach der besonders fundreichen Westseite hin noch zu erweitern (Abb. 3). Wertvolle Funde und Aufschlüsse konnten darüber hinaus in einer $15 \mathrm{~m}$ westlich des Pumpenhauses gelegenen weiteren Baugrube („Sandfang“) gewonnen werden.

Die angewandte $\mathrm{Gr}$ a b ung s t e c h n i k entspricht den modernen Methoden einer Siedlungsgrabung mit Abdeckung der Fundschichten in dünnen Lagen, wobei Funde und Erdverfärbungen in Art und Ausdehnung zur späteren Deu-

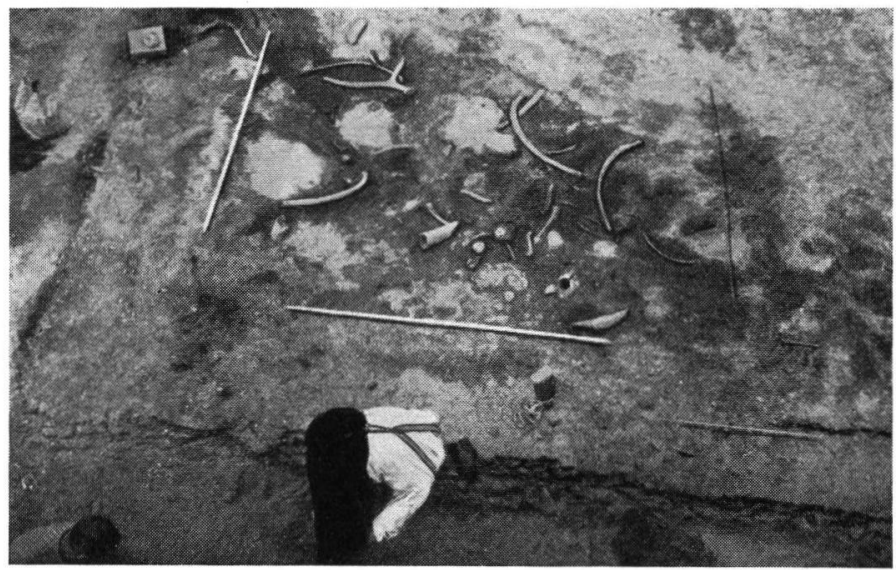

Abb. 3. Typisches Bild der Fundschicht. 
tung des Gesamtbefundes in Plänen, Profilen und Fotos festgehalten werden. Aus der Untersuchung der zahlreichen an Spezialforscher gegebenen Schichtund Materialproben und aus der Bestimmung der zunächst nur sorgfältig registrierten Funde der einzelnen Schichten ergibt sich dann das Gesamtergebnis, das erst nach längeren Auswertungsarbeiten vorgelegt werden kann.

An wissenschaftlichen und technischen Kräften waren außer dem Verfasser ständig etwa 8 Personen im Einsatz, und zwar zwei Prähistoriker (Dr. F. Niquet, Braunschweig, oder Frau G. STelzer, Braunschweig), ein Photograph (W. ReNnau), zwei Zeichner (O. Rothenstein und R. Fricke), ein Präparator (F. Grabau), ferner drei Museumstechniker und zwei Arbeiter, letztere in erheblichem Umfange auch für rein geologische Aufgaben eingesetzt.

Von den Geologen, die in größerer Zahl die Grabung besuchten und dort Studien machten, sind amtlich beteiligt vor allem der Landesgeologe Prof. Dr. Konrad Richter, Hannover (vgl. dessen Bericht) und der Bezirksgeologe Dr. F. Preul, Hannover. Letzterer unternahm im Auftrage des Amts für Bodenforschung umfangreiche Aufgrabungen, Bohrungen und Profilaufnahmen, über die er selbst in seinem Vorbericht erste Ergebnisse mitteilt.

Das zoologische Material bearbeitete Dr. KLEINSCHMIDT vom Naturhistorischen Museum, Braunschweig, die Pollenanalyse W. Selle, Braunschweig, das übrige botanische Material K. Pfaffenberg, Sulingen. Weitere Studienergebnisse auf Grund von Lebenstedter Material werden voraussichtlich später in der Monographie in Erscheinung treten. Durch Bodenproben, Gipsabgüsse, Lackabzüge sowie einen Kulturfilm ist die Grabung weitgehend auch für spätere Zeiten festgehalten. Die Bearbeitung ist auf allen Gebieten im Gange und soll möglichst im Winter 1953/54 zum Abschluß gebracht werden. 


\section{Die geologische Bearbeitung des paläolithischen Fundplatzes bei Salzgitter-Lebenstedt}

(F. Preul, Hannover, Amt für Bodenforschung.) Mit 3 Abb.

Die Fundstelle liegt westlich der Straße Lebenstedt-Broistedt an der Einmündung des Krähenriede-Baches in das Fuhse-Tal am Fuß der MittelterrassenHochfläche (vgl. Abb. 1). Das Tal, in dem heute Flothe und Fuhse fließen, ist früher einmal von einer „Ur-Innerste“ bzw. von einer „Ur-Nette“ benutzt und ausgestaltet worden. Die beiden Flüsse entwässern jetzt über Derneburg zur Leine, sind aber im Pleistozän zeitweise über den $\mathrm{Paß}$ von Grasdorf nach Nordosten abgeflossen (vgl. P. Woldstedt 1928, H. Spreitzer 1931). Sie haben die Mittelterrasse aufgeschottert, die danach von der Grundmoräne der SaaleHauptvereisung überdeckt wurde. Später sind Geschiebemergel und Mittelterrassenschotter z. T. wieder ausgeräumt und eine Niederterrasse ausgebildet worden, welche heute noch in Resten am Rande der Mittelterrassen-Hochfläche einige Meter über der jüngeren Talaue sichtbar ist.

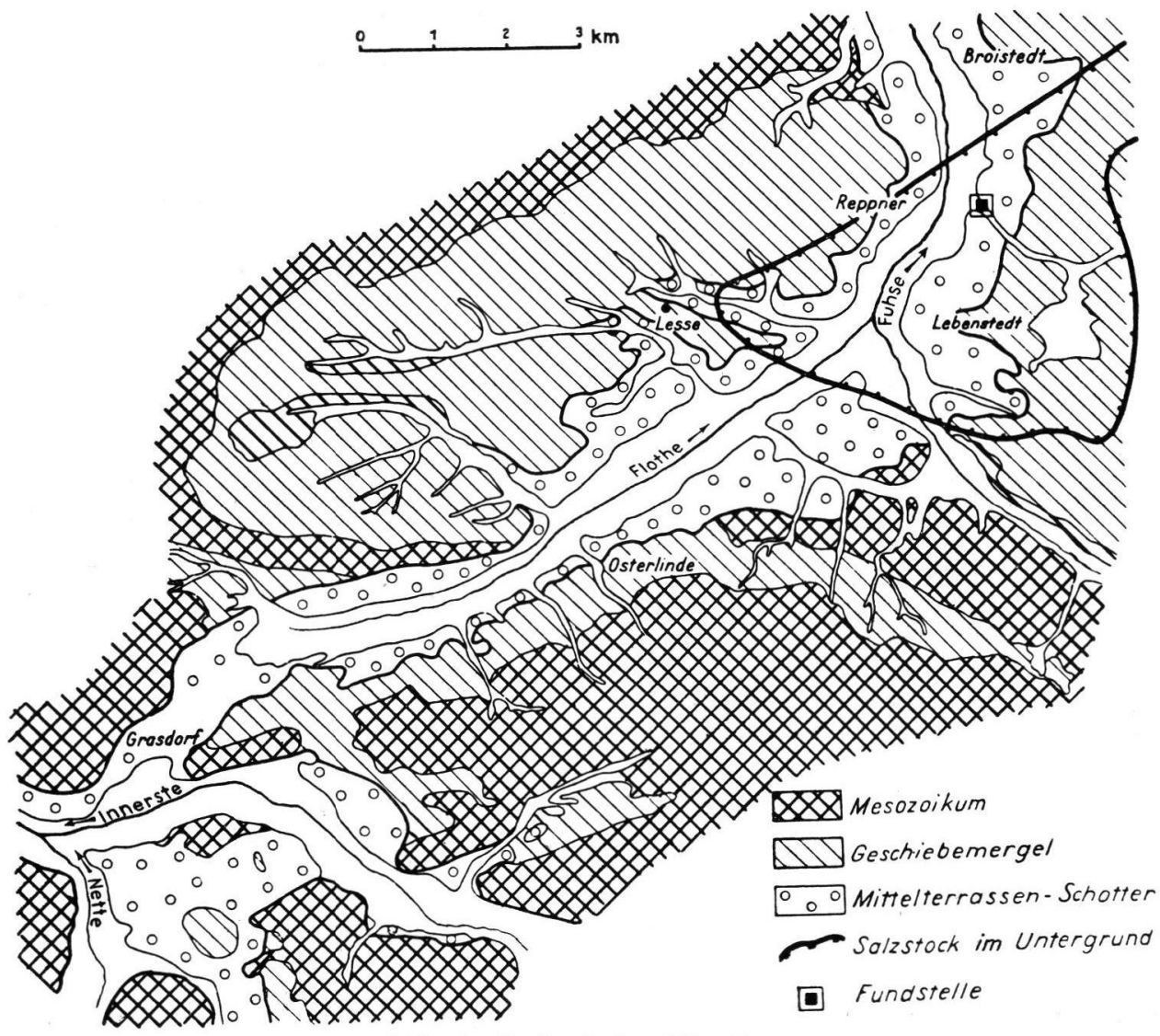

Abb. 1. Geologische Situation. 
Die Fundschichten liegen teils unter dieser kleinen Terrasse, teils unter der Talaue. Sie wurden an der zur Talaue hin abfallenden Böschung der Niederterrasse in einer rd. $15 \times 15 \mathrm{~m}$ großen Fläche freigelegt. Dabei entstand ein $6 \mathrm{~m}$ tiefer Anschnitt, der zusammen mit einer $15 \mathrm{~m}$ tiefen Erkundungsbohrung einen guten Aufschluß über den Aufbau des tieferen Untergrundes bot.

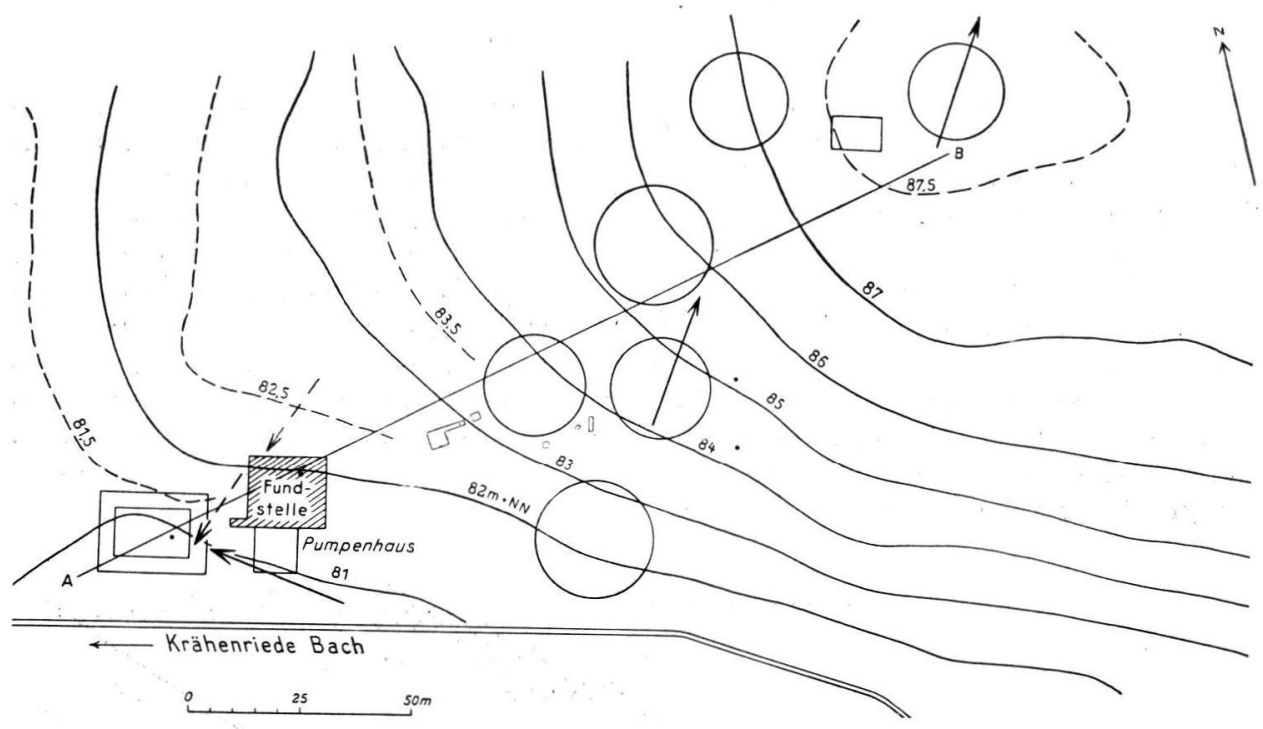

Abb. 2. Lageplan. Pfeile ausgezogen: Strömungsrichtungen; Pfeile gestrichelt: Gleitrichtungen; Linie A-B: Profillinie (vgl. Abb. 3 links).

Auf diese Weise wurde folgendes, hier zusammengefaßtes Profil erschlossen (vgl. den Lageplan Abb. 2 und das Profil Abb. 3):

Mächtigkeit in $\mathrm{m}$ :

0,5 Auelehm über auskeilendem alluvialem Torf der Talaue (Schicht "a" im Profil A.bb. 3.

$1-3,0 \quad$ Schluff, zum Liegenden hin zunehmend sand- und kieshaltig (" $b$ "). Steinlage aus vorwiegend einheimischen Geröllen vom Harz und aus dem Harzvorland ("c").

$1,0 \quad$ Schluff, ebenschichtig ("d").

$0,5 \quad$ Mittelsand, schräg geschichtet ("e").

2,0 Wechselfolge von Schluff und Sand, besonders im unteren Teil kiesstreifig, enthält im Schluffanteil z. T. reichlich Pflanzenreste und eine Schneckenfauna. Die Schichtenfolge ist stark durchbewegt (Fließerde "f").

1,5 Fundschichten. Vorwiegend einheimische Flußschotter mit einzelnen großen nordischen Geschieben. Unregelmäßig beckenförmige Einschaltungen von humosem Sand. Gelegentlich Einschaltungen geringmächtiger Torflinsen von örtlich beschränkter Ausdehnung. Frostbildungen nachweisbar ("g").

0,5 Sand, schräggeschichtet, mit Frostbodenstruktur ("h"). Steinlage aus großen nordischen Geschieben ("x-x").

$0,5 \quad$ Sand ("k").

10,0 Wechselfolge von einheimischen Fluß-Schottern und Sand mit einigen geringmächtigen Lehmeinlagerungen (erbohrt). ("s").

Eine ganz andere Schichtenfolge war weiter östlich, etwa $2 \mathrm{~m}$ unterhalb der Mittelterrassen-Hochfläche durch tiefe Ausschachtungen zum Bau eines Tropfkörpers der Kläranlage aufgeschlossen und erbohrt worden. 
Mächtigkeit in $\mathrm{m}$ :

0,5 Löß ("m“).

1,0 Fluß-Schotter, einheimisches Material in einer durch Frosteinwirkung unregelmäßigen Lagerung ("o“).

2 Sandiger Lehm und lehmiger Sand mit nordischen Geschieben. Fließerscheinungen ("p" und "q").

$6 \quad$ Kiessreifiger Sand mit überwiegend nordischem Geröllinhalt, schräggeschichtet ("r").

über 10 Wechselfolge von einheimischem Flußschotter und Sand (erbohrt).

Die Hauptaufgabe bei der Altersdeutung der Fundschichten bestand nun darin, das Altersverhältnis zwischen den beiden genannten Schichtenfolgen zu
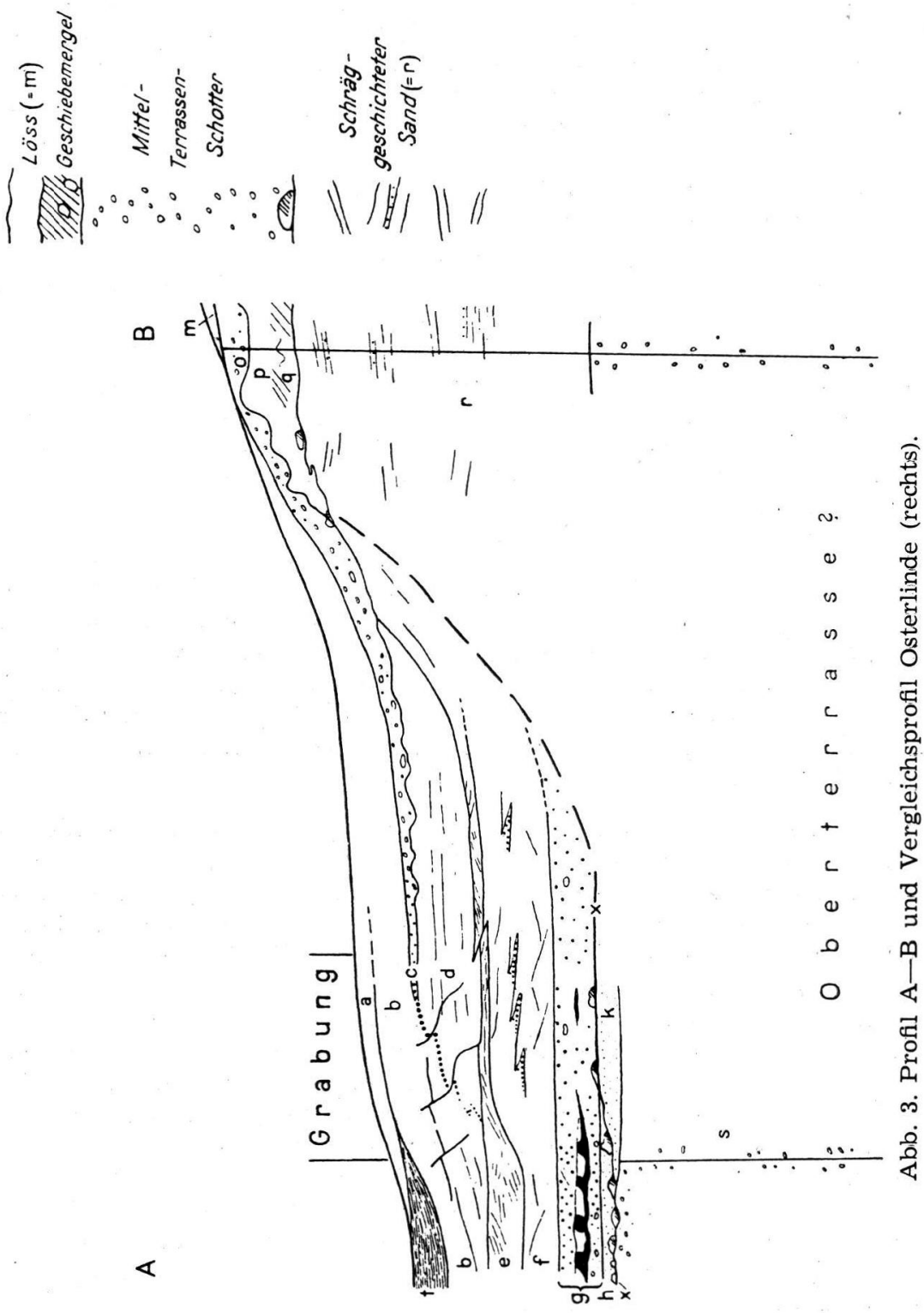
klären und zum „Normalprofil“ dieser Gegend, wie es in Osterlinde gefunden wurde, in Beziehung zu setzen.

Die von Löß bedeckten Fluß-Schotter in dem zuletzt genannten Profil sind Mittelterrassenschotter, wie die Kartierung der Blätter Lesse und Barum ergeben hat. Da wir wissen, daß sie vor der Saale-Hauptvereisung abgelagert wurden, sind sie uns eine wichtige Zeitmarke, von der die Altersdeutung ausgehen kann. Der Geschiebemergel der Saale-Hauptvereisung fehlt hier über den Mittelterrassenschottern. In den Aufschlüssen am westlichen Talrand ist noch das vollständige Profil mit Geschiebemergel über den Mittelterrassenschottern erhalten. Dort liegt unter den Mittelterrassenschottern vielfach schräggeschichteter Sand, wie das in Abb. 3 auf der rechten Seite dargestellte Profil von Osterlinde erkennen läßt. Hier dagegen wird der schräggeschichtete Sand zunächst von einer geschiebelehmähnlichen Fließerde überlagert, die nach den Bewegungsspuren an ihrer Basis von NNO gekommen ist; das entspricht annähernd dem heutigen Hanggefälle. Über dieser Fließerde liegen dann erst die Mittelterrassenschotter und zwar in verringerter Mächtigkeit. Die Fließerde könnte aus der Saale-Moräne entstanden sein. Diese müßte nach einer Erosionsphase unter periglazialen Klimabedingungen vom Rande der Mittelterrassenhochfläche - als ihrem ursprünglichen Ablagerungsraum - hangabwärts gewandert und danach von ebenfalls abwärts kriechenden Mittelterrassenschottern überdeckt worden sein. Der Nachweis einer Erosionsphase zwischen diesen beiden Fließvorgängen und einige andere Beobachtungen, die sich in dieses Bild und die vorhandene Kartierung nicht zwanglos einordnen lassen, erfordern eine weitere Überprüfung. Da diese Frage aber für die Altersdeutung der Fundschichten keine unmittelbare Bedeutung zu haben scheint, wird sie später an anderer Stelle ausführlich behandelt werden.

Die Hanglage der Fundstelle und das Vorhandensein des Salzstockes von Broistedt-Engelnstedt im Untergrund ließen es ratsam erscheinen, die gegenseitige Abgrenzung der beiden oben genannten Schichtenfolgen mit möglichst großer Sorgfalt unter Verwendung der verschiedensten Untersuchungsmethoden durchzuführen, zumal es zunächst den Anschein hatte, als könne die Pollenanalyse in diesem Fall für die Altersdeutung der Fundschichten keine brauchbaren Ergebnisse liefern. Die zwischen den beiden großen Aufschlüssen angelegten Schürfe gestatteten die Parallelisierung wichtiger Schichten.

Mit gutem Erfolg konnten hierzu Schottervergleiche benutzt werden. Es ergab sich nämlich bei der Bestimmung des Gewichtsanteiles einzelner Schotterkomponenten eine bemerkenswerte Gesetzmäßigkeit. Die eiszeitlichen Terrassenschotter dieser Gegend bestehen überwiegend aus Gesteinen des Harzes und dessen Vorlandes. Dabei scheint nach den bisher vorliegenden Untersuchungen der Gewichtsanteil des aus dem Harz stammenden Lydites (Kulmkieselschiefer) zusammen mit ähnlichen dunklen Kieselschiefern ohne besondere Gesetzmäßigkeit um bestimmte Mittelwerte zu schwanken, wenn man übereinander entnommene Schotterproben aus den benachbarten Terrassenaufschlüssen miteinander vergleicht. Hier ist das jedoch nur im unteren Teil der unter den Fundschichten erbohrten Schotterserie ("s") der Fall. Darüber nimmt der Lydit-Anteil zum Hangenden immer mehr zu, bis er in der Steinlage ("c") mit 70\% sein Maximum erreicht. Eine vorübergehende Unterbrechung erfährt diese Entwicklung - soweit die Bohrungen bisher bearbeitet sind - lediglich an der Basis der Fundschichten, indem dort der Lyditanteil plötzlich zurückgeht, dann aber nach oben hin — wie zuvor - allmählich ansteigt. 
Eine ganz ähnliche Schotterzusammensetzung wie die Steinlage ("c") hatten die hangabwärts gewanderten Mittelterrassenschotter unmittelbar westlich des zuletzt beschriebenen Aufschlusses. Durch Aufgrabungen und Bohrungen konnte nachgewiesen werden, daß die Steinsohle ("c") nur einen Ausläufer dieser Fließerde darstellt.

Außer den Schottervergleichen wurden auch Korngrößen-Untersuchungen durchgeführt, die ich $\mathrm{H}$. Sindowski verdanke. Aus beiden Untersuchungen ergab sich, daß die Schichtenfolge von der Steinlage (" $x-x$ ") an der Basis der Fundschichten aufwärts allmählich zum Hang der Mittelterrassenhochfläche emporzieht und dort auskeilt (vgl. Abb. 3). Sie überlagert seitlich mit normalem Kontakt die schräggeschichteten Sande im Sockel der Mittelterrassen-Hochfläche (" $r$ ").

In diesen Sanden ("r"), sowie in den Sanden und Kiesen der Fundschichten und der darüberliegenden Schichtenfolge ("e" bis "g") wurden Schrägschichtungsmessungen vorgenommen. Zur Konstruktion der Schichtflächen aus je zwei beliebigen Anschnitten einer Schichtfläche im Aufschluß wurde die Schmidt'sche Halbkugel-Projektion benutzt. Aus diesen Messungen ergaben sich bemerkenswerte Unterschiede in der Schüttungsrichtung. Die Sande im Sockel der Mittelterrasse sind nämlich (ebenso wie die darüberliegenden Terrassenschotter) in Richtung des Haupttales von SW her aufgeschüttet worden (vgl. Abb. 2). Die Fundschichten wurden dagegen, ebenso wie ihr Hangendes, von SE eingeschüttet, also in Richtung des kleinen Nebentales, an dessen Einmündung in das Fuhsetal die Fundstelle liegt. Wir müssen daraus schließen, daß der Ablagerung der Fundschichten eine kräftige Erosion voranging, die an dieser Stelle einen generellen Wechsel in der Entwässerungsrichtung einleitete.

Auf Grund dieser rein geologischen Feststellungen kommen wir zu folgender vorläufigen Altersdeutung der Fundschichten: Nach der Saale-Hauptvereisung erfolgte eine kräftige Erosion, die den Geschiebemergel und die Mittelterrassenschotter ausräumte und die Steinsohle an der Basis der Fundschichten zurückließ. In diesem Erosionstal kamen die Fundschichten und ihr Hangendes zur Ablagerung. Diese Schichtenfolge von der Basis der Fundschichten bis zur oberen Steinlage ("c" bis "g") ist in ihrer Sedimententwicklung sowie in ihren Klimaspuren einheitlich ausgebildet. Wir schließen dieses -abgesehen vom Faunen- und Floreninhalt der Schichten — aus folgenden Anzeichen:

1. aus der gleichzieligen Veränderung der Schotterzusammensetzung,

2. aus der stetigen Zunahme des Kalkgehaltes im Feinkorn-Anteil vom Liegenden zum Hangenden und

3. aus den Froststrukturen in den Fundschichten und den Fließerscheinungen in den darüberliegenden Schichten.

Die Brodelstrukturen in den Fundschichten müssen während der Schichtenablagerung entstanden sein, denn sie sind stellenweise von den oberen Fundschichten angeschnitten und diskordant überlagert. Die Fundschichten sind also in einer Kaltzeit abgelagert. Der Zeitpunkt der tiefsten Temperaturen scheint allerdings erst nach Ablagerung der Fundschichten und zumindest des unteren Teiles der darüberliegenden Schichten ("f") eingetreten zu sein, wie aus Art und Menge des darin enthaltenen Faunen- und Floreninhaltes zu schließen ist. Im Hangenden der Fundschichten sind zwei Fließerden vorhanden, die möglicherweise zwei Kältemaxima anzeigen. Eine kleine Erosion und die Ablagerung der Schichten "e" und "d" liegen dazwischen. Sie sind vielleicht als Ausdruck einer Klimaschwankung (kurzfristige Erwärmung) zu werten. 
Demnach könnten die Fundschichten in einer Spätphase der Saale-Vereisung oder am Beginn der Weichsel-Eiszeit abgelagert sein. Für eine Einstufung in die späte Saale-Eiszeit haben sich bisher keinerlei Anhaltspunkte ergeben. Insbesondere fehlt über den Fundschichten jegliche Spur eines Interglazials. Wir müssen darum die gesamte Schichtenfolge "e" bis "g" in die Weichsel-Eiszeit stellen.

Dabei bleibt zunächst noch ungeklärt, ob die Fundschichten an den Beginn der Weichsel-Vereisung oder in ein frühes Weichsel-Interstadial, noch vor die Zeit der Haupt-Fließerdebildung, einzustufen sind. Wir hoffen, daß es mit Hilfe der Pollenanalyse möglich sein wird, diese Frage zu klären. Nach freundlicher Mitteilung von W. Selle überwiegen in den bisher untersuchten Proben aus den Fundschichten stark die Kräuterpollen. Unter den Baumpollen herrscht die Kiefer vor. Daneben hat die Birke einen größeren Anteil. Außerdem sind Weiden, Erlen und Fichten vorhanden. „Es herrschte eine subarktische Steppe, die nur gering mit Bäumen durchsetzt war."

Eine weitere Möglichkeit zur Einstufung der Fundschichten gibt uns die reiche Fauna, über die A. KLEInschmid gesondert berichtet. Darüber hinaus wird die Bearbeitung der Pflanzenreste aus den Fundschichten und aus den darüberliegenden Sedimenten, sowie die Bestimmung der aus der Fließerde über den Fundschichten ("f") ausgeschlämmten Fossilien weitere Anhaltspunkte für die Einstufung der Fundschichten geben. Nach den bisher durchgeführten Untersuchungen müssen wirdie Fundschichten in den Beginn der Weichsel-Eiszeit stellen.

Die erbohrten Schotter unter den Fundschichten ("s") zeigen besonders in ihrem unteren Teil große Ähnlichkeit mit den an anderen Stellen untersuchten Oberterrassen-Schottern. Die Oberterrasse ist hier in der nähtren Umgebung an der Erdoberfläche nicht bekannt. Wahrscheinlich haben wir in diesen Schottern von der Erosion verschonte Teile der Oberterrasse vor uns. Die unter den schräggeschichteten Sanden im Sockel der Mittelterrasse erbohrten Schotter sind sehr ähnlich und scheinen daher dem gleichen Schotterkörper anzugehören. Ihre Untersuchung ist bisher noch nicht abgeschlossen. Der Bearbeitung von Bohrproben muß es vorbehalten bleiben, festzustellen, ob noch Spuren eines Interglazials nachzuweisen sind. Über weitere Untersuchungen, die u. a. auch die erbohrte Schotterserie umfassen, wird K. RIChten berichten, der freundlicherweise eine Reihe geeigneter Schotterfraktionen für Verrundungsmessungen übernahm.

\section{Literaturverzei chnis}

P. Woldstedt: Über eine Innerste-Terrasse zwischen Derneburg und Broistedt. 21. Jahresber. niedersächs. geol. Verein, S. 1-9, 1928.

H. Spreitzer: Die Talgeschichte und Oberflächengestaltung im Talgebiet der Innerste. Jb. geogr. Ges. Hannover 1931.

Geolog. Karten 1:25000 mit Erläuterungen, herausgegeben von der Preuß. Geol. Landesanstalt.

Blatt: aufgenommen und erläutert durch:

Lesse (1933) P. Woldstedt, Th. Schmierer, F. Dahlgrïn

Barum (1932) F. Behrend, F. KüHNe.

Ms. eingeg.: 3. 2.1953.

Anschrift d. Verf.: Dr. F. Preul, Amt für Bodenforschung, Hannover, Wiesenstr. 72-74. 


\title{
3. Geröllmorphometrische und Einregelungsstudien in den pleistozänen Sedimenten der paläolithischen Fundstelle Salzgitter-Lebenstedt
}

\author{
(Konrad Richter). Mit 1 Abb.
}

Die große wissenschaftliche Bedeutung der sehr typenreichen paläolithischen Fundstelle von Salzgitter-Lebenstedt macht es notwendig, die geologische Bearbeitung der Altersstellung und Entstehung der Fundschichten mit recht vielen Methoden zu versuchen, um möglichst gesicherte Ergebnisse zu erzielen. Es war deshalb bei der kurzen Dauer der Grabungszeit nicht möglich, alle Methoden mit einem Bearbeiter durchzuführen. Der Verfasser beschränkte sich im wesentlichen auf geröllmorphometrische und Einregelungsstudien. Es soll gezeigt werden, daß es schon mit diesen Methoden allein möglich ist, das Alter der Fundschichten als frühweichseleiszeitlich wahrscheinlich $\mathrm{zu}$ machen.

Die genannten Arbeitsmethoden eignen sich für den vorliegenden Fall besonders, weil die Fundstelle im Bereich zahlreicher, genetisch verschiedener Sedimente liegt, welche reich an Geröllen sind. Die weitere Umgebung wird von einer Hochfläche gebildet, die auf einem Sockel von zum Teil elstereiszeitlichen Schmelzwassersanden und Terrassensanden einen mehrere Meter mächtigen Komplex pleistozäner Mittelterrassenschotter trägt. Letztere wurden in der Saaleeiszeit von einer geringmächtigen Geschiebelehmdecke und später von Löß überlagert. Diese ziemlich ebene Landschaft wird durch das Fuhsetal zerschnitten. In ihn mündet bei Lebenstedt das kleine Seitental des KrähenriedeBaches, an dessen Rand bei der Mündung in das Haupttal die prähistorischen Fundschichten angetroffen wurden. Knochen und Artefakte sind hier in überwiegend kiesigen Schichten eingebettet, deren Alter es festzustellen galt. Unterlagert werden die Fundschichten von Sand und dieser wieder von einem mehrere Meter mächtigen Komplex pleistozäner Flußschotter. Der Hang von der großen vorgenannten Ebene zum Fuhsetal und seinem Seitentälchen ist sehr sanft und zu letzterem hin im Frühjahr 1952 durch mehrere Baugruben aufgeschlossen. Ihre geröllführenden Sedimente wurden im allgemeinen von oben aus hangabwärts gehend mit nachstehenden Ergebnissen analysiert.

\section{Einregelung smessungen}

Der höchst gelegene Aufschluß für das oberste städtische Klärbecken zeigt unter Löß einen unregelmäßig, offenbar sekundär verlagerten Flußterrassenschotter mit überwiegend Lyditen. Das Einregelungsdiagramm hat ein sehr ausgeprägtes und spitzes Maximum zwischen 50 und $60^{\circ}$ (siehe Lageskizze Lokalität I), was der örtlichen geringen Hangneigung in seiner Einfallsrichtung entspricht. Unter diesen Schottern und in sie übergehend liegt ein geschiebelehmähnliches Sediment mit überwiegend nordischem Gesteinsinhalt. Letzterer zeigt ein klares, aber breiteres Einregelungsdiagramm ebenfalls mit. Maximum zwischen 50 und $60^{\circ}$ (Lageskizze Lokalität I). Etwas hangabwärts zwischen oberster und nächst-tieferer Klärgrube sind beide Sedimente stärker vermischt und ausgedünnt. Das Einregelungsdiagramm hat wieder ein klares, ziemlich spitzes Maximum zwischen 50 und $60^{\circ}$ (Lageskizze Lokalität II). Weiter hangabwärts dünnt dieses Sediment in den Aufgrabungen von Herrn Preul zu mehr oder weniger einer einzigen Steinlage aus, die unterhalb der letztgenannten Bau- 
grube und in der Nordostecke der Grabungsgrube abermals im Diagramm ein Finregelungsmaximum zwischen 50 und $60^{\circ}$ (Lageskizze Lokalität III und IV) ergibt. In der Grabungsgrube nimmt das Einfallen zum Gebäude des Pumpenhauses hin über den prähistorischen Fundschichten etwas zu. Diese Steinsohlenbildung dürfte mit den im niedersächsischen Flachland weit verbreiteten Steinsohlen wesens- und altersgleich sein, die als periglaziales Äquivalent der Weichseleiszeit aufgefaßt werden.

Unter ihr folgt in der Grabungsgrube im allgemeinen ein schluffig-feinsandiges Sediment ohne Steine. Im tieferen Teile schalten sich aber wieder kiesige Lagen ein. Aus einer solchen neben einem stark humosen Fleck, der schon das Ausgehende eines lebensfreundlicheren Klimas andeutet, als es durch die periglaziale Steinsohle wahrscheinlich gemacht ist, wurde noch über den eigentlichen Fundschichten ein Einregelungsmaximum bei $120^{\circ}$ festgestellt, das sich indes bis $140^{\circ}$ ausbreitet (Lageskizze Lokalität VI). Es weicht stark von der vorbeschriebenen Serie ab und entspricht der Längsrichtung des Seitentälchens. Diese Richtung, die nun nicht mehr zur Hangneigung in Beziehung steht, wird vielleicht durch die Erstreckung der torfigen Sedimente in den tieferen Kieslagen mit prähistorischen Funden verständlich. Sie scheinen ein anmooriges Bachbett anzudeuten. Die torfigen Schichten sind brodeltopfähnlich zerrissen. Die Kieslage, welche die großen „Brodeltöpfe“ oben horizontal abschneidet, hat ein deutliches Einregelungsmaximum zwischen 20 und $30^{\circ}$, aber auch ein kleineres Nebenmaximum bei $100^{\circ}$ (Lageskizze Lokalität VII).

Offenbar bestand im Zuge des vorgenannten Seitentälchens zu dieser Zeit ein fließendes Gewässer mit wechselnder Strömungsstärke, in dem als Altwasserbildungen torfige Sedimente mit Tundrenvegetation und nesterweise Sphärien abgelagert wurden. Die Basis dieses kiesigen Komplexes hat an zwei verschiedenen Meßpunkten je ein deutliches Einregelungsmaximum in Nord-SüdRichtung (Lageskizze Lokalität VIII), also auch noch ähnlich, nur daß hier das Gegenmaximum bei $110^{\circ}$ lediglich in einem Diagramm auftritt. Die Strömung muß hier zeitweise stärker gewesen sein, da Blöcke von über Kopfgröße darin

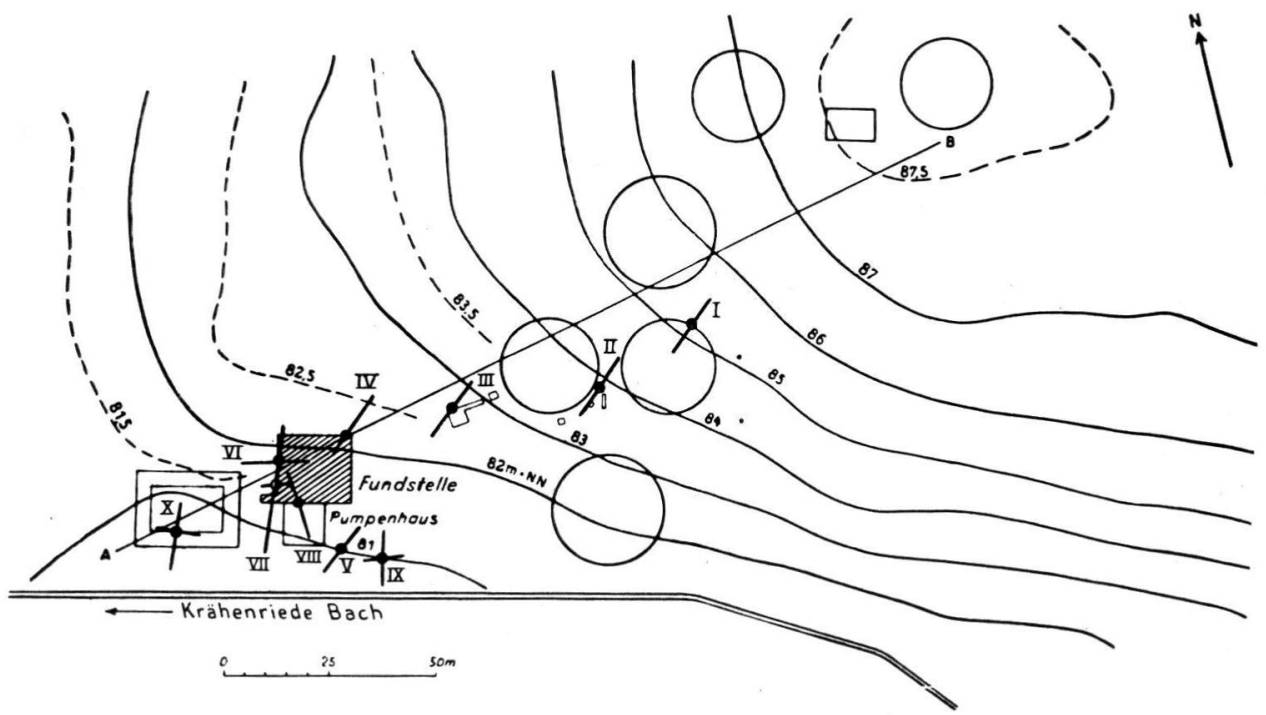

Abb. 1. Lageskizze der Einregelungsmessungen. 
vorkommen. Die kleineren gemessenen Steine wurden zu Zeiten stärkerer Strömung flottierend bewegt und senkrecht dazu mit rollender Bewegung bei geringerer Strömung mit der Längsachse der Gerölle senkrecht zur Rollrichtung. Natürlich bleibt das Endstadium einer rollenden Bewegung fossil leichter erhalten als das der flottierenden, so daß die seitentalparallele Strömungsrichtung in den Diagrammen weniger gut ausgeprägt erscheint als die senkrecht dazu liegende Rollachse der Gerölle.

In dem schon völlig im Nebentälchen liegenden Kanalgrabeneinschnitt westlich vom Pumpenhaus fallen offenbar die erstbehandelte Steinsohle und der letztgenannte Kieskomplex aufeinander, denn hier hat der oberste Kies ein Einregelungsmaximum zwischen 50 und $60^{\circ}$ wie die Steinsohle (Lageskizze Lokalität V), während $30 \mathrm{~cm}$ tiefer wieder Maximum und Gegenmaximum wie bei dem fluviatil bewegten Kies auftreten (Lageskizze Lokalität IX).

Einige Meter weiter, fast bei der Mündung des Nebentälchens ins Fuhsetal, ist in dem gleichen Kieskomplex von der Steinsohlenrichtung nichts mehr festzustellen, und es treten nur Hauptmaxima der Einregelung zwischen 10 und $20^{\circ}$ sowie kleinere Gegenmaxima zwischen 90 und $110^{\circ}$ auf (Lageskizze Lokalität X). Wieder liegt also eine fluviatile Ablagerung aus dem Seitentälchen vor, die älter ist als die Zeit der Steinsohlenbildung.

Einregelungsbeobachtungen an Knochen und Artefakten sollen von anderer Seite dargestellt werden.

\section{Zurundungs- und Abplattungsmessungen}

Wiederum wurden die Messungen von der obersten Baugrube aus zum Liegenden hin durchgeführt. Bei den sehr häufigen, aber harten Kieselschiefern zeigten sich keine nennenswerten Unterschiede der Zurundung in den einzelnen Horizonten. Kieselschiefer sind für derartige Untersuchungen meist ziemlich unbrauchbar. Von den ausgewerteten Gesteinen seien hier nur die Messungen an grau-weißen Sandsteinen und Quarziten aufgeführt, die in allen kiesigen Horizonten in einigermaßen ausreichender Häufigkeit vorkommen, sowie an Plänerkalken aus Bohrgut von Flußterrassenschottern, die älter als die Fundschichtenkiese und von ihnen durch Sand getrennt sind.

Noch oberhalb der obersten Baugrube hat Dr. Preul die Mittelterrassenschotter in scheinbar originaler Lagerung aufgegraben. Ihre grau-weißen Sandsteine ergaben mit der Methode von Cailleux und Tricart nach der Formel $\frac{2 \mathbf{r}_{1}}{\mathrm{~L}}$ (vgl .Richter 1952, Eiszeitalter und Gegenwart, Bd. 2) ein Zurundungsmaximum zwischen 100 und 150. Das entspricht dem Basis- wie auch dem Hangendteil des Mittelterrassenkörpers der weiteren Umgebung. Der Mittelteil letzterer Terrassen hat Maxima in höheren Zurundungsgruppen. In vorliegendem Falle dürfte also die Basis des Mittelterrassenkörpers erschürft sein.

Die umgelagerten Mittelterrassenschotter in der vorgenannten obersten Klärgrube (Lageskizze Lokalität I) haben bei dem gleichen Gestein ebenfalls ein Maximum in der Gruppe 100 bis 150, aber die Gruppen 0 bis 100 sind gleichfalls stark besetzt. Damit zeigt sich eine Zuschärfung der Kanten gegenüber dem unverlagerten Terrassenschotter des vorigen Fundpunktes. Es dürfte sich darin ein periglaziales Klima mit Bodenfließen äußern, wodurch die Umlagerung des Schotters zu erklären ist.

Unter ihm liegt ein geschiebelehmähnliches Sediment mit der Geschiebezusammensetzung der Saalevereisung. Normalerweise sollte ein echter saale- 
eiszeitlicher Geschiebelehm hier a uf Mittelterrassenschottern liegen. Er ruht aber auf glazialen Schmelzwassersanden. Sandsteine aus beiden haben jeweils ein Zurundungsmaximum in der Gruppe 150 bis 200. Zuschärfungen durch periglaziale Verlagerung des "Geschiebelehmes" sind also nicht erfolgt. Die Verlagerung, die ja gefordert werden muß und auch aus der vorbeschriebenen Einregelung erkenntlich ist, kann also nur unbedeutend gewesen sein.

Etwas hangabwärts, wo umgelagerter Schotter und umgelagerter Geschiebelehm zu einem ausgedünnten Sediment verschmolzen sind (Lageskizze Lokalität II), haben die grau-weißen Sandsteine auch ihr Zurundungsmaximum in der Gruppe 150 bis 200, und die Gruppe 50 bis 100 ist wieder stark besetzt wie bei dem periglazial verlagerten Terrassenschotter. Wo sich dann dieses Sediment weiter hangabwärts bis zur Steinsohle ausdünnt, ist das Zurundungsmaximum schon in der Gruppe 100 bis 150, wobei die Gruppen von 0 bis 100 auch stark besetzt sind (Lageskizze Lokalität III u. IV). Hier ist also die Zuschärfung im periglazialen Wandergeröll sehr klar erkennbar.

Damit sind wir wieder in der Grabungsgrube angelangt, wo der oberste Teil des Kieses im Liegenden der Steinsohle, der aber schon Schneckengehäuse enthält, noch die gleichen Zurundungsverhältnisse aufweist und somit noch als periglazialer Wanderkies erkannt wird. Erst in den eigentlichen Fundschichten haben die grauweißen Sandsteine ein höheres Zurundungsmaximum bei 200 . Das Maximum ist breiter als die vorhergehenden und mit starker Besetzung in der Gruppe 50 bis 100 , aber auch zwischen 250 und 300. Es ist also ein überwiegend fluviatiles Zurundungsmaximum, das allerdings Einflüsse kalten Klimas zeigt.

Im Liegenden der Fundschichtenkiese finden sich Sande, Unter ihnen wurde ein Flußschotterkörper ganz durchbohrt. Aus den 6 in verschiedener Tiefe des Flußschotterkörpers entnommenen Proben konnten in erster Linie die Plänerkalke auf ihre Zurundungs- und Abplattungsverhältnisse untersucht werden, da nur sie aus allen Proben in völlig ausreichender Menge zur Verfügung standen. Bei Anwendung der Formel $\frac{2 \mathrm{r}_{1}}{\mathrm{~L}}$ ergeben sich vom Liegenden zum Hangenden keine wesentlichen Unterschiede, wie das auch bei Ausmessung von Plänerkalken in anderen Schotterkörpern mehr oder weniger festgestellt wer-

den konnte. Dagegen zeigt die Abplattung nach der Formel $\frac{L+1}{2 \mathrm{E}}$ vom Liegenden zum Hangenden eine gesetzmäßige Abwandlung wie in anderen Profilen aus pleistozänen Flußterrassenschottern. Die Basisprobe (Nr. 6) hat ein Abplattungsmaximum in der Gruppe 200 bis 250, Probe 5 desgleichen. Aber hier ist die Gruppe 250 bis 300 schon fast so stark vertreten. Probe 4 hat das Maximum zwischen 300 und 350. In Probe 3 sind die Kolonnen zwischen 200 und 250 einerseits und 250 bis 300 andererseits gleich groß. Die Abplattung nimmt also wieder etwas ab. Das ist noch stärker der Fall in Probe 2, die ein sehr überragendes Maximum in der Gruppe 200 bis 250 hat. In der Probe 1 läßt das Maximum mit 150 bis 200 die geringste Abplattung erkennen. Wir haben also einen klaren Wandel von geringer Abplattung der Gerölle in der Schotterbasis zu stärker gerundeten im Mittelteil des Schotterkörpers und gering abgeplatteten im Hangendsten des Schotterkörpers. Ähnliches ist in zahlreichen pleistozänen Flußterrassenschottern zwischen Braunschweig und Minden festzustellen, wie der Verfasser 1952 auf der Tagung der Deutschen Geologischen Gesellschaft in Osnabrück vortrug. Diese Veränderungen wurden von ihm im Sinne eines klimatischen Wandels von periglazialem Klima über interglazialem zu peri- 
glazialem Klima gedeutet (vgl. auch K. Richter 1952, Eiszeitalter und Gegenwart, Bd. 2). In den Diagrammen ist die Streuungsbreite bei Probe 6, also in der Basis, nach rechts am größten und wird zum Hangenden hin geringer. Vielleicht ist daraus zu schließen, daß das Ausgangsmaterial des Schotterkörpers gerundeter war, also aus einem noch älteren Flußschotter umgelagert ist. Bei Untersuchungen in Mittelterrassenaufschlüssen der Nachbarschaft wurde nichts Gleichartiges festgestellt, so daß hierin möglicherweise ein Hinweis auf ein höheres Alter der erbohrten Kiese vorliegen könnte. Vergleichende Untersuchungen in dieser Hinsicht sind aber bisher nicht umfangreich genug, um einen solchen Schluß zu erhärten. Immerhin ergeben sich aus der Zusammensetzung der Geröllgemeinschaft Anhaltspunkte für ein höheres Alter der erbohrten Schotter, worauf von anderer Seite eingegangen werden wird.

Eine gleichartige Klimaabwandlung, wie aus den Plänerkalken ersichtlich, ist bei Verwendung der Formel $\frac{2 \mathrm{r}_{1}}{\mathrm{~L}}$ auch aus den Zurundungsverhältnissen hellgrauer quarzitischer Sandsteine der 6 Bohrproben herauszulesen. Hier liegen die Maxima in die Basisprobe zwischen 100 und 150, in der Schottermitte zwischen 150 und 200 und im Hangendsten zwischen 100 und 150. Allerdings ist die Anzahl der verwendeten Steine so gering, daß die Angaben nicht absolut sicher scheinen. Sie passen indes vorzüglich in das erwartete Bild.

Stratigraphische Auswertung der Ergebnisse

Aus vorstehenden Angaben ergibt sich folgendes Bild der Entstehung des Schichtenprofiles, das die prähistorischen Fundlagen enthält:

Unter den kiesigen, tiefsten Fundschichten findet sich bei Punkt VIII der Lageskizze ein Sand, der von einem mehrere Meter mächtigen Flußterrassenschotter unterlagert wird. Die Gerölle dieses Schotterkörpers haben an der Basis periglaziale, in der Mitte interglaziale und im Hangendteil wieder periglaziale Zurundungs- und Abplattungsverhältnisse. Verglichen mit anderen pleistozänen Flußterrassenschottern ähnlicher geographischer Position liegt ein vollständiger Zyklus vor. Die Abplattungsverhältnisse in der Basis zeigen mit der Breitestreuung ein Abweichen von anderen Mittelterrassenschottern, die auf etwas höheres Alter hinweisen könnten. Demnach wäre der Mittelterrassenschotter im Zuge der Grabungsstelle später völlig ausgeräumt und die Sande über den älteren Schottern evtl. mit einem tieferen Teil der glazialen Schmelzwassersande zu parallelisieren, die bei Punkt I der Lageskizze den periglazial umgelagerten Geschiebelehm unterlagern. Die obersten Meter dieses Sandes von Punkt I sind also bei Punkt VIII erodiert und durch die Fundschichtenserie ersetzt. Saaleeiszeitlicher Geschiebelehm ist in gleicher Weise erodiert, und es folgen bei Punkt VIII der Lageskizze fluviatile Schotter, die, aus älterem Terrassenschotter umgelagert, recht kühles Klima anzeigen. Die Einregelung ihrer Komponenten zeigt zwei Maxima, wie sie in fluviatilen Absätzen meist, in Periglazialschutt aber niemals auftreten. Die ermittelte Streuungsrichtung entspricht der des Seitentälchens. In diesen Komplex sind torfige Absätze eingebettet, die in kaltem Klima zu brodeltopfartigen Gebilden zerrissen sind, ohne daß zumeist die Kieslagen selbst mit „verbrodelt" wären. Diese Töpfe werden also von ähnlichem fluviatilem Kies unter- wie überlagert. Die etwas jüngeren schneckenführenden Kiese ohne prähistorische Funde (Punkt VII der Lageskizze) haben die Zurundungsformen eines periglazialen Wanderkieses und eine Einregelung, die zur Richtung des Seitentales paßt. Sie sind wohl als fluviatil bei stärkerer Strömung mit flottierender Bewegung der Gerölle abgesetzt zu denken. Im tieferen Kies wechselt dagegen die Strömungsgeschwindigkeit, so 
daß die Gerölle sowohl flottiert wie gerollt wurden, und daher in den Diagrammen Maximum und Gegenmaximum der Einregelung auftreten. Die ermittelte Fließrichtung folgt dem Seitentälchen.

Überlagernde schluffige Sande sind im oberen Teil steinfrei, und erst dann folgt (z. B. bei Punkt VI und IV der Lageskizze) eine Schicht, die zumeist nur aus einer einzigen Steinlage besteht. Es ist das die typische Steinsohle eines periglazialen Schuttwanderns auf sehr flach geneigter Fläche, die nur in der Grabungsgrube selbst etwas stärker einfällt. Diese Steinsohle läßt sich, wie vorerwähnt, von der Grabungsstelle aus hangaufwärts (z. B. Punkt III der Lageskizze) verfolgen. Sie hat dabei stets die Zurundungsformen einer periglazialen Steinsohle und eine Einregelung, die mit der allgemeinen schwachen Gehängeneigung identisch ist. Sie nimmt hangaufwärts an Mächtigkeit wie an sandiglehmigen Komponenten zu und läßt sich schließlich bei Punkt I der Lageskizze untergliedern in einen Liegendteil, der das Aussehen eines Geschiebemergels hat und einen hangenden, der aus Terrassenschotter besteht. Beide liegen noch etwas tiefer zu NN, als der Schotter der Mittelterrasse und der überdeckende Geschiebelehm der Saalevereisung normalerweise zu erwarten wären. Die Einregelungsrichtung ist die gleiche wie bei der eben behandelten Steinsohle, in die beide Pakete auch übergehen. Besonders in echtem Geschiebelehm wäre eine andere Einregelungsrichtung wahrscheinlicher gewesen.

Es scheint also durch periglaziales Bodenfließen eine Inversion der Lagerung erfolgt zu sein. Völlig auf der Hochfläche liegt normalerweise unter Löß zunächst die Grundmoräne der Saalevereisung mit dem Mittelterrassenschotter als Liegendem. Als nach der Saalevereisung zur Zeit des nächsten größeren Eisvorstoßes - mithin der Weichselvereisung - wieder periglaziales Klima in unserem Raum herrschte, mußte zuerst der saaleeiszeitliche Geschiebelehm am Talrand zum inzwischen wieder geschaffenen Fuhsetal hangabwärts fließen. Erst als er örtlich völlig entfernt war, konnte auch der Mittelterrassenschotter ins Wandern geraten. So kam es, daß im oberen Teil des Hanges ein geschiebelehmähnliches Sediment mit nach bisheriger Auffassung saaleeiszeitlicher Geschiebeführung unter Schottern der Mittelterrasse zu liegen scheint. Der grobe Anteil dieses Wanderbodens dünnt sich weiter hangabwärts zur Steinsohle aus und liegt über den Schichter mit prähistorischen Funden. Dr. Preul, der zunächst zu dem gleichen Ergebnis kam, hält auch noch eine kompliziertere Deutung für möglich, über die er später berichten wird.

Zwischen dem Wanderboden und den Fundschichten läßt sich kein wesentlicher klimatischer Hiatus nachweisen, falls man nicht z. B. das stärkere Gefälle der Steinsohle in der Grabungsgrube und die so entstehende kleine Diskordanz als Ausdruck einer Unterbrechung der Periglazialsedimentation auffassen will. Solche Unterbrechungen wären im Zusammenhang mit verschiedenen Phasen der letzten Eiszeit durchaus zu erwarten, wie das Dr. Preul in seinem Bericht darstellt. Die Fundschichten müssen also ein Alter haben, in dem das Klima der Weichseleiszeit sich zwar schon bemerkbar macht, das Maximum dieser Kaltphase mit der regional weit verbreiteten periglazialen Steinsohlenbildung aber noch nicht erreicht ist.

Diese Ergebnisse scheinen mit den auf anderen Wegen gewonnenen geologischen Daten und mit den Fundtypen des Paläolithikums gut überein zu stimmen.

Manuskr. eingeg. 9. 10. 1952.

Anschr. d. Verf.: Prof. Dr. K. Richter, Hannover, Amt für Bodenforschung, Wiesenstraße $72-74$. 


\title{
4. Pollenanalytische Untersuchungen an der paläolithischen Fundstelle bei Salzgitter-Lebenstedt
}

\author{
(Willi S e 11 e, Braunschweig-Riddagshausen)
}

\section{A. Die Fundschichten}

Die ehemalige Oberfläche, in der sich die Funde befinden, enthält an mehreren Stellen kleinere Torf- und Gyttja-Linsen, die eine pollenanalytische Untersuchung ermöglichten. Da die Sedimente arm an Baumpollen sind und mittels Flußsäure aufgeschlossen werden müssen, ist die Analyse sehr zeitraubend, so daß sie bislang nicht zum Abschluß gebracht werden konnte. Die bisherigen Ergebnisse sind aber so einheitlich, daß sie mit einiger Sicherheit zusammengefaßt werden können. Die geringe Baumpollendichte pro Präparat und die hohe NBP-Frequenz in Verbindung mit den stark minerogenen Ablagerungen zeigen, daß die Waldbedeckung sehr gering gewesen sein muß und keine geschlossene Vegetationsdecke bestand. Von den Baumpollen besitzt die Kiefer die höchsten Werte, daneben treten die Birke, Weide und Fichte regelmäßig auf, sporadisch ist Alnus vorhanden, während von den wärmeliebenden Bäumen kein Blütenstaubkorn gefunden wurde. Unter den NBP nehmen die Cyperaceen den größten Raum ein, sie erreichen zum Teil mehrere Hundert Prozent. Die Gramineen-Pollen besitzen zwar nicht die hohen Werte wie sie die Sauergräser aufweisen, aber ihre Beteiligung ist in der Regel groß. Die übrigen Kräuterpollen, bzw. Sporen sind gering vertreten; es konnten festgestellt werden: Helianthemum, Selaginella selaginoides, Artemisia, Calluna, Empetrum, Umbelliferen, Caryophyllaceen, Chenopodium, Compositen, Rosaceen, Plantago, Polygonium bistorta, Galium, Sphagnum, Lycopodium.

Wir dürfen daher annehmen, daß diese Ablagerungen in einem späten Stadium der Kiefernzeit, am Ausgang eines Interglazials, bzw. am Anfang eines Glazials, entstanden sind. Mit der Kiefernzeit hat dieser Abschnitt die hohen Werte von Pinus, das regelmäßige Auftreten von Betula, Salix und Picea, das sporadische Vorkommen von Alnus und die Beteiligung von Sphagnum und Empetrum gemeinsam. Er unterscheidet sich von der Kiefernzeit durch die geringe BP- und die hohe NBP-Frequenz, die gefundenen Sporen von Selaginella selaginoides und das Fehlen von Carpinus. Die geringe Beteiligung von Betula und Salix und die niedrigen Werte von Artemisia, Helianthemum und Selaginella selaginoides der Fundschichten lassen andererseits vermuten, daß die Ablagerungen in einer Zeit entstanden sind, als das voll arktische Klima des Glazials noch nicht herrschte. Das Klima war subarktisch mit geringer atlantischer Neigung, und die Vegetation bestand aus einer grasreichen Tundra.

Die kleinen Hohlformen enthalten Braunmoos-Seggen-Torfe und tonig-sandige Gyttjen, in denen Pediastrum boryanum vorkommt. $\mathrm{Da}$ in den Gyttjen Mollusken gefunden wurden, die vielfach gut erhalten sind, müssen die $\mathrm{Ab}$ lagerungen primär liegen. Herr Dr. Steusloff hat festgestellt, daß die Epidermis bei einigen Exemplaren erhalten ist, wie das im periglazialen Gebiet Nordwestdeutschlands häufiger der Fall ist. Aus dem geringen Material, das ich ihm zusandte, konnte er Pisidium amnicum und Sphaerium corneum, forma dupli-

11 Eiszeit und Gegenwart 
catum bestimmen. Für seine Untersuchungen sei ihm auch an dieser Stelle herzlichst gedankt.

B. Schluff-und S a n d s chichten (b-f) im Hangenden der Fundschichten, sowie Gyttja und Torf nahe der Oberfläche (t; vgl. Abb. 3 im Beitrag Preul).

Die bisherigen Ergebnisse aus den hangenden Schichten der Fundhorizonte sind weniger gesichert, da sie nicht vollständig untersucht sind und es außerdem fraglich ist, ob die Schwemmlöße für die Pollenanalyse brauchbar sind. Es scheint allerdings, als ob sekundäre Pollen nicht vorkommen, da die Pollenbilder denen der Fundschichten ähneln. Die oberen Ablagerungen weisen eine höhere Beteiligung von Salix und Betula auf, so daß anzunehmen ist, daß sie in einer späteren Zeit entstanden sind. Wärmeschwankungen, also Interstadiale, konnten bislang nicht festgestellt werden. Ihr Fehlen erklärt sich entweder aus der unvollständigen Untersuchung oder daraus, daß das Becken bereits im Frühglazial ausgefüllt wurde.

An der südlichen Seite des Aufschlusses befinden sich unter 1,56 m mächtigen Torfen sandig-kalkhaltige Gyttjen, die möglicherweise in der Kiefernzeit des letzten Interglazials zur Ablagerung kamen. Da die Bildung dieser Gyttja bislang nicht geklärt werden konnte, ist es möglich, daß sie allochthon entstanden und für die Pollenanalyse nicht brauchbar ist. Die Torfe liegen äiskordant über diesen Sedimenten und beginnen vermutlich in der jüngeren Dryaszeit. Da die Torfe ab 1,16 m Störungen aufweisen, konnte kein klares Bild der nacheiszeitlichen Vegetationsentwicklung gewonnen werden.

Ms. eingeg.: 10, 2. 1953.

Anschr. d. Verf.: W. Selle, Braunschweig-Riddagshausen, Am Kreuzteich 6.

Anm. des Herausgebers während des Druckes:

Sollten bei den oben genannten sandigen Gyttjen letztinterglaziale Bildungen i $\mathrm{m}$ $\mathrm{H}$ angenden der Funds chichten vorliegen, so müßten letztere älter, $d$. $h$. möglicherweise warthestadial sein. Die weiteren Untersuchungen sollen hauptsächlich der Klärung dieser Frage dienen. 


\title{
5. Planzenreste aus den Fundschichten von Lebenstedt
}

\author{
(Kurt Pf a f e n berg, Sulingen)
}

Die untersuchten Proben stammen aus zwei etwa $1 \mathrm{~m}^{2}$ großen, geringmäch. tigen Torflagern, die in der Nähe der Basis und im oberen Drittel der prähistorischen Fundschichten liegen. Im Niveau zwischen diesen Torflinsen waren in humosen Schichten besonders viele Wirbeltierreste und Artefakte enthalten. Die humosen Schichten und der darüberliegende Torf zeigen eine durch Frosteinwirkung veränderte Lagerung. Die beiden Torflager werden im folgenden als „oberes“ und „unteres“ Torflager bezeichnet. Es handelt sich um hochgradig verwitterte Flachmoortorfe, die sich in ihrem Pflanzeninhalt stark voneinander unterschieden.

\section{Unteres Torflager}

Folgende Pflanzenarten wurden nachgewiesen:

Splachnum ampullaceum L. (Moos). Einige gut erhaltene Stämmchen und einzelne Blätter.

Splachnum vasculosum L. (Moos). Einige Stengelstücke mit vollständigen Blättern.

Drepanocladus cf. Sendtneri Warnst. (Moos). Zahlreiche Stengelstücke. Das derbe Zellnetz der Blätter und die kräftige Blattrippe machen die Bestimmung wahrscheinlich.

Chrysohypnum stellatum Loeske (Moos). Mehrere gut beblätterte Stengel.

Drepanocladus sp. Moenкem. (Moose). Zahlreiche Stengel mit schlecht erhaltenen sichelförmigen Blättern.

Potamogeton gramineus L. (Gras-Laichkraut). 3 gut erhaltene Steinkerne.

Potamogeton cf. alpinus BALB. (Alpen-Laichkraut). 1 gut erhaltener Steinkern. Die Rückenklappe, die vom Griffel weit zurückbleibt, macht diese Art wahrscheinlich.

Salix polaris WAHLEnb. (Polarweide). Sehr viele wohl erhaltene Blätter. Ihre GröBenmaße schwanken in der Länge zwischen 2,5 und $4,5 \mathrm{~mm}$ und in der Breite zwischen 2,5 und $4,2 \mathrm{~mm}$.

Salix herbacea L. (Krautweide). Sehr zahlreiche gut erhaltene Blätter. Ihre Länge beträgt $2,7-7,2 \mathrm{~mm}$, ihre Breite $2,3-5,3 \mathrm{~mm}$. Durchschnittlich sind diese Blätter größer als von Salix polaris.

Salix sp. Sehr viele Blätter mit beschädigten Rändern, weshalb die Zugehörigkeit zu einer der genannten Weidenarten nicht sicher erkannt werden konnte. Andere Arten als Salix polaris und Salix herbacea kommen vermutlich nicht in Frage. Mehrfach fanden sich Reiserstückchen mit sehr eng liegenden Knospenanlagen, sowie Blüten und Kelchreste von Salix.

Armeria cf. arctica WALLR. (Polar-Grasnelke). Es fanden sich 9 Fruchtkelche, die zu dieser Gattung gehören. Bei diesen Kelchen sind nur die kräftigsten Teile erhalten geblieben. Die dünne, weiße Haut, die sonst die Kelchzipfel verbindet, ist gänzlich aufgelöst. C. A. WEBER (1914) schreibt von seinen Funden, daß die Härchen auf dem Fruchtkelch nur auf den Haupt- und Nebenrippen beschränkt sind. Er rechnet deshalb diese Art zu Armeria arctica. Die Pflanze ist heute nur im arktischen Nordamerika, in Grönland und Nordsibirien verbreitet. Bei den Lebenstedter Funden ist die $\mathrm{Be}-$ haarung der Fruchtkelche nicht eindeutig auf die Rippen verteilt. Einige Kelche sind vielmehr zerstreut behaart. GAMS (o.J.) macht darauf aufmerksam, daß andere und ähnliche Funde als Armeria maritima bestimmt wurden. Es müßte mit der Möglichkeit gerechnet werden, daß auch andere Sippen vorliegen können, insbesondere Armeria montana. Fossil seien auch Armeria maritima und Armeria arctica kaum unterscheidbar. Da Armeria in den Torfen von Lebenstedt mehrfach vorkommt, bringen vielleicht weitere Funde die notwendige Klarheit und Sicherheit. 
Lychnis flos cuculi A. Br. (Kuckucksnelke). Gefunden 6 Samen. Ihre Größe schwankt zwischen 0,9 und $1,1 \mathrm{~mm}$. Die kegelförmigen Buckel, in Reihen um den Nabel angeordnet, lassen nur diese Art in Frage kommen.

Pflanzengallen. Mehrfach fanden sich Gallen, die sicher von Weidenblättern stammen. Ihre Zugehörigkeit konnte noch nicht ermittelt werden.

\section{Oberes Torflager}

Nachgewiesen wurden folgende Pflanzenarten:

Drepanocladus revolvens Moenkem. (Moos). Zahlreiche Stämmchen.

Drepanocladus Sendtneri WaRnst. (Moos). Mehrere Stämmchen.

Drepanocladus sp. Zahlreiche Moosstengel, deren sichelförmigen Blätter stark zerrissen oder beschädigt sind. Eine sichere Bestimmung ist deshalb nicht möglich.

Ceratodon purpureus BRID. (Moos). Ein kleines Stengelstückchen.

Splachnum ampullaceum L. (Moos). 2 gut erhaltene Biätter.

Splachnum vasculosum L. (Moos). 3 Stengelstückchen.

Carex sec. Carex (Segge). 30 Nüßchen ohne Schlauch.

Carex sec. Vignea (Segge). 12 Nüßchen ohne Schlauch.

Rumex sp. (Sauerampfer). $1 \mathrm{Nu}$ ohne Perigon, weshalb eine Artbestimmung nicht möglich ist.

Potamogeton cf. alpinus BaLb. (Alpen-Laichkraut). 1 Steinkern. Die Rückenklappe, die in weiterer Entfernung vom Griffel bleibt, läßt diese Art vermuten.

Die Pflanzenlisten von beiden Torflagern zeigen einen sehr verschiedenen Inhalt. In dem unteren Torflager herrschen in starkem Maße die Weiden vor. Von den beiden angetroffenen Arten hat Salix polaris ein rein arktisches Verbreitungsgebiet. Salix herbacea ist dagegen nicht nur auf die Arktis beschränkt. Sie wird auch in den Hochgebirgen Europas, meist oberhalb der Waldgrenze, angetroffen. Durch beide Arten, besonders durch Salix polaris, wird der arktische Charakter der Torfbildung betont.

Salix herbacea wächst mit Vorliebe in den Schneetälchen und in kleinen mit Schneewasser getränkten Mulden. Dieses sind auch die Standorte der aufgefundenen Laubmoose. Drepanocladus und Splachnum finden sich jetzt auch in der gemäßigten Zone. Doch ist ihr optimales Verbreitungsgebiet die Arktis und Subarktis. Auffallend ist vielleicht das Vorkommen von Lychnis flos cuculi. Das Verbreitungsgebiet dieser Pflanze reicht ebenfalls bis in die subarktische Zone. Dasselbe gilt von Potamogeton. Lychnis flos cuculi gedeiht noch jetzt fast bis zum 68. Breitengrad. Sie erreicht also im subarktischen Norwegen und Schweden das Tundrengebiet. Danach haben wir uns für das Torflager von Lebenstedt die klimatischen Verhältnisse so vorzustellen, wie sie noch heute im nördlichsten Skandinavien herrschen. Damit stehen auch im Einklang die zahlreichen Funde von Mammut und Rentier. Die großen Tiere benötigen zu ihrer Ernährung bedeutende Mengen von Pflanzen, die nicht in der Hocharktis, wohl aber in den subarktischen Gebieten zu finden sind.

Vegetationsmäßig hat die obere Torflinse einen ganz anderen Charakter. Während im unteren Torflager die Weiden vorherrschen, fehlen diese hier ganz und gar. An ihre Stelle treten Laubmoose und Seggen. Herzog (1926) unterscheidet für die Arktis die beiden Vegetationstypen der feuchten und trockenen Tundra. In der feuchten Tundra, deren Mulden und Senken stets mit Schneewasser gefüllt sind, herrschen die nassen Mooswiesen vor. Als eine solche Bildung haben wir die obere Torflinse aufzufassen. Die klimatischen Verhältnisse zur Zeit ihrer Entstehung werden die gleichen gewesen sein, wie sie für das untere Lager anzunehmen sind. In der trockeneren Tundra überwiegt niedriges Weidengebüsch. Doch handelt es sich bei der Entstehung der beiden Torflager 
nicht um zwei zeitlich streng getrennte Vegetationsformen. Nach den jeweiligen Verhältnissen gehen die nassen Mooswiesen in trockene Mooswiesen und Gebüschfluren über oder wechseln miteinander ab.

Schriftenverzeichnis

Gams, H.: in Hegr, G. Illustr. Flora von Mitteleuropa. Bd. V 3. München o. J.

Herzog, Th.: Geographie der Moose. Jena 1926.

Moenkemeyer, W.: Die Laubmoose Europas. IV. Bd. Ergänzungsband. Leipzig 1927.

Pfaffenberg, K.: Das Interglazial von Haren (Emsland). - Abh. nat. Ver. Bremen. 31. 1939.

Weber, C. A.: Die Mammutflora von Borna. - Abh. nat. Ver. Bremen. 23. 1914.

Ms. eingeg.: 5. 2. 1953.

Anschr. d. Verf.: Kurt Pfaffenberg, Sulingen (Hannover), Parkstraße 24. 


\section{Die zoologischen Funde der Grabung Salzgitter-Lebenstedt 1952}

(Adolf Kleins ch midt, Braunschweig). Mit $18 \mathrm{Abb}$.

Im Januar 1952 wurde ich vom Leiter des Landesmuseums Braunschweig, Herrn Dr. A. Tode, gemeinsam mit Herrn Dr. Kolbe vom Erzbergbau Salzgitter zur Begutachtung von Knochenfunden gebeten, die dank der Initiative von Herrn Stadtschulrat Zobel, Salzgitter, aus der Fundamentgrube des Pumpenhauses der im Bau befindlichen neuen Kläranlage von Salzgitter-Lebenstedt geborgen worden waren. Es handelte sich um 106 einzelne Fundstücke aus dem untersten Aushub der rund $6 \mathrm{~m}$ tiefen Baugrube. Die Artzugehörigkeit der Funde verteilte sich nach dem damals aufgenommenen Protokoll wie folgt:

$\begin{array}{lc}\text { Rentier } & 63 \% \\ \text { Elephas (vermutlich darunter } & \\ \quad \text { auch Rhinoceros) } & 21 \% \text {, viele Knochensplitter } \\ \text { Rind (Wisent) } & 6 \% \\ \text { Pferd } & 3 \% \\ \text { zunächst nicht bestimmbar } & 7 \%=\text { Knochensplitter! }\end{array}$

Diese Funde bildeten den ersten Hinweis auf die dann später von Februar bis Juni mit aller Sorgfalt durchgeführten Grabungen. Die hier vorliegende Anhäufung gleichartiger tierischer Einzelknochen auf engerem Raum, unter denen von vornherein eine Anzahl großer Rengeweihstücke besonders ins Auge fielen, ließ uns schon damals vermuten, daß es sich hier nicht um eine zufällige Ansammlung und Einbettung etwa g a n zer Tierleichen handeln könne, sondern daß ein irgendwie durch besondere Ereignisse herbeigeführtes Konzentrat vorliegen müsse. Die Lage des Fundplatzes in einer Nische bzw. Bucht des alten Innerste- bzw. Nette-Zuges der Saale-Eiszeit (fide KolBE) schien zunächst für eine Zusammenschwemmung zu sprechen. Die Nicht-Zufälligkeit hat die spätere Grabung bestätigt, jedoch eindeutig als Ursache den Eiszeitmenschen ausgewiesen, wenn auch die Datierung des Fundplatzes wesentlich später, und zwar auf frühes W ü rmgla zi a l anzusetzen ist (s. Berichte Tode und Preul).

Obwohl ich während der Grabung ganz besonders mein Augenmerk auf Hinweise richtete, die die Einbettung von ganzen Tierleichen oder wenigstens von größeren Teilen anzeigten - um spezielle Anhaltspunkte für biostratonomische Gesichtspunkte im Sinne von J. Weigelt zu erhalten - haben sich bis auf ganz dürftige Einzelfälle keine derartigen Feststellungen machen lassen. Lediglich einige in noch natürlichem Verband angeordnete Wirbel von Ren und Wisent und einige vollständige Füße vom Ren einschl. der Metakarpalia bzw. Metatarsalia können in diesem Sinne gewertet werden und haben auch einige brauchbare Schlüsse auf das Einbettungsgeschehen und -Schicksal ermöglicht.

Im übrigen ist überhaupt nur ein ganz geringer Prozentsatz der Knochen in vollständigem Zustand eingebettet worden, und zwar trifft dies nur für kleinere Knochen wie Zehenglieder u. dgl. zu. Von allen größeren und großen Röhrenknochen fanden sich nur irgendwie isoliert liegende größere und kleinere bis kleinste Bruchstücke. Und zwar traten im allgemeinen derartige Knochenstücke von Groß-Säugern (z. B. Mammut, Wisent) in Stücken von etwa $20-30 \mathrm{~cm}$ Länge und bis $10 \mathrm{~cm}$ Breite auf, während die markhaltigen Röhrenknochen vom Ren durchweg in distalen und proximalen Bruchstückenden mit immer irgendwie sehr gleichartigen Abbruchlinien und Bruchkanten aufgefunden wurden. Offen- 
bar haben wir es hier mit gleichmäßigen Abschlägen bzw. einer gleichmäßigen Art der Zertrümmerung der Knochen durch den seine Jagdbeute verwertenden Menschen zu tun. Diese Annahme erscheint umso gerechtfertigter, als auch alle anderen archäologischen Beobachtungen das Bild in dieser Weise eindeutig vervollständigen. Liegen doch nicht nur Knochenteile mit noch viel deutlicheren spezifischen Verletzungen vor, sondern auch solche, die Bearbeitungsmerkmale durch Werkzeuge erkennen lassen, wie solche, die offensichtlich selbst zu Werkzeugen hergerichtet worden sind (s. ToDE).

Der Erhaltungszustand der Kn ochen zeigt im wesentlichen zwei Formen, entsprechend den zwei Haupteinschlußmitteln, je nachdem, ob die Knochen in groben bis feinen Sanden oder in muddigem, das heißt mehr oder weniger stark mit Pflanzenresten durchsetztem, also humosem dunklem und feinkörnigem Medium eingeschlossen waren. In den Sanden kam es dann zuweilen zusätzlich noch zu einer Inkrustierung mit Eisenoxyden.

Die in Sand eingeschlossenen Knochen zeigen eine helle Farbe und neigen infolge des fast vollständigen Verlustes aller leimgebenden Substanzen nach starkem Ab- und Austrocknen zum schichtweisen Abblättern und Zerfall. Die Knochen aus den humosen Schichten besitzen dagegen bei dunkelbrauner bis bronzeartiger Verfärbung auch nach ihrem Austrocknen eine große Festigkeit. Offenbar hat bei ihnen durch die Humussäure eine weitgehende Konservierung

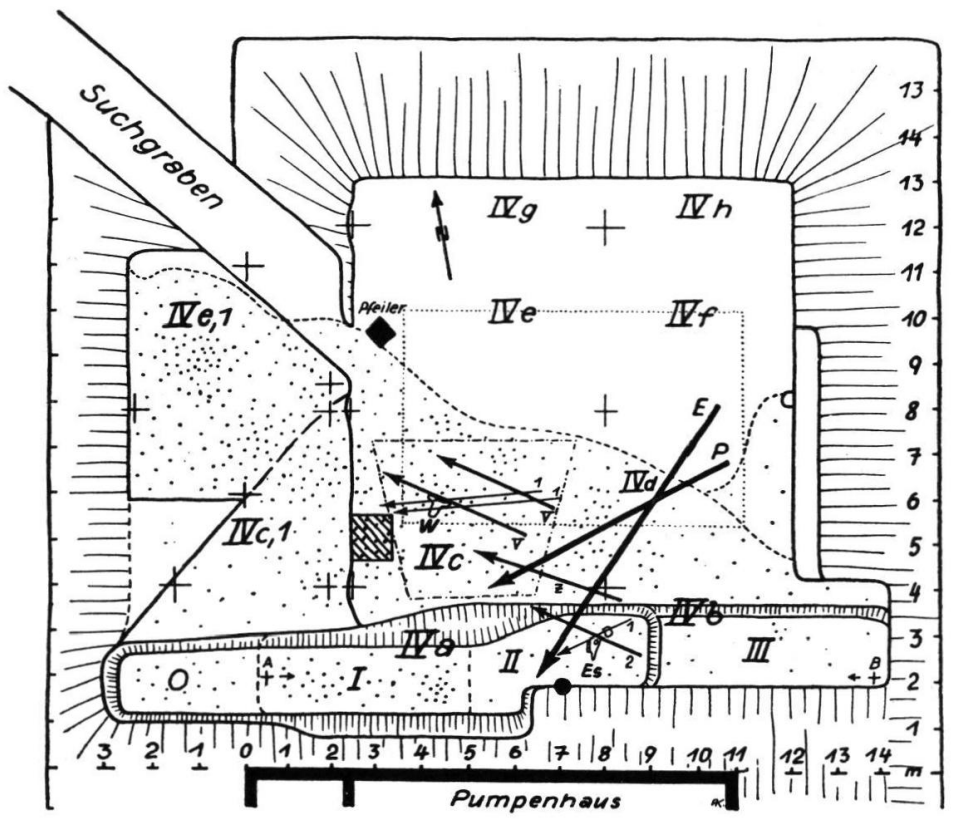

Abb. 1. Situationsplandes Grabungsfeldes von Salzgitter-Lebenstedt, Januar-Juni 1952, mit seitlich aufgetragenen $K$ oordinaten in m. Me $\beta$ basis: Nordseite des Pumpenhauses, Grund-M $\beta$ stre cke : A-B. $\mathrm{Grab}$ u g f flä ch e n : I, 1. Versuchsgrabung; dann Fortsetzung II und III; IV a-h, Hauptgrabung; IV c 1, „Dreiecksfläche“; IV e 1 „Trapezfläche“. Darüber großer S u c h graben nach NW. Punktierte Fläche: schematische Angabe der gesamten horizontalen Verteilung und Dichte von Knochenfunden. Gestrichelte Lin ie : deren Begrenzung nach Norden. Es: Fundplatz des Pferdeschädels, W: Fundplatz des Wisentschädels. E, P und z: gleiche Bezeichnung der Resultanten wie in $\mathrm{Abb} 5$. Die Bezeichnung der Pfeile bei Wisent- und Pferdeschädel entspricht den Bezeichungen in Abb. 7, 10, 11. Schraffierte Fläche: Lage von Abb. 3. 
der kollagenen Knochensubstanzen stattgefunden. Jugendliche oder in Entwicklung begriffene Knochenteile sind aber auch in diesem Einschlußmittel sehr schlecht erhalten. Dies trifft vor allem z. B. bei jugendlichen Wirbelkörpern von Mammut und offensichtlich B a s t geweihenden zu. Hier ist die Spongiosa äuBerst hinfällig, und die äußere Deckschicht bzw. Knochenlamellen sind meist nicht mehr vorhanden ${ }^{1}$ ).

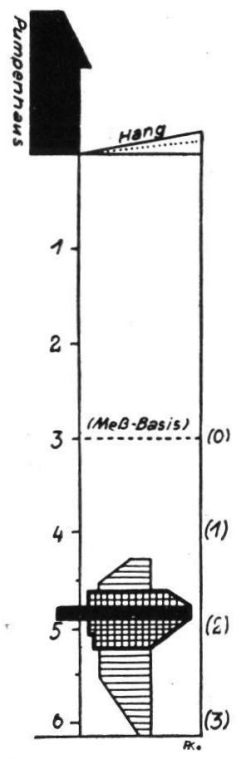

Abb. 2. Vertikale Verteilung und Dichteder Knochenfunde (vgl. hierzu Tab. I). 1. horizontale Striche: Gesamtfundschicht; 2. gekreuzte Striche: Hauptfundschicht; 3. schwarz: Zentralfundschicht.

Anm. ${ }^{1}$ ). Große Schwierigkeiten bereitete die Konservierung derartiger empfindlicher Knochenteile im Grabungsfeld. Direkte sofortige Behandlung mit Acetonlack sowie auch vorherige Austrocknung mit der Lötlampe erwiesen sich wegen der Hinfälligkeit und der übergroßen Wasserhaltigkeit der Objekte als nicht anwendbar. Wir haben sie deshalb nach Abdeckung mit Seidenpapier von oben in situ eingegipst und nach Unterschrämen durch Einschluß auch des dicht anliegenden Einbettungsmittels durch Auflage einer Gipsschicht von unten fest abgeschlossen. Die gleiche Methode wurde dann später zur Gewinnung von Schauplatten in größerem Ausmaß (bis $2 \times 2 \mathrm{~m}$ ) angewandt, indem vorher ein Holzrahmen, in einigen Fällen noch unterteilt, um das entsprechende Objekt erstellt wurde. Kleinere empfindliche Knochen wurden nach der Bergung über 70\% Mastixlösung überführt. Die Stärke dieser Mastixlösung war so gehalten, daß sie zwischen den Fingerbeeren klebrig wirkte. Verbleib in den einzelnen Lösungen je nach Größe 5-30 Minuten. Bei größeren Objekten empfiehlt es sich, im Alkohol mit einer Wasserstrahlpumpe die Objekte zu entlüften. Nach dem Mastixbad, das auch in steigender Reihe mit höheren Konzentrationen noch wiederholt werden kann, erfolgt einfaches Abtrocknen auf Fließpapier und evtl. noch Überzug mit einem etwas dauerhafteren Acetonlack (Schellack). Die größeren Knochen (auch die oben erwähnten jugendlichen Knochenteile) wurden nach gutem Austrocknen in einem kühlen Raum im Landesmuseum nach folgender Methode (Präp. Grabau) behandelt:

drei Lösungen: a) $100 \mathrm{~g}$ Tafelleim auf 8 Liter Wasser

b) $100 \mathrm{~g}$ Tafelleim auf 4 Liter Wasser

c) $100 \mathrm{~g}$ Tafelleim auf 2 Liter Wasser

zu allen 3 Lösungen für je $100 \mathrm{~g}$ Leim Zusatz:

10 g Leinöl,

$10 \mathrm{~g}$ Terpentin oder TerpentinöI,

5 g Karbolsäure (odẹr Thymol).

Lösungen heiß ansetzen, Einwirkungsdauer 18-24 Stunden; nach jedem Lösungsbad in kühlem Raum abtrocknen lassen. 
Die $\mathrm{r}$ ä u m liche Verteilung der Knochen im Grabungsstoß deckt sich hinsichtlich der Begrenzung ihres Vorkommens und ihrer Konzentrierung nicht ohne weiteres mit der der Stein-Artefakte, die z. B. vor allem horizontal weiter verstreut lagen (vgl. ToDE). Die Wirbeltierknochen treten in einer breiten Schüttung auf, und zwar in einer etwa $100 \mathrm{qm}$ großen, fast dreieckigen Fläche im Südwestteil des ca. $180 \mathrm{qm}$ großen Grabungsfeldes, wie wir sehen werden, im wesentlichen an einem von Nordosten nach Südwesten einfallenden Hang bzw. vor diesem (vgl. hierzu auch die anderen Berichte und Abb. 1). Die horizontale Fundverteilung des Knochenfeldes ist aus Tabelle I und Abb. $2 \mathrm{zu}$ entnehmen. Diese Einteilung ist aber zunächst nur als eine methodisch-s chema$t$ is che nach der Fund-Dichte in den einzelnen $5 \mathrm{~cm}$ mächtigen horizontalen Grabungs-Schnitten anzusehen. Sie entspricht demnach nicht ohne weit e r e s einer natürlichen Anordnung nach etwa faziellen Einheiten!

Tabelle I. Horizontale Gliederung der Knochenfunde

\begin{tabular}{c|c|c|c|c}
\hline & $\begin{array}{c}\text { Lage unter } \\
\text { Erdoberfläche } \\
\mathrm{cm}\end{array}$ & $\begin{array}{c}\text { Mächtigkeit } \\
\mathrm{cm}\end{array}$ & \multicolumn{1}{c}{ Fund-Dichte } \\
\cline { 2 - 5 } & $\mathrm{a}$ & $\mathrm{b}$ & $\mathrm{c}$ & $\mathrm{d}$ \\
\hline 1. & $\begin{array}{l}\text { Gesamt- } \\
\text { Fundschicht }\end{array}$ & $425-610$ & 185 & $\begin{array}{l}\text { schwach bis mittel } \\
\text { Konzentrat-Zunahme oben } \\
\text { schneller als unten } \\
\text { Konzentrat-Abnahme }\end{array}$ \\
\hline 2. & $\begin{array}{l}\text { Haupt- } \\
\text { Fundschicht }\end{array}$ & $460-520$ & 60 & $\begin{array}{l}\text { groß } \\
\text { oberhalb der 5m-Grenze } \\
\text { größere Häufung als in } \\
\text { tieferen Abschnitten }\end{array}$ \\
\hline 3. & $\begin{array}{l}\text { Zentral- } \\
\text { Fundschicht }\end{array}$ & $480-490$ & 10 & sehr groß
\end{tabular}

Die Schilderung der Einschlußmedien und ihre Anordnung in den einzelnen Horizonten wird mehr Gegenstand der anderen - geologischen und archäologischen - Fachberichte sein. Hier sei zunächst nur erwähnt, daß in der Zentral-Fundschicht die Knochen sich vornehmlich in dem humosen Medium vorfanden und an mehreren Stellen (Abb. 1 und 3) in klar erkenntlich, wenn auch stratigraphisch wenig Spezifisches aufweisenden, größeren Packungen und Anhäufungen bzw. dichter angeordnet waren. Hierbei handelte es sich allerdings stets um besonders große und sperrige Knochenteile: Rippen von Wisent und Mammut sowie Rengeweihe.

Derartige Anhäufungen können natürlich rein zufällig, etwa durch Zusammenwerfen, zustande gekommen sein. Andererseits können sie ihre Entstehung einem Zusammenführen durch eine Strömung verdanken, worauf die Sperrigkeit ihrer Einzelteile hinweist, die sich im strömenden Wasser leicht festsetzen und dann auch weitere herangeführte, weniger sperrige Knochenteile festhalten. Die Unregelmäßigkeit der sie zusammensetzenden Gebilde verhinderten zunächst Feststellung und Nachweis strömungsfunktioneller Strukturen innerhalb solcher Packungen. Dazu kommt, daß im Gesamtbild aller einzeln liegenden Knochen der Grabung ebenfalls zunächst keinerlei Einregelungsmodi nachzuweisen waren, die den Schluß auf einen bestimmten Strömungsverlauf rechtfertigen (vgl. Abb. 2 im Beitrag Tode II). 


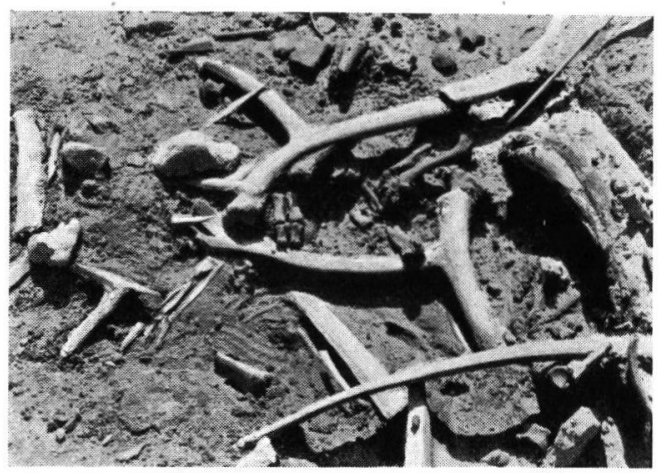

Abb. 3. Freigelegte oberste Schicht der Pa ckung sperriger Knochenteile in Fläche IV c (Lage vgl. Abb. 1, schraffierte Fläche).

Um den Einbettungsverlauf zu klären, ist man schon auf Detailbeobachtungen und deren gegenseitige Abstimmung angewiesen. Hierfür konnten bis jetzt einmal $\mathrm{Nachweise}$ individueller $\mathrm{Zusammengehö-}$ rigkeit einzelner Knochenteile innerhalb des ganzen Fund-Konglomerates herangezogen werden. Ferner haben hier Einzelanalysen der E in b e t t ung sund Lagerungsverhältnisse bei einem Wisent-und einem Pferdeschädel Beachtung zu finden, da sie uns Wirkungsmechanismen in bestimmten Teilen des Fundfeldes erschließen. Obgleich es sich in diesen Fällen jeweils nur um örtlich enger umrissenes Geschehen handelt, dürften ohne Zweifel diese Beobachtungen ihr Teil zum Verständnis und zur Deutung des Gesamttatbestandes, den der Fund in sich schließt, beisteuern. Können doch diese Dinge nicht allein, sondern nur im Rahmen einer Gesamtschau gesehen und gewertet werden.

Individuelle Zusammengehörigkeit von einzelnen Knochenteilen konnte bisher in folgenden Fällen nachgewiesen werden:

1. ein Ober- und Unterkiefer-Molar vom Mammut durch Herrn Dr. E. GuenTHER, Kiel, der die Bearbeitung der Elephas-Molaren dankenswerterweise übernommen hat (s. dessen Bericht);

2. zwei Rengeweihstangen (Abb.4), die sich so stark gleichen, daß bei der hohen Variabilität dieser Organe eine Zusammengehörigkeit angenommen werden kann;

3. Kopfknochen eines Hechtes, von denen drei mit einwandfreien Fund-Coordinaten vorliegen und entsprechend auswertbar sind (s. Tab. IV);

4. Teilstücke eines Pferdeschädels (s. Tab. IV).

Bei den Elephas-Molaren handelt es sich um die eines jugendlichen Tieres. Ihre Daten gibt Tab. II wieder. Die Tiefenstreuung beträgt $115 \mathrm{~cm}$, die Streuung in W-O-Richtung $815 \mathrm{~cm}$, in N-S-Richtung $75 \mathrm{~cm}$. Das westliche Stück liegt also nördlicher und höher, das östliche tiefer und südlicher. Guenther betont daher mit Recht, daß hieraus keinerlei Schlüsse „,auf relatives Alter von Funden noch auf Zusammengehörigkeit" gezogen werden können. Umsomehr, da diese auffälligen, großen und schweren Zähne mit hoher Wahrscheinlichkeit von den Jägern einzeln und willkürlich fortgeworfen sein können, und zwar noch dazu von ganz verschiedenen Standpunkten aus. Nur mit diesem Vorbehalt ist allenfalls eine Diskussion der Lagewerte im Rahmen der weiteren Befunde erlaubt. 
Tabelle II. Funddaten der individuell zusammengehörigen Elephas-Molaren

\begin{tabular}{|c|c|c|c|c|c|c|c|c|}
\hline & \multirow{2}{*}{$\begin{array}{c}\left.\text { Lfd. }{ }^{2}\right) \\
\text { Nr. }\end{array}$} & \multirow{2}{*}{$\begin{array}{c}\left.\text { Fund- }{ }^{2}\right) \\
\text { Nr. }\end{array}$} & \multirow{2}{*}{ Datum } & \multirow{2}{*}{ Fläche } & \multicolumn{3}{|c|}{ Fund-Coordinaten } \\
\hline & & & & & & Tiefe & $\left.\mathrm{W}-\mathrm{O}^{3}\right)$ & S-N $\left.{ }^{4}\right)$ \\
\hline & a & b & c & d & e & $\mathrm{f}$ & g & $\mathrm{h}$ \\
\hline & & & & & & $\mathrm{cm}$ & $\mathrm{cm}$ & $\mathrm{cm}$ \\
\hline 1. & $\mathrm{M}^{1}$ oder $^{2}$ r. $\mathrm{o}$. & M 10 & $916 a$ & 10. 6. & IVco (IV) & 495 & 85 & 590 \\
\hline 2. & $\mathrm{M}_{2} \mathrm{l} . \mathrm{u}$. & M 23 & - & 6. 6 . & IVd (VII) & 610 & 900 & 515 \\
\hline 3. & Differenz & & & & & 115 & 815 & 75 \\
\hline
\end{tabular}

Anm. 2). Nicht alle eingemessenen und auf die Pläne eingetragenen Fundstücke haben während der Grabung sofort eine Nummer zugeteilt erhalten. Erst nach der Determinierung erfolgte jeweils innerhalb der Artzugehörigkeit eine nochmalige durchlaufende Nummernzuteilung unter einem entsprechenden Kennbuchstaben, bei der alle, auch die sogenannten "Lesefunde“ (= nichteingemessenen, lagemäßig unsicheren oder aus dem Abraum aufgelesenen Fundstücke) erfaßt wurden. Das Verfahren erleichtert Durchfinden bei der Bearbeitung sehr.

Anm. ${ }^{3}$ ). Parallel der $\mathrm{M}$ e $\mathrm{Bb}$ a s is $=$ Nondwand des Pumpenhauses (s. Abb. 1).

Anm. ${ }^{4}$ ). Senkrecht zur Meßbasis = annähernde Nordrichtung (s. Abb. 1).

Die zwei Rengeweihstangen sind ein rechtes und linkes Basalstück, die beide in etwas verschiedenem Abstand oberhalb der Hintersprosse abgebrochen sind. Die distalen Enden der Augen- und Eissprosse fehlen ebenfalls (vgl. Abb.4). Ihre Lagedifferenzen sind nach allen Seiten sehr unbedeutend. Immerhin liegt auch hier das westliche Stück höher und nach Norden, das östliche südlicher und tiefer. Die Höhendifferenz entspricht dabei dem normalen Abstand der Rosenstöcke am Schädel bei seitlicher Lagerung. Für beide Stücke dürfte im übrigen das gleiche wie für die Elephas-Molaren gelten.

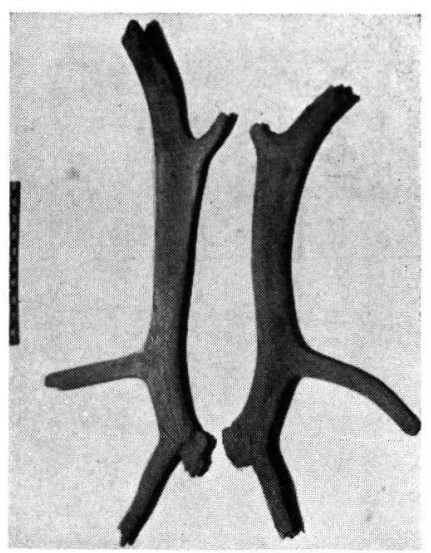

Abb. 4. Zwei individuell zusammengehörende $\mathrm{R}$ e $\mathrm{n}$ ge wei h s t a n gen (s. Text).

Tabelle III. Funddaten der individuell zusammengehörigen Rengeweihstangen

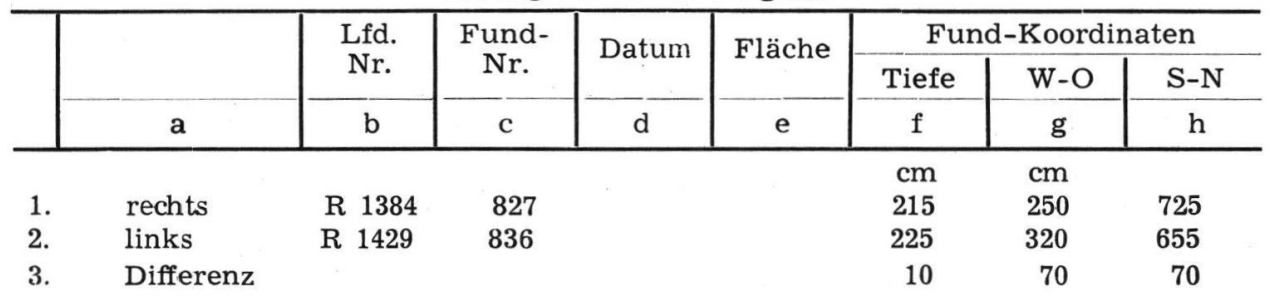


Ganz anders liegen aber die Dinge bei den beiden folgenden Fällen. Vor allem bei den Knochen des $\mathrm{Hechts} \mathrm{ch}$ ädels. Selbstverständlich ist für den Hecht auch anzunehmen, daß er eine Jagdbeute war; aber ebenso sicher ist wohl auch die Annahme, daß die Eiszeitjäger nicht die einzelnen relativ kleinen Hechtschädelknochen ausgelöst und sinnvoll in der Gegend verstreut haben. Sondern sie haben den Kopf im ganzen abgetrennt und fortgeworfen. Dieser hat sich dann irgendwo am Hang in seine Bestandteile aufgelöst, und diese sind nun nach und nach über kurze Strecken durch irgendwelche, aber bestimmt nicht willkürlich menschliche, Kräfte zerstreut worden. Bei der Prüfung der Fund-Koordinaten ergibt sich nun, daß die zwei am nördlichsten gelegenen Stücke erheblich höher und östlicher liegen als das südlicher gelegene Stück, ferner, daß von den beiden ersteren das östlich gelegene eine geringe Lagedifferenz nach Süden sowie eine etwas größere nach Osten aufweist. Ein alle

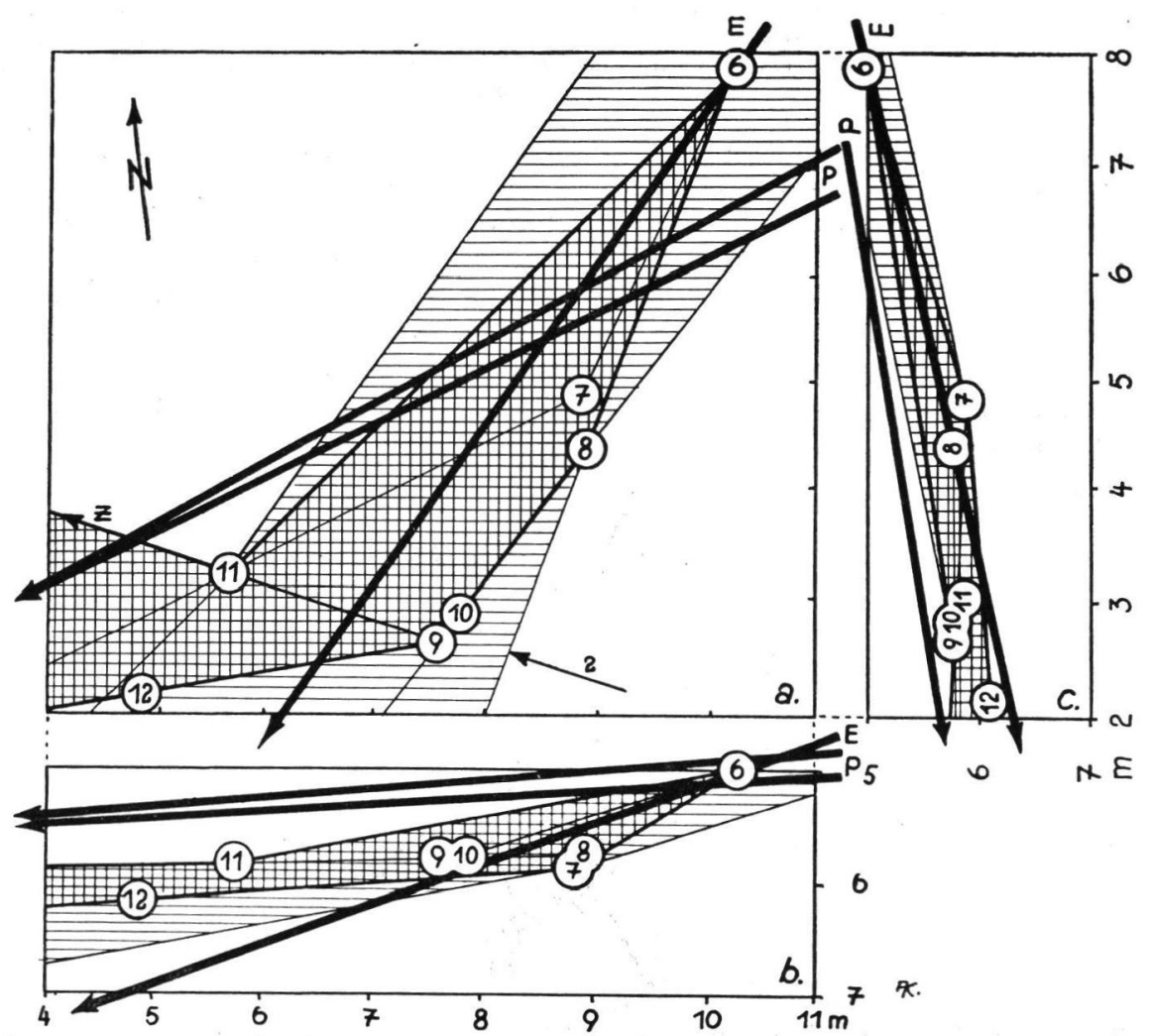

Abb. 5. Richtungs-und Gefällediagramm derzerstreut aufgefundenen Teilstücke des Pferdeschädels (s. Tab. IV, 6-13 u. Text). a) in horizontaler Aufsicht, b) vertikal im W-O-Profil, c) vertikal im N-S-Profil. 6-12: Lage der Knochenteile; die Verbindung dieser Punkte untereinander umreißt die gekreuzt schraffierten Räume. $\mathrm{E}$ ist darin die Hauptresultante aller Richtungen, bezogen auf den am höchsten gelegenen Punkt 6, von dem aus alle übrigen Teile in der Grundrichtung $\mathrm{E}$ sich zerstreut haben müssen. Parallelen durch die seitlichen Extrempunkte (in a: 8 und 11, in b: 7, in c: 7 und 9) geben die engere Variationsgrenze dieses Bewegungsvorganges (= einfach schraffierter Raum) im Schichtpaket an. $\mathrm{z}=$ verlängerte Verbindungslinie zwischen 9 und 11 in a und der Pfeil 2 entsprechen den gleichen Bezeichnungen in Abb. 1 und 11. - $\mathrm{P}=$ entsprechende Resultanten der Hechtschädelknochen (s. Tab. IV, $1-5 \mathrm{u}$. Text). 
Fundpunkte verbindendes Dreieck liegt also mit seinen längsten Seiten deutlich nach Südwesten geneigt und auch mit seiner südlichen Basis etwas nach dieser Seite hin abfallend (vgl. hierzu Tab. IV und Abb. 5, P). Bezogen auf das am tiefsten gelegene westliche Stück läßt sich eine Hauptneigungs-Resultante innerhalb des Grabungsstoßes für diese drei Fundpunkte berechnen, deren Verlauf aus Abb. $5 \mathrm{zu}$ entnehmen ist: sie ist eine im wesentlichen schwach von $\mathrm{O}$ nach W, etwas stärker von $\mathrm{N}$ nach $\mathrm{S}$ und deutlich von NO nach $\mathrm{SW}$ gerichtete Linie.

Für die Darstellung eines solchen Vorganges noch günstiger sind die Verhältnisse bei den sieben Einzelstücken eines $\mathrm{Pferdeschädels,} \mathrm{da} \mathrm{die}$ größere Zahl der Fundpunkte die Beurteilung einer Streuung besser ermöglicht. Das Ergebnis ist ebenfalls aus Tabelle IV und Abb. 5 abzulesen. Zwar weichen die Resultate für Hechtschädel und Pferdeschädel von einander $a b$, sind aber im Grunde doch prinzipiell gleichsinnig ausgerichtet:

1. die NS-Neigung ist bei beiden so gut wie gleich;

2. die OW-Neigung ist in einem Falle zwar stärker, aber einwandfrei gleichsinnig;

3. das gleiche gilt für die Horizontalrichtung, die allerdings für den Pferdeschädel etwas stärker nach Osten abweicht.

Tabelle IV. Fund-und Lage-Verhältnisseder individuellzusammengehörenden, aber zerstreut aufgefundenen Hechtund Pferdeschädelteile:

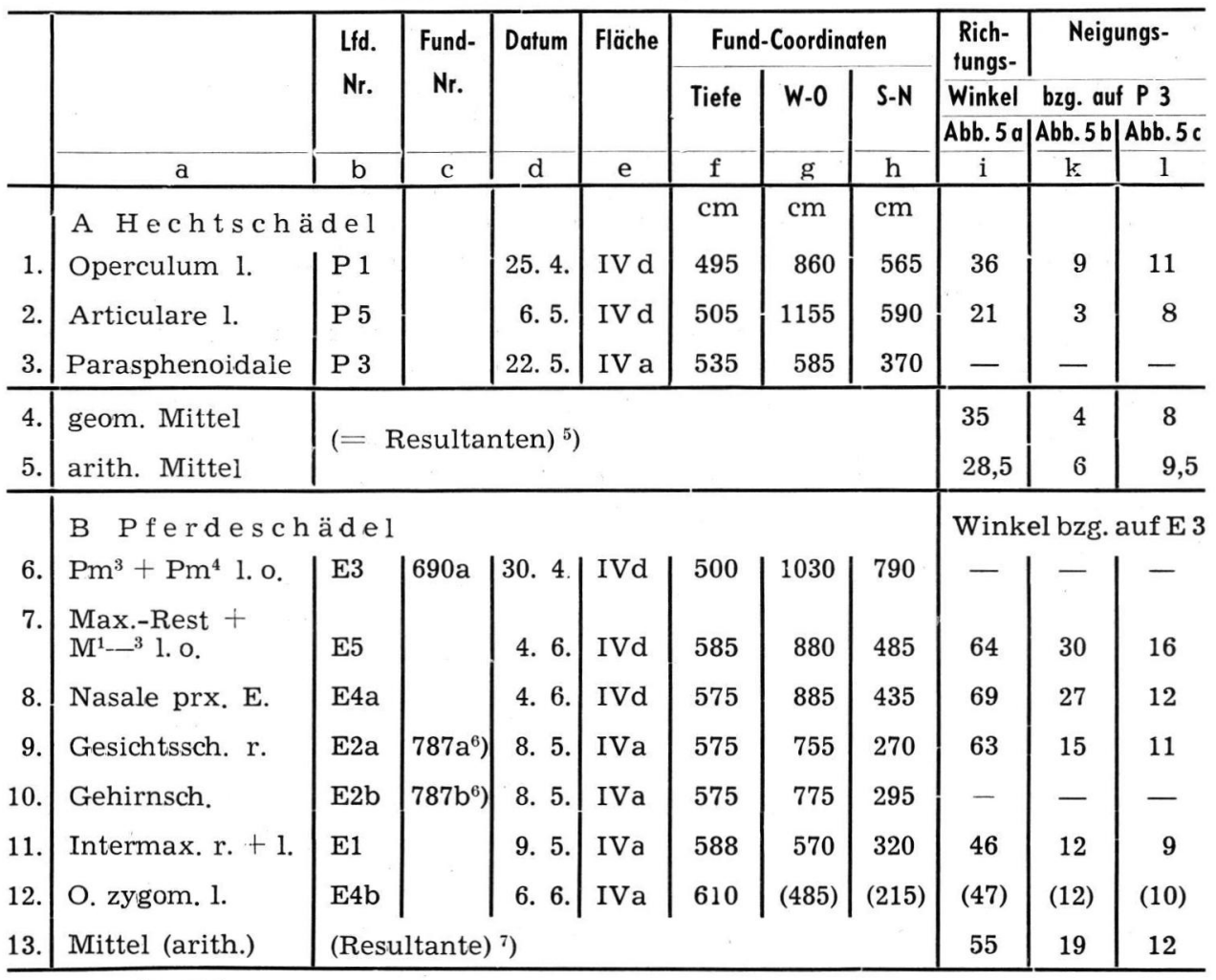

Anm. ${ }^{5}$ ). Abb. 5 „P“.

Anm. ${ }^{6}$ ). E 2a $==$ Abb. 11, C; E 2b = Abb. 11, B.

Anm. ${ }^{7}$ ). Abb. 5 „E“. 
Hierbei fällt in die Augen, daß bei Berücksichtigung der Streuung für die Gefällewerte nach Süden und Westen eine Tendenz zum Einbiegen in die Horizontale besteht. Für die Differenzen der Resultanten in der horizontalen Richtung wie in ihrer WO-Neigung bei Pferd und Fisch sind vielleicht Schwereverhältnisse verantwortlich zu machen: der leichtere Knochen wurde weiter nach Westen transportiert, und damit kam auch ein flacheres OW-Gefälle bei der graphischen Darstellung zustande.

Fassen wir die einzelnen Fundpunkte, sowohl der Hechtkopfknochen wie auch der Pferdekopfknochen jeweils für sich, als Teile eines gemeinsamen Systems auf, wozu wir auf Grund der Zusammengehörigkeit der Knochenteile berechtigt sind (sie gehören im ersten Falle auf Grund ihrer Größendimensionen, im anderen Falle nach Größe und dem gnauen Ineinanderpassen der Bruchkanten zusammen), so kommen wir zur Vorstellung von übereinander liegenden Schichtflächen, die im Grabungsstoß sowohl von NO nach SW schräg einfallen als auch nach Süden geneigt sind. In diesen Einheiten dürfte nicht nur ein gleichsinnig räumliches, sondern auch gleich zeitiges Geschehen zum

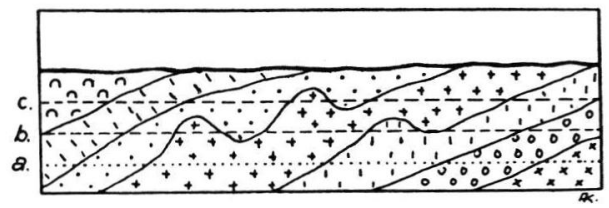

Abb. 6. Schema gleichsinnig geneigter Schichtflächen, die bei horizontalem Anschnitt im Fall a (gepunktet) eine ungestörte zeitliche Abfolge von Anschnitten ergeben, dagegen nicht im Fall b und c (gestrichelt) infolge der dort vorhandenen Reliefverschiedenheiten.

Ausdruck kommen: da das System der Hechtknochen über dem der Pferdekopfknochen liegt, dürften die letzteren f r ü h e r, die ersteren ihren Fundplatz s päter erreicht haben. Jede dieser Schicht-Flächen-Einheiten ist aber nun weiter für sich zu beurteilen, da eine Verallgemeinerung der Variabilität ihres Reliefs und möglicher Reliefveränderungen - z. B. durch Frosbodenerscheinungen („Brodelungen“) - nicht ohne weiteres Rechnung trägt, noch tragen kann. Hinweise auf diesen Umstand sind aber ohne Zweifel die Fundpunkte, die den Verbindungslinien zu den anderen, die in der allgemeinen Richtung der Resultanten liegen, e $n t g$ e g e $n \mathbf{l}$ a u f e $n, d$. h. einen Neigungsabfall nach Osten oder Norden zeigen. Sind es doch im ganzen viel zu wenig Fundpunkte, als daß sie uns ein wirklich genaues Bild der Oberfläche der jeweiligen Schichtebene vermitteln könnten (s. Abb.6).

Die Gleichsinnigkeit der Resultanten bei Hechtschädel und Pferdeschädel dürfte aber die Grundtendenz des Verlaufs einer Schüttung nach Richtung und Gefälle bereits weitgehend verdeutlichen. In diese damit gewonnene Vorstellung eines Systems lassen sich nun vielleicht auch, d. h. mit gebotener Vorsicht, die Befunde an den individuell zusammengehörenden Mammutzähnen und Rentiergeweihstangen einordnen. Das heißt, daß, bei der Beurteilung von Zusammenhängen innerhalb des Fundstoßes, diese in Vorstehendem nachgewiesene hangparallele und gleichzeitige, von $\mathrm{O}$ nach $\mathrm{W}$ abfallende Neigung fazieller Einheiten zu berücksichtigen ist, was ich schon oben bei der horizontalen Gliederung der Knochenfunde andeutete.

Welche Kräfte im einzelnen für die in diesen Systemen zutage tretenden Bewegungen verantwortlich zu machen sind, ist dann noch eine weitere Frage, deren Beantwortung zunächst zurückgestellt sei. Bei ideeller ungestörter Aufeinanderfolge solcher geneigten Schichtflächen ergibt sich bei horizonta- 
lem AufschluB, wie er bei unserer Grabung durchgeführt wurde, eine zeitlich hintereinander angeordnete Abfolge von entsprechenden Anschnitten auf der Grabungsfläche bzw. Schnittebene. Bei Reliefverschiedenheiten der geneigten ursprünglichen Schichtflächen aber ist diese Abfolge notwendigerweise selbstverständlich uneinheitlich und gestört. Infolge der erheblichen Frostbodenerscheinungen muß hiermit in unserem Falle besonders gerechnet werden, da diese die Ablagerungsschichten teilweise sehr stark verwürgten bzw. zerbrodelten (vgl. Abb. 12). Doch muß ich die Beurteilung dieser Dinge den geologischen Fachbearbeitern überlassen, glaube aber, daß mit den hier geschilderten Dingen ein methodischer Beitrag für die Gesamtbeurteilung geliefert wurde, deren Wert sich im einzelnen noch erweisen wird.

Ferner wurden nun von mir zwei eingehende Einzelanalysen der Ein be ttungs- und Lagerungsverhältniss e bei einem Wisent- und einem Pferdeschädel durchgeführt. Hierbei wurden die Ausrichtung der Einzelteile bzw. auch der diese umgebenden, eng benachbarten andersartigen Knochenteile, sowie das umgebende Einschlußmittel nach Korngröße, Sortierung, Art und Form seiner Anordnung im einzelnen berücksichtigt.

Abb. 7. Halbschematische Darstellung des Wisentschädelrestes mit denihnumgebenden Geweihstücken und Knochenresten in situ mit den beiden Muddkegeln A und B. $M=$ Mammutmolar (Nr. M 11). R 1 = Ren, Ellbogengelenk. R $2=$ Ren, Geweihstangen. W $1=$ Rippen. $\mathrm{E}=$ Pferd, Metatarsale. Die Pfeile (V, 1, 2, 3) geben Strömungsrichtungen an. Strichelung neben $\mathrm{R} 2$ und $\mathrm{W} 1=$ hellgraue, sehr feinkörnige (schmierige) tonige

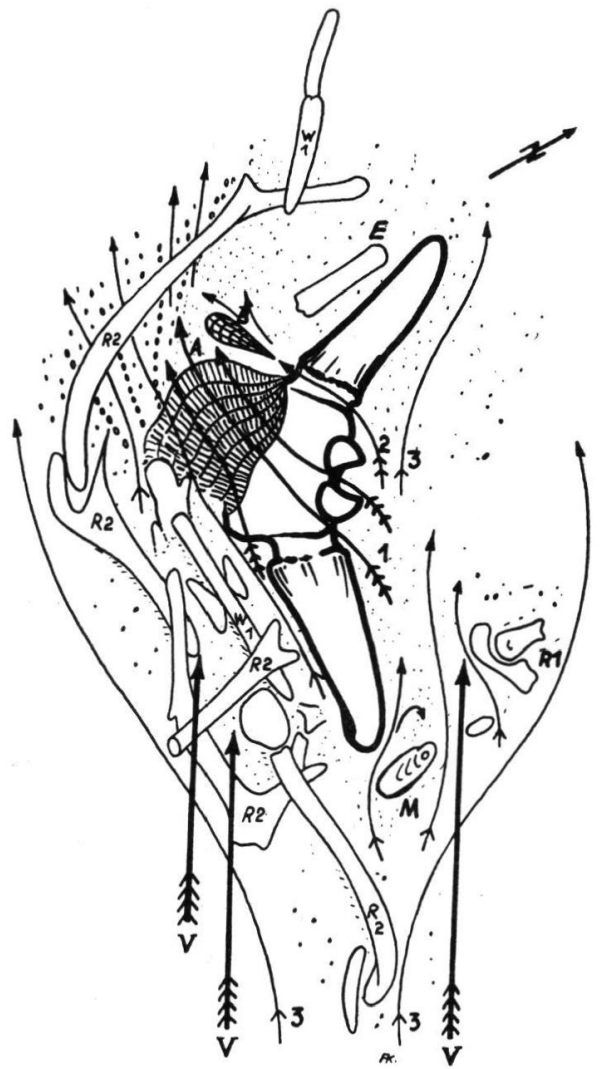

Für den Wisentschädel (Abb. 7-10) konnten dabei folgende Feststellungen gemacht werden:

a) Die um den Schädel liegenden Knochenteile zeigen eine deutliche Ausrichtung allgemein von Ost nach West, besser nach NW, nahezu gleichsinnig im Sinne der gemeinsamen Richtung der beiden Hornzapfen (Abb. 7, 9). 
b) Der Wisentschädel lag auf dem Stirnteil, seine Unterseite nach oben gekehrt. Vom Gebiß des Oberkiefers war nichts erhalten (abgeschoren?), ebenso fehlte die linke Hornspitze in einer Länge von ca. $7-8 \mathrm{~cm}$. Der Unterkiefer war ebenfalls nicht vorhanden.

c) Auf der Mitte des Schädels, seine Basis weitgehend bedeckend, lag ein breiter Schuttkegel aus muddiger, dunkler humoser Erde, der sich etwa von der Mittellinie des Schädels schräg nach vorn in ziemlich genau westlicher Richtung abflachte (s. Abb. 7, 8, A).

d) Nach NW lag neben diesem Muddekegel (A) ein weiterer, ganz flacher, birnenförmig sich zuspitzender Muddekegel auf einer Unterlage feinkörnigsten reinen Sandes, der mit seiner Spitze genau auf den linken, tief eingeschnittenen Hornhals zeigte (Abb. 7 u. 8, B).

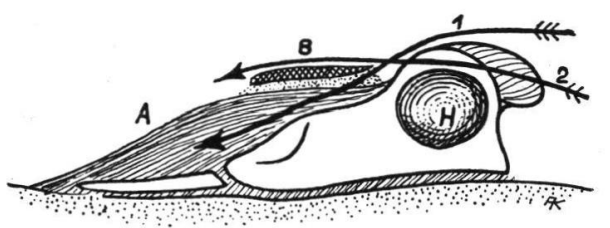

Abb. 8. Querschnittschemadurch den $\mathrm{W}$ is entsch ädel. A = breiter Muddkegel. $\mathrm{B}=$ flache, birnenförmige Muddlinse auf Sandsockel. $\mathrm{H}=$ Hornzapfen-Querschnitt, darüber der Hornzapfenhals, durch den die flache Strömung 2 geht. - Abb. 9 (rechts). B lick a us NW auf den fast ganz freigelegten $\mathrm{W}$ is entsch äd el mit den ihn umgebenden Knochenteilen. Man erkennt deutlich, daß die Knochenpackung, auf der dem Beschauer abge-

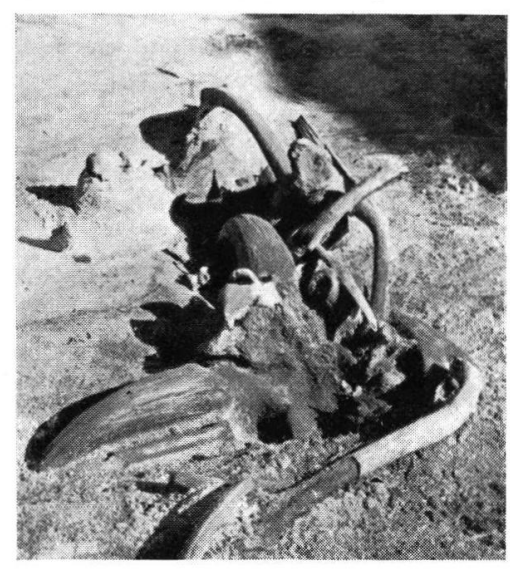
wandten Seite, mit einer weit vorspringenden Spitze der auf Abb. 7 mit V bezeichneten Hauptstromrichtung entgegengerichtet ist, dagegen in der Stromrichtung, zum Beschauer hin, sich verbreitert.

Phot. A. KLEINSCHMidT.

e) Unterhalb des östlichen Endes des großen Muddekegels (A) fanden sich die beiden Nasenbeine in normaler Lagerung und Zusammenhang, das heißt, ohne gegeneinander verschoben zu sein. Jedoch zeigte sich die Achse der Schädelbasis gegenüber der Mittellinie der beiden Nasenbeine um einen deutlichen Betrag verschoben; und zwar ließ sich bei Auswertung von Photographien zeigen, daß der Schädelteil mit den Hornzapfen gegenüber den Nasenbeinen auf der Spitze des rechten Hornzapfens um einen bestimmten Betrag gedreht worden war (vgl. hierzu Abb. 10, a, b, c).

Aus diesen Feststellungen dürfte folgendes abzulesen sein: Der Schädel ist (ohne Unterkiefer?) ursprünglich mit dem Gebiß nach oben in einer Lage zur Ruhe gekommen, in der seine Achse in einer Richtung zeigte, die der Mittellinie der Nasenbeine entsprach (Abb. 10, $x_{1}$ ). Eine von der Seite her wirkende Kraft, durch die vermutlich auch der Gebißteil abgeschoren wurde, und durch die damit die Verbindung zwischen den Nasenbeinen und der Schädelbasis unterbrochen wurde, drehte dann diesen letzteren Teil auf der rechten Hornspitze in der unter e angegebenen Weise. Gleichzeitig mit diesem einigen Kraftaufwand erfordernden Vorgang wurde eine ganz Anzahl von Knochenteilen an und in die Nähe des Schädels herangeführt und lagerte sich um diesen in der unter a gekennzeichneten Weise. Daß diese Kraft eine ziemlich starke Strömung gewesen sein muß, ist nicht von der Hand $\mathrm{zu}$ weisen, denn dem entsprechen auch die Sortierungen der Korngrößen des umgebenden Sandbettes (vgl. hierzu Abb. 7a und 10). 


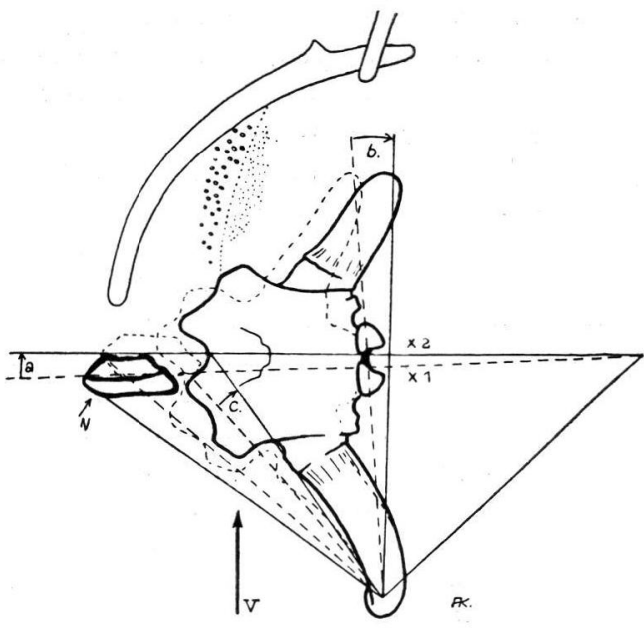

Abb. 10

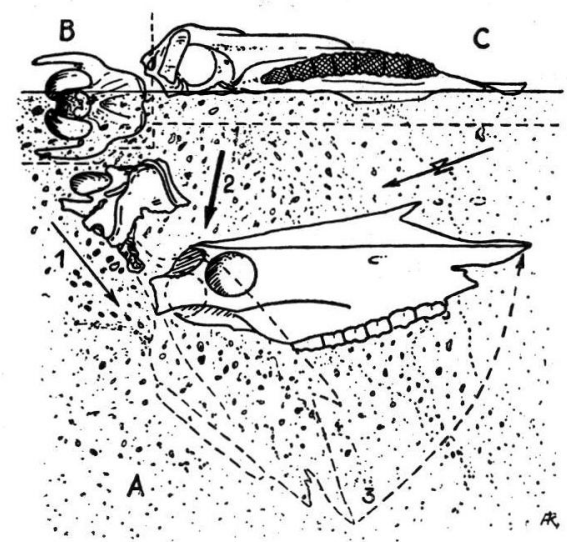

Abb. 11

Abb. 10. Schematische Darstellung der Verschiebung des Wisentschädels aus der ursprünglichen Lage $x_{1}=$ Richtung der Schädelachse, bezogen auf die in situ aufgefundenen Nasenbeine N. x2 = Richtung der Schädelachse, bezogen auf die in situ aufgefundene Schädelbasis; a. b. c. = Betrag der jeweiligen stattgehabten örtlichen Verschiebung.

Abb. 11. Halbschematische Darstellung des Pferdeschädels. A: Aufsicht von oben; Schädelteile ausgezeichnet: Lage in situ. Gestrichelt: ursprüngliche Lage der rechten Gesichtshälfte, die durch die Schwenkung 3 in die vorgefundene Lage gedreht wurde. B: Einbettungszustand des Hinterhaupts; Blick von Osten. C: Einbettungslage der rechten Gesichtshälfte; Blick von Westen. Aus B und C geht die relative frühere Festlegung des Hinterhaupts gegenüber dem Gesichtsschädelteil hervor. Beachte ferner die Verteilung der Korngröße der einschließenden Sande.

Diese starke Strömung ist aber anscheinend nur eine zeitlich begrenzte Erscheinung gewesen. Dies lehren die beiden Muddekegel (vgl. oben c. d.). Da diese aus sehr feinkörnigem und pflanzenhaltigem Material bestehen, können diese nur in einer sehr viel weniger heftig fließenden Strömung abgelagert sein. Die Wassermenge muß also in diesem Falle erheblich abgenommen haben und damit der Wasserspiegel gesunken sein. Solange dieser noch über das am weitesten emporragende Hinterhaupt, die beiden Condylen des Hinterhauptgelenkes, hinwegging, konnte sich so im Stromwinkel dahinter, etwa über der Mitte des Schädels, der Muddekegel A durch die dort auftretende Stromwalze aufbauen. Zwischen den parallelen Knochenlagen neben dem ostwärts gerichteten Hornzapfen setzten sich außerdem zu diesem Zeitpunkt in stromfreieren Winkeln tonige Niederschläge ab.

Bei weiterem Absinken des W a s e rstandes kann schließlich nur noch ein feiner Wasserfaden gerade durch den schmalen linken, etwas tiefer liegenden Hornzapfenhals geflossen sein. Die mit diesem Wasser durchtretenden Muddeteilchen bauten auf dem inzwischen stetig um den Muddekegel A angespülten, feinkörnigen Sand eine flache birnenförmige Muddelinse auf, die mit der Spitze auf den Hornhals zu zeigte (vgl. oben d), bis mit weiterem Absinken des Wassers auch hier die Strömung aufhörte und diese nur mehr längs des linken nach Westen zeigenden Hornzapfens weitergehen konnte. Diesem Verlauf entsprechen auch dort wie im Ganzen die Sortierungen der Sandkorngrößen.

Es läßt sich also damit nicht nur ein we chs elnder Strö mung s ver1 a u f mit verschiedener Kraftwirkung, sondern auch ein Wechsel der Wasser- 
menge und Fülle und damit ein Wechsel der Wasserhöhe und des Wasserstandes nachweisen. Und zwar nimmt demnach bei sinkendem Wasserstand die Strömung eine etwas andere Richtung ein; die Stromrichtung verläuft bei höherem Wasserstand mehr nach NW, bei niedrigerem mehr nach Westen.

Eine Bestätigung dieser fluktuierenden Stromrichtungen und Wirk ung en läßt sich auch an dem Pf e r d e s c hä d el ablesen. Dieser Schädelteil war, wie oben schon geschildert wurde, - es handelt sich um den Pferdeschädelteil lfd. Nr. E 2a/b - aus allgemein nordöstlicher Richtung an seinen Fundplatz gelangt. Auf diesem Wege waren ihm wesentliche Teile der rechten Gesichtshälfte verloren gegangen und hangaufwärts liegen geblieben (vgl. Tab. IV Ziffer 6-8). An seinem Fundplatz nahm das Reststück nun zunächst eine Lage ein, in der das fast vollständig erhaltene und damit schwerere und sperrige gesamte Hinterhaupt sich festlegte, dagegen der leichtere rechte Gesichtsschädelteil in südwestliche Richtung eingeschwenkt bzw. eingerichtet wurde. Das Hinterhaupt wurde nun sehr bald zur Hälfte in gröberen Kies unverrückbar eingebettet. Das nur mit ihm durch eine schwache Knochenbrücke noch verbundene übrige rechte Schädelstück blieb aber bis zu einem gewissen Zeitpunkt noch verschiebbar, solange es noch mit seiner Unterseite dem Boden auflag. Ihm fehlte ja der entsprechende linke Teil; es war also nicht so fest einsedimentiert wie das Hinterhaupt (vgl. hierzu Abb. 11). Wechselnde Strömungsrichtungen trennten vermutlich dann beide Teile und schwenkten den damit freigewordenen rechten Gesichtsschädelteil um einen ziemlichen Betrag nach Süden (Abb. 11, A/3 etc.). Vielleicht haben bei dieser Trennung auch Frosterscheinungen eine Rolle gespielt. Hierbei lassen sich zwei grundsätzliche, sich überschneidende wirksame Stromrichtungen annehmen, die in Abb. $11 \mathrm{~A}$ mit 1 und 2 gekennzeichnet sind.

Utberträgt man nun die bisherigen Beobachtungsergebnisse aus dem Richtungs- und Gefällediagramm der Abb. 5 und die Stromrichtungswerte der Abbildungen 7, 10 und 11 auf die Verhältnisse des gesamten Fundplatzes in die Abbildung 1, so ergibt sich folgendes:

a) die Richtung der stärkeren Strömung am Wisentschädel (Abb. $7 \mathrm{u}$. 18, V = starker Pfeil) sowie die Stromrichtung 2 beim Pferdeschädel (s. Abb. 11) und die Verbindungslinie der Fundorte 9 und 11 in Abb. 5a (z) verlaufen prinzipiell gleich in etwa nordöstlicher Richtung parallel der nördlichen Begrenzung des Hauptfundfeldes der Knochen, wie sie in Abb. 1 erkennbar ist. Faßt man diese Grenze als eine Uferlinie auf, so verläuft diese Stromrichtung normal, d. h. uferparallel.

b) Die nächstschwächere Stromrichtung am Wisentschädel (Abb. 7,1) und die Stromrichtung, 1 am Pferdeschädel (Abb.11) haben westliche bis südliche Tendenz. Ihre Richtung entspricht etwa der allgemeinen Längs-Achse der unteren großen Steinsohle (s. Abb. 4 in Beitrag Tode II), die dicht unterhalb der $6 \mathrm{~m}$-Grenze zum Vorschein kam.

c) Die Richtung der Resultanten $\mathrm{E}$ und $\mathrm{P}$ (Abb. 5) zeigen im Mittei die gleiche Richtungstendenz nach SW, in das sich auch das im OW- und NS-Aufriß aufgezeigte Hanggefälle einordnen läßt.

Hierbei dürfte der Fall a einem Zustand großer Wasserfülle entsprechen, bei dem das Tal weitgehend oder stärker ausgefüllt war. Im Falle b, bei sinkendem Wasserspiegel, folgt das Wasser im Ablaufen der freiwerdenden Hangneigung zur tiefsten Stelle, deren Verlaufsrichtung mehr nach Südwesten gerichtet ist, entsprechend der Lage und Richtung der in $6 \mathrm{~m}$ Tiefe vorhandenen großen Steinsohle (vgl. deren Abbildung im Beitrag Tode). 


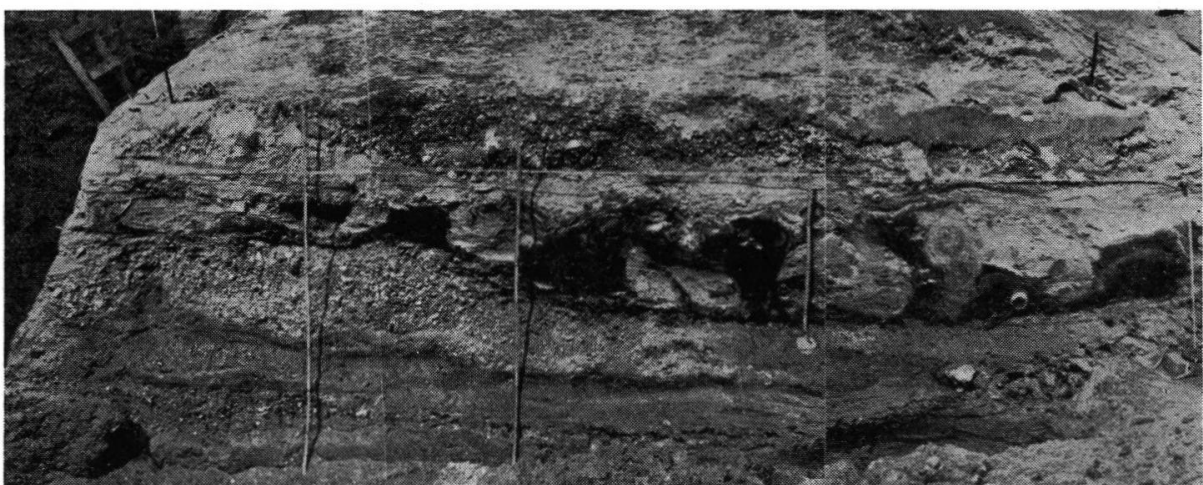

Abb. 12. Derstark verbrodelte Horizont der Hauptfundschicht i m W e stprofil im Stoß der Dreiecksfläche (IV c 1; vgl. Abb. 1 und 13). Man erkennt in den Muddschichten einzelne Knochen (ganz rechts Wisenthornzapfen).

Phot. A. KLEINSCHMidT.

Wie ich oben schon betonte, müssen aber alle derartigen Beobachtungen zunächst einzeln und ganz für sich betrachtet werden, da durch die FrostbodenErscheinungen und die damit verbundenen Aufbrodelungen das Bild allenthalben gestört ist (Abb. 12). Die Lage des einzelnen Knochens bei seiner Auffindung ist also immer unter diesem Gesichtspunkt zu prüfen. Nun läßt sich aber zeigen, daß der Einfluß der Brodelungen durchaus nicht durchgängig und allgemein ist. Sehr charakteristisch sind in unmittelbarer Nähe der runden, hellfleckigen Brodeltöpfe, inmitten des dunklen Bodens, aufgekantete und aufgestellte Knochenteile, die nur mitsamt des sie umgebenden Mediums in diese Lage gebracht sein können: eben eine Folge der kryoturbaten Bodenbewegungen. Diese scheinen sich aber immer nur in einem relativ eng umgrenzten Bezirk ausgewirkt zu haben. Denn unmittelbar neben einem solchen Brodeltopf fanden sich auch ungestörte Verhältnisse, wie ein Renfuß lehrt, dessen Knochen sich noch von der Fußwurzel bis zu den Zehenspitzen in den natürlichen Lagebeziehungen vorfanden. Die vollkommene ungestörte Lagerung dieses Fundes wird außerdem durch den Umstand noch unterstrichen, daß das eine Griffelbein vermutlich, nach Lockerung seiner Verbindung zum Lauf durch Fäulnis, lediglich seiner Schwere folgend, ohne seitliche Verschiebung in dem weichen, losen Mudd nach unten abgesunken war, und zwar distal wesentlich stärker als proximal, wo das zwar stark durch Fäulnis gelockerte, aber immerhin noch vorhandene Gewebe dem entgegenwirkte.

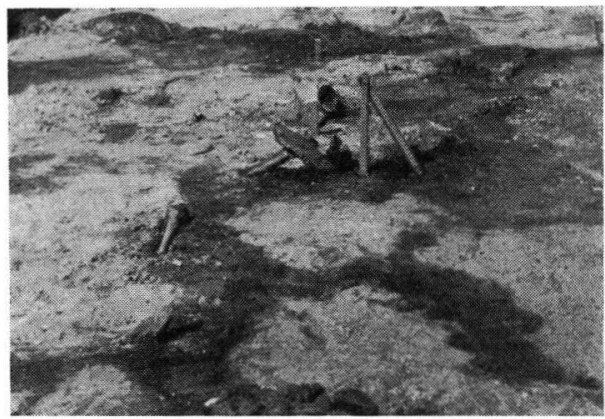

Abb. 13. Durch E is brodelung bzw. kryoturbate Vorgänge a u f g r i c h t e t e $\mathrm{K}$ n o c hen (Pferd, Metarcarpus; Renunterkiefer). Davor die kreisrunden hellen, sandigen Flecke der „Brodeltöpfe“.

Phot. A. KLEINSCHMidT. 
Unter Berücksichtigung solcher Umstände lassen sich nun auch manche andere Anordnungsstrukturen von Einzelknochen, selbst in dem so verwickelten, durch Brodelungen weitgehend gestörten Fundfeld verstehen, so z. B. eine Knochengruppe mit einem jugendlichen Mammutkiefer, der auf die Kaufläche seiner Mahlzähne herumgeklappt war und mit seiner Spitze auf den Verlauf einer gradlinigen Grenze zwischen dunklem Muddboden und hellem Sandboden zeigte. Längs dieser Grenze lagen, zu ihrem größten Teil mehr in dunklem Boden, eine Anzahl langer Knochen (Rippen von Ren, Mammut und Wisent). Diese waren alle im wesentlichen in der Richtung dieser Grenzlinie ausgerichtet, die ein Teilstück der oben angenommenen Uferrandlinie sein dürfte, so daß wir hier unter diesen Voraussetzungen von einer uferparallelen Ausrichtung sprechen können. Auch die Lage des Mammut-Unterkiefers zeigt ihre mechanische Besonderheit. Ein Elefanten-Unterkiefer besitzt so stark abgerundete und gebogene Unterkanten, daß er auf diesen aufliegend, sehr leicht bewegt und vor allem sehr leicht nach rückwärts über seine Gelenkfortsätze hinweg umgekippt werden kann. Der Mammutkiefer hat sicher ursprünglich mit seiner Spitze in ostwärtiger Richtung gelegen und ist dann herumgeschlagen und so auf die Kauflächen seiner Mahlzähne zu liegen gekommen. Die Gelenk- und Muskelfortsätze drangen dann infolge der Schwere des Objektes tiefer in den Boden. Es sei dahingestellt, ob Mensch oder Wasserkraft dies veranlaßte. Auffällig ist jedenfalls die gleiche Richtung dieses Vorganges zu den vorher erwähnten parallel gelagerten Knochenteilen. Ich glaube, daß sich bei weiterer sorgfältiger Prüfung der Verhältnisse im Knochenfeld noch mehr derartige Beispiele beibringen und analysieren lassen.

Wollen wir uns aber eine Deutung der Fundplatzverhältnisse in größerem Rahmen erlauben, müssen wir, über die bisher mechanisch-morphologischen Erörterungen hinaus, auch biologische Daten heranziehen. Dies geschieht am besten auf Grund der Fundliste der Arten, soweit sich diese bisher im einzelnen klären ließ.

Hier seien einige technische Bemerkungen eingefügt: Wie oben unter der Tabelle II in einer Anmerkung schon erwähnt, erhielten nach Freilegung, Einmessung und Aufnahme eine ganze Anzahl von Fundstücken keine Fundnummern, sondern lediglich nur Etiketten mit ihren Fund-Koordinaten. Erst im Laboratorium wurde dann die Etikettierung vervollständigt und eine neue Numerierung gleich unter artlicher Aufteilung vorgenommen, so daß damit ein besserer Überblick über die weit über 2000 Einzelstücke gewonnen wurde. Die topographischen Verhältnisse liegen ja eindeutig durch die Koordinaten und die Lagepläne fest. Nur in 5 Einzelfällen wurden größere Flächen im ganzen in der ebenfalls oben geschilderten Weise eingegipst. Zu diesen gehört auch die Fläche mit dem Mammut-Unterkiefer. Diese Platten sind für die Verwendung in Schausammlungen bestimmt, u. a. z. B. auch für das Landesmuseum Hannover, wo eine derartige Platte zur Zeit bereits aufgestellt ist.

Um den Anteil der einzelnen Tierarten festzustellen, wurden vor allem solche Knochen ausgezählt, nach denen die Anzahl der Einzelindividuen festgestellt werden konnte. Es ergaben sich folgende Anteile:

1. Ren ca. $72 \%$, nach Geweihbasen ca. 80 Tiere (dabei etwa 15 juv.)

2. Mammut "14\%, „ Molaren und Unterkiefern ca. 16 Tiere

3. Wisent " 5,4\%, " Schädelteilen ca. 6-7 Tiere

4. Pferd " 4,6\%, " " 4-6 "

5. Nashorn " 2\%, \# Zahnresten ca. 2 Tiere

Funde von Einzelindividuen:

6. Wolf

7. Bisamspitzmaus

8. Schwan 
9. Ente

10. Ohrengeier

11. Flußbarsch

12. Hecht; außer den 3 oben erwähnten Knochen liegen noch eine Anzahl Lesefunde aus dem Abraum vom Hecht vor, die der Größe nach gut zum gleichen Individuum gehören könnten;

13. eine kleine, nicht zu determinierende Fischart (wenige kleine Grätenreste).

Ferner wurden bisher aus Bodenproben ausgeschwemmt:

14. Insektenreste: Coleopteren (Elytren)

Trichopteren (Larvengehäuse)

15. Krebse: Cladoceren (Daphnia-Ephippien)

Ostracoden (Cypriden-Schalen)

16. Mollusken: Limnaea

Pisidium

Sphaerium.

Faunistisch und ökologisch läßt sich hieraus folgendes ablesen: Mammut, Rhinoceros und Re $n$ sind in diefser Aufteilung die typischen Kälteformen. Das Zurücktreten des Rhinoceros in den Knochenfunden besagt hierbei nichts über dessen allgemeine Häufigkeit, da dieses gefährliche Großtier ohne Zweifel dem Eiszeitmenschen nur ausnahmsweise zur Beute fiel. Das gleiche gilt in gewissem Umfang auch für das Mammut. Überwiegen doch in der Beute durchaus die jugendlichen (oder weiblichen ?) Tiere. Das Ren dürfte am leichtesten zu erlegen gewesen sein und daher die ermittelte Individuenzahl die tatsächliche Populationsdichte am ehesten wiedergeben, wobei natürlich das Jagdgebiet (Siedelfläche) und die Zeiteinheit, in der die nachgewiesene Beutemenge zusammengebracht wurde, eine Rolle als unbekannte Größe spielt. Klimatisch beweist jedenfalls das Auftreten von Mammut und Rhinoceros, daß mit ziemlich tiefen Durchschnittstemperaturen zu rechnen ist. Jedoch auch wieder nicht zu kalt, da z. B. der rein arktische Moschusochse, als hierfür typisches Leitfossil, fehlt. Auffällig ist ferner auch, daß kein Lemming nachgewiesen wurde.

Das Ren ist ohne Zweifel ein Kältetypus, doch nicht in so hohem Maße wie Mammut und Rhinoceros. Es paßt ebenso gut auch in die Gruppe der beiden folgenden Tiere: W is e n t und Pfe $r d$. Vor allen Dingen das letztere dürfte zwar als klimatisch widerstandsfähiger Typus bezeichnet werden. Wie die im Gang befindlichen Untersuchungen aber zeigen, gehören die Lebenstedter Pferdereste einer Form an, die in die Gruppe der sogenannten g roßen Dilu$\mathrm{vi}$ i l- oder Waldpferdtypen zu stellen ist, deren ausgesprochenster das Heiligenstädter Pferd E. abeli Antonius mit $1,80 \mathrm{~m}$ Schulterhöhe und einem NeHring-Schädelindex von über 240 (Länge $\times$ Breite) ist ${ }^{8}$ ). Es ist daher anzunehmen, daß die Lebenstedter Pferde keine Bewohner absolut baumloser Flächen gewesen sind, was ja auch vom Wisent anzunehmen ist. Ebenso ist, wie schon angedeutet, auch das Ren in einer baumbestandenen Landschaft denkbar. Die Pollenanalyse (s. Beitrag W. SELLE) hat nun bisher nur einen sehr geringen Waldbaum-Anteil ergeben, in welchem die Kiefer die höchsten Werte hatte. Demnach haben wir uns wohl eine subarktische Landschaft etwa mit Tundracharakter, aber mit einzelnen geringen Kiefernbeständen (vorwiegend) vorzustellen.

Anm. ${ }^{8}$ ). Der maßgebende NenRING-Index (NI) beträgt für das Lebenstedter Pferd 561 bei $208 \mathrm{~mm}$ größter Stirnbreite und $543 \mathrm{~mm}$ Basilarlänge (ohne Incisivi). Der Wert entspricht also voll der Forderung nach einem ü b e r 240 liegenden NI für die Waldpferdgruppe (vgl. Adametz, Kronacher, Lundholm, v. Reichenau). 
Läßt sich so der Charakter des großräumigen Biotops umreißen, sind für das engere $\mathrm{Milie} u$ des Ortes folgende Kleintiere kennzeichnend: Fis che sowie die $\mathrm{Schwimmvögel} \mathrm{Schwan}{ }^{9}$ ) und Ente kennzeichnen die Nähe tieferen Wassers, für die allerdings noch nicht das engste Milieu des eigentlichen Fundplatzes, sondern auch die in nicht allzu weiter Entfernung vorbeiströmende alte Innerste bzw. Nette ins Auge gefaßt werden muß, an der die Jäger ohne Zweifel dem Fischfang und der Vogeljagd obgelegen haben, wie sie ja die Großtiere sicher nicht nur in der engsten, sondern auch in der weiteren Umgebung jagten.

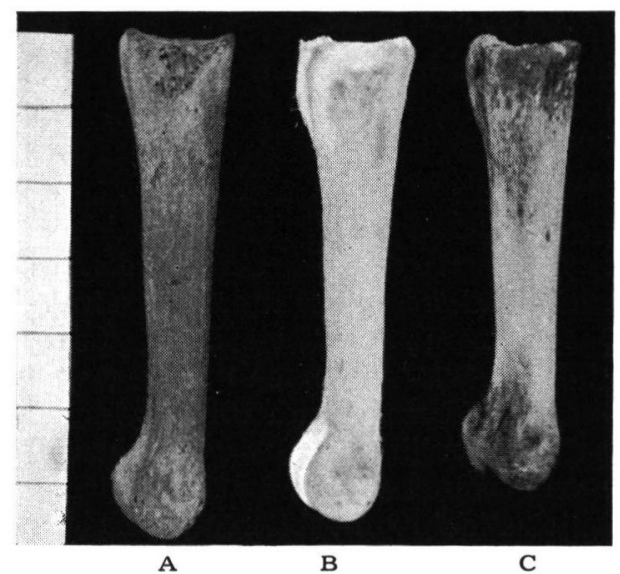

Abb. 14. Oberstes Glied der Mitte l z e h e rechts vom S c h w a n. A: Lebenstedter Fund (T. 540/Co.: 485/655 [IV c]). B: Cygnus olor. C. Cygnus cygnus. B und C beides alte Männchen.

Phot. Johannes.

Die Bisamspitzma k kennzeichnet nun schon das engere Milieu bedeutend besser. Sie ist ein Tier feuchtsumpfiger Niederungen, liebt aber mehr F'rischwasser als ausgesprochenen Sumpf. So kommt die heutige Form nur mehr im Tal der großen südrussischen Ströme, des Donez und Dnjepr vor ${ }^{10}$ ), ist also ein ausgesprochen feuchtigkeitsliebender stenöker Typus, der sich weitgehend mit dem der Bisamratte deckt. Diese ist zwar nicht so ausgesprochen stenök, besitzt aber, obwohl sie einer ganz anderen Tierordnung angehört (den Nagetieren; die Bisamspitzmaus ist dagegen ein Insektenfresser) weitgehend äußere morphologische Ähnlichkeiten: z. B. den seitlich zusammengedrückten Ruder-

Tabelle V. Maße der Phalanx proximalis digit. III. ped. von Cygnus.

\begin{tabular}{c|c|c|c|c|c|c}
\hline & \multicolumn{3}{|c|}{ cygnus } & olor & Lebenst. & bucc. \\
\cline { 2 - 6 } & 1 & 2 & 3 & 4 & 5 & 6 \\
\hline max. Länge & 55,7 & 58,9 & 59,0 & 62,5 & 65,8 & 68,9 \\
min. Breite & 6,3 & 6,7 & 6,9 & 6,9 & 7,0 & 7,3
\end{tabular}

1-4. Museum Braunschweig; 6. Am. Mus. New York No. 4768.

Anm. ${ }^{9}$ ). Von dem S $\mathrm{ch}$ w a n liegt lediglich das oberste Glied der rechten Mittelzehe vor. Es ist durch Größe und Schlankheit ausgezeichnet und paßt deshalb weder zu C. color (GMelin), dem Höckerschwan, noch zu C. cygnus (L.), dem Singschwan. Der nordamerikanische C. buccinator RIcHands (Trompeterschwan) ist wieder größer, hat aber ähnliche Proportionen. Eine artliche Determinierung nach rezentem Material ist daher vorerst nicht möglich (Abb. 14). 
schwanz und Schwimmhäute zwischen den Zehen. Der Biotopcharakter des nördlichen Verbreitungsgebietes der Bisamratte in ihrer Stammheimat Nordamerika, in der kanadischen Subarktis, dürfte vermutlich weitgehend dem diluvialen unseres Lebenstedter Fundplatzes entsprechen ${ }^{11}$ ).

In dieses Bild sind nun auch die Insekten-, Krebs- und Molluskenfunde einzuordnen, die den Gewässercharakter kennzeichnen. Trichopteren verlangen in jedem Fall fließendes sauerstoffreiches Wasser, und sei es noch so dürftig und eng begrenzt; vor allem die aufgefundenen Larvengehäuse kennzeichnen eindeutig Formen aus solchem Gewässtertyp. Dagegen verweisen Daphnien- und Cypridenreste ebenso wie auch die Mollusken auf ein zumindest sehr langsam fließendes bis stagnierendes Gewässer. Die Diskrepanz in diesem Befund dürfte durch die schon oben angedeuteten sehr wechselnden Wasserund Bodenverhältnisse erklärbar sein. Die Sphaerien- und Pisidiumschalen lagen in dichten Packungen am Ostrand der Fundgrube in schmalen Bändern angeordnet, innerhalb deren sie eine gewisse Einregelung erkennen ließen, das heißt, ihre noch fast durchgängig mit dem äußeren gelblichen Periostracum versehenen Schalen zeigten parallele Anordung der Schalenränder bzw. ihres Schalenspaltes (vielfach befanden sich beide Schalen noch im natürlichen Zusammenhang). Diese Sphaerienschichten (soviel ich bis jetzt sehen kann, überwiegt Sphaerium gegenüber Pisidium) sind aber sehr stark gestört, das heißt, durch Bodenfrosterscheinungen aufgebrodelt. Durch eine genaue Formanalyse der Molluskenschalen läßt sich vielleicht noch eine genauere Definition des Gewässertyps herbeiführen. Ganz allgemein sind ja diese kleinen Erbsen- und Kugelmuscheln kennzeichnend für langsam fließendes bis stagnierendes Wasser. Auf jeden Fall sind sie aber in der aufgefundenen Anhäufung durch einen Strömungsvorgang zusammengeführt worden, um dann, wie schon gesagt, sekundär durch kryoturbate Vorgänge in ihre vorgefundene Lage gebracht worden zu sein.

Wolf und Ohrengeier sind Wandergäste, zunächst ohne größeren biotop-kennzeichnenden Wert. Sie sind sekundäre Nutznießer an den Beute-

Anm. $\left.{ }^{10}\right)$. Das heutige, sehr eng begrenzte Vorkommen der großen Bisamspitzmaus (Desmana moschata moschata, PaLlas) am Dnjepr und Donez ist erst eine Folge der starken Verfolgung als Pelztier. Ihre endgültige Ausrottung dürfte z. Zt. nur durch die strengen Schutzmaßnahmen der Sowjets seit den zwanziger Jahren aufgehalten sein. Ursprünglich erstreckte sich das Verbreitungsgebiet weit nach Norden bis etwa zum 59. Breitengrad längs der Fluß-Systeme des Don und der Wolga bis in den Ural längs der Flüsse Kama, Ufa und Ural, südlich bis an den Rand der Kirgisensteppe, östlich um den Kaspi herumgreifend auch zwischen diesem und dem Aral-See. Maßgebend für Existenz und Vorkommen ist Frischwasser und nicht der Biotopcharakter des umgebenden Geländes, wie ihr Auftreten in den Flüssen Kama, Ufa und Ural zeigt (s. hierzu Ognev u. a. russische Autoren n. Schreuder). Es ist daher nicht angängig, die große Bisamspitzmaus wegen ihres heutigen engbegrenzten Vorkommens im Schwarzerdegebiet Südrußlands ökologisch als „Steppentier“ zu bezeichnen.

Anm. ${ }^{11}$ ). In diesem Zusammenhang dürfte der Hinweis von Interesse sein, daß sich die nördlichste Verbreitungsgrenze der amerikanischen Bisamrattenformen annähernd mit der der Wald- und Berg-Ren-Formen deckt. Nur in Nord-Labrador dringt die Form O. z. aquilonia BANGS in das Gebiet der Nord-Ren-Gruppe (der Form caboti ALLEN) nach Ungava ein. Sonst verläuft die nördl. Verbreitungsgrenze westlich der Hudson-Bay der Barren Grounds (O. z alba Sabina) zum Yukon n. Alaska (spatulata OGSOOD) bis zum Cookfjord in SW-Alaska (zalopha Hollister). Diesen entsprechen in den Barren Grounds die Renform R. c. silvestris Richardsson und in Alaska von $O$ nach $\mathrm{W}$ die Formen $R$. osborni Allen, mcquirei Figgins und stonei Allen (s. Miller). Ich halte diesen Hinweis zur Beurteilung faunistisch-ökologischer Zusammenhänge für nicht unwichtig, ebenso wie auch für die Beurteilung der europäischen diluvialen Renformen, auf die ich an anderer Stelle bei der Behandlung der Lebenstedter R e n e eingehen werde. 


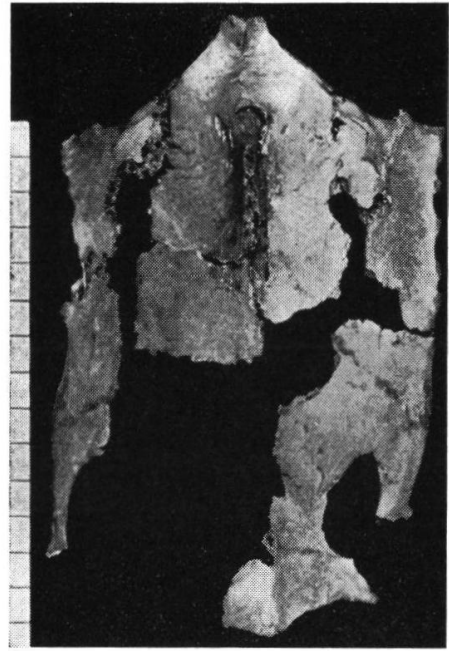

Abb. 15. Das Brustbein von Torgos tracheliotus todei, forma nova.

Phot. JoHannes

resten des Jägerlagers. Jedoch stellt allgemein-zoologisch wie zoogeographisch die Feststellung eines Ohrengeiers in Lebenstedt, noch dazu in einer besonders ausgeprägten Form, etwas Besonderes dar. In seinem rezenten Vorkommen ist der Ohrengeier auf Afrika beschränkt. Nur einmal wurde er vor rund $100 \mathrm{Jah}-$ ren als Irrgast in Europa - an der Rhonemündung - nachgewiesen (HARTERT). Fossil, auch diluvial, ist diese Form bisher noch nicht bekannt geworden LAMBRECHT, WetMone). Besondere Beachtung verdient aber, wie gesagt, der Fund dadurch - es liegen vor: der größte Teil des Brustbeins (Abb. 15), das proximale Ende des Tibiotarsus (Abb. 16), ein Radius- und ein Ulna-Bruchstück - daß sich an ihm intermediäre morphologische Charaktere nachweisen lassen, die dem Lebenstedter Geier eine Zwischenstellung zwischen den afrikanischen Ohrengeiern (Torgos) und den ostasiatischen Ohren- oder Kahlkopfgeiern (Sarcogyps) zuweisen. Er konnte daher als ne u e Form Torgos tracheliotus todei von mir beschrieben werden, indem ich ihn dem verdienstvollen Leiter der Grabung,

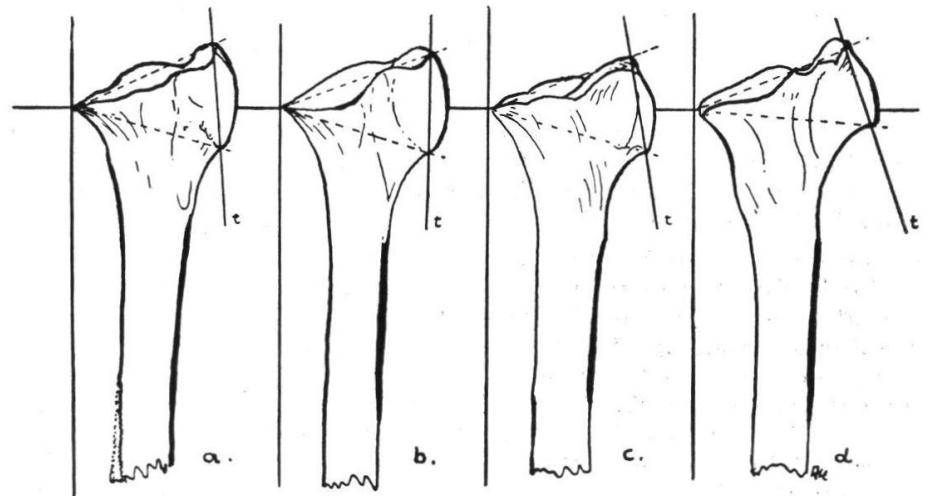

Abb. 16. Proximale Tibiotarsus-Enden. a. Lebenstedter Ohrengeier, b. T. t. nubicus (H. SmiтH). c. Kuttengeier, Aeg. monachus (L.). d. Gänsegeier, G. fulvus (HABL.). Beachte die arttypische Form der Crista tibialis media, die in der Neigung ihrer freien Kante zum Ausdruck kommt (Richtung der Linie t). 
Dr. Tode, widmete und ihm damit zugleich meinen Dank für die liberale Beteiligung an dem Unternehmen und ständige freundliche Unterstützung meiner Arbeiten abstatte.

Trotz des für die Lebenstedter Bisamspitzmaus zu fordernden subarktischen Biotop-Charakters, sind aber Bisamspitzmaus und Ohrengeier Faunenelemente, die ursprünglich einer wärmeren Umwelt angehören. Der morphologische Zusammenhang des Lebenstedter Geiers mit dem ostasiatischen Sarcogyps weist hier deutlich in südöstlicher Richtung. Oder besser: beide Tiere sind Relikte einer sich in dieser Richtung zurückziehenden Fauna. Spricht man doch vom „miozänen (warmen) Charakter" der heutigen ostasiatisch-indonesischen Fauna! Auch die wenigen bisher bekannt gewordenen Reste fossiler Bisamspitzmäuse lassen m. E. diese Tendenz erkennen. Formenmäßig klar differenziert treten sie uns zunächst in kleineren Formen im unteren und mittleren Cromerien entgegen: Im unteren Cromerien durch D. kormosi Schreuder (in Westungarn und am Mittelrhein - Gundersheim) und D. nehringi Konmos (ebendaher), im mittleren Cromerien durch D. thermalis Konmos (in Mittelungarn, Holland - Tege-len und Wassenaar (Schreuder) - sowie Niederösterreich - Hundsheim E. Thenius). Vom oberen Cromerien an treten dann Formen auf, die schon zum Formenkreis der rezenten Desmana moschata Pallas gehören: im oberen Cromerien: D. m. magna Owen von SO-England und D. m. moravica Schreuder aus Mähren. In der „Hauptfauna" der Mosbacher Sande (Prae-Riß): D. m. mosbachensis (Schmidtgen), deren Vorkommen von A. Schreuder auch für Nordholland (Bergambacht) sehr wahrscheinlich gemacht ist. Und schließlich D. $m$. hungarica Kormos aus dem Magdalénien von Nordungarn sowie von Meiendorf und Stellmoor in Holstein.

Die Lebenstedter Form gehört infolge ihrer Göße zu dem zuletzt genannten Formenkreis. Sie ist größer als die rezente Form und könnte ohne Zweifel

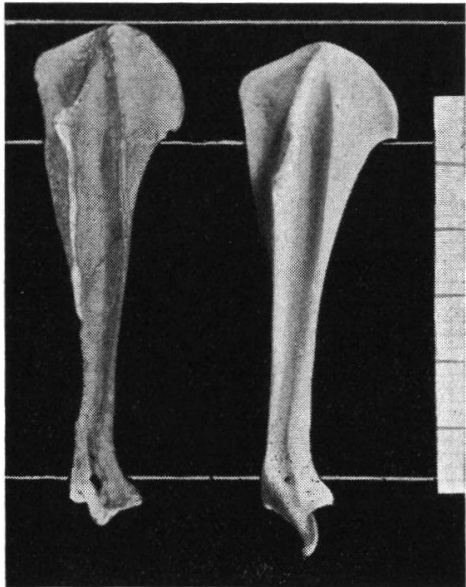

Abb. 17

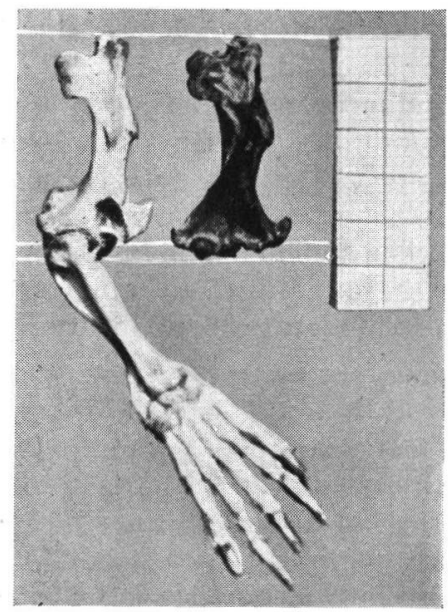

Abb. 18

Abb. 17. Linkes Schulterblatt, Ansicht der äußeren Fläche mit den $\mathrm{z}$ we $\mathrm{i}$ Spinae scapulae: A. Desmana moschata lebenstedtensis A. KL., größer! (glenoidaler Fortsatz der oberen Spina fehlt!) B. Desmana moschata moschata PALL. (rezent, Museum Leiden $\mathrm{Nr}$. 6614) kleiner! Phot. Johannes.

Abb. 18. A. Rechte Vorderextremität von Desmana moschata moschata PALL. rezent (Museum Leiden Nr. 6614) und B. rechter Oberarm von Desmana moschata lebenstedtensis A. KL. Phot. LinHaRDT. 
nungarica zugerechnet werden, wie das die Bearbeiter der Funde von Meiendorf und Stellmoor (Krause/Kollau) für die dortigen Desmana-Funde annahmen, die allerdings kein sicheres Urteil erlaubten, da sie von zu jungen Tieren stammten. Da aber Lebenstedt sicher wesentlich älter zu datieren ist als die Holsteiner Funde, käme ebensogut die Form mosbachensis in Betracht, deren Alter allerdings wieder höher ist. Leider liegt aber von der Mosbacher Form kein geeignetes Vergleichsmaterial für die Lebenstedter Funde vor. Ich fühle mich daher veranlaßt, die Lebenstedter Form zunächst pro usu als Desmana moschata lebenstedtensis form. nov. zu benennen. Sie ist auf jeden Fall klarer gekennzeichnet als die holsteinischen Funde aus dem Magdalénien, die wie gesagt, von nicht ausgewachsenen Tieren stammen (s. Abb. 17 u. 18).

Es sei mir schließlich der Versuch gestattet, die Verhältnisse des Lebenstedter Fundplatzes zur Zeit seiner Entstehung noch einmal mit allem Vorbehalt zu schildern, wie sie sich mir nach den bisherigen eigenen Ermittlungen sowie in Anlehnung an die mir bekannt gewordenen Ergebnisse der anderen Fachbearbeiter darzustellen scheinen.

Der Fundplatz liegt am Ende eines früh-würmeiszeitlichen Tälchens an dessen Einmündung in das alte Innerste-Tal der Saale-Eiszeit. Sein Talboden wurde von einem Gewässer mit mehr oder weniger stark wechselndem Wasserstand durchströmt. Als Folge von Frostbodenerscheinungen traten hier jeweils zwei Dinge auf: Einmal konnten größere Mengen plötzlich anfallenden Wassers (Regenfälle oder jahreszeitlich bedingte größere Abtauungen, wie z. B. Frühjahrsschmelze) nicht sofort im Boden versickern, sondern flossen schnell und in groBem Schwall mit stärkerer Strömung ab (vgl. Wisentschädel etc.). Zeugen hierfür sind entsprechende Strömungsmarken, Einregelungen und Materialaufschüttungen sowie auch evtl. gewisse Auskolkungen oder Wannenbildungen kleineren und größeren Ausmaßes. Normalerweise aber floß nur ein schwaches Rinnsal von Osten her in dem Tälchen entlang, dessen Bodenrelief außer durch das gelegentliche Hochwasser durch die Bodenfrosterscheinungen (Brodelungen) eine sehr wechselnde Oberfläche erhielt. Hierdurch wurde der Verlauf des Wassers zu ständig mäanderndem Wechsel veranlaßt, und es entstanden außerdem in Verbindung mit den oben erwähnten Auskolkungen größere und kleinere Stillwasserbecken mit entsprechender Kleinfauna (vgl. das oben für die Insekten-, Krebs- und Mollusken-Vorkommen Gesagte). Zeitweise mag der Talboden fast trocken gelegen haben. Seine Auffüllung erfolgte nicht nur durch die vom Wasser herangeführten und, entsprechend den wechselnden Wassermengen, ganz verschieden großen Gerölle, sondern auch vor allem vom Nordosthang her.

In der vermutlich vor dem kalten, von den Gletschern her wehenden Nordwind geschützten Talsenke, die, wie gesagt, wohl den weitaus größten Teil des Jahres fast trocken lag, etablierten sich die Vorzeitjäger. Welcher Grund sie zu dieser Platzwahl veranlaßte, läßt sich außer dem Windschutz nur vermuten. Entweder lag der Platz an einer günstigen Kreuzungsstelle von Wildwechseln, wie auch der nahe Fluß sicher gute Gelegenheit zur Fischwaid und Schwimmvogeljagd bot. Sicher ist, daß sich die Reste ihrer Jagdbeute im wesentlichen am Fuße des Hanges auf dem Talboden anhäuften, und daß sehr wahrscheinlich die daran befindlichen reichlichen Fleischreste Wolf und Geier herbeizogen. Dazwischen jagte die Bisamspitzmaus auf das sich reichlich ansammelnde Insektengeschmeiß und seine Brut. Alle drei Nutznießer fielen sicher auch durch Steinwürfe gelegentlich dem Menschen zum Opfer. Vom Hang wie auch sicher aus näherer Umgebung her wurden so viele Knochenreste mitsamt den anderen kulturellen menschlichen Hinterlassenschaften in einem gewissen Zeitintervall 
angereichert. Wie groß der Zeitabschnitt war, der den von uns geborgenen Fundkomplex entstehen ließ, läßt sich wiederum zunächst nur mutmaßen. Man müßte hierzu eine Vorstellung über die Größe der Jägerhorde gewinnen, wie auch über deren durchschnittlichen Verbrauch an Jagdtieren. Ein Jahr erscheint mir auf jeden Fall zu gering, andererseits ist die Zahl der Tierindividuen auch wiederum nicht so groß, daß sie das Ergebnis der Jagd von mehreren Generationen sein könnte. Man wird hier nach einem Mittel zwischen diesen beiden Feststellungen suchen müssen.

Schließlich noch ein botanischer Hinweis. Holz und Rindenstücke, die bei der Sortierung der Knochenfunde noch anfielen, scheinen ganz den oben erwähnten Kiefernpollenfunden zu entsprechen. Mit diesem Vorhandensein eines Baumbestandes hängt nun auch offensichtlich das Auftreten von konsolenbildenden Pilzschwämmen zusammen, von denen im ganzen 14 mehr oder weniger große Stücke einer Feuerschwamm-artigen Form aufgefunden wurden. Nach den Angaben des Fachbearbeiters (Dr. Johannes, Biol. Bundesanstalt, Braunschweig-Gliesmarode) handelt es sich wahrscheinlich um einen Basidio-Mycet (zu welcher Mitteilung mich Dr. JoHANNEs ausdrücklich hier ermächtigte, wofür ihm herzlich gedankt sei).

Zum Abschluß ist es mir eine angenehme Pflicht, allen denjenigen Herren zu danken, die mich in entgegenkommender Weise bei den bisherigen Arbeiten durch Bereitstellung des meist seltenen Vergleichsmaterials unterstützten oder mich mit schwer zugänglichem Schrifttum versorgten. Es sind dies die Herren: D. Amadon und E. Mayr vom Americ. Mus. Nat. Hist. New York; D. A. Hoorjer, A. M. Husson und G. C. A. Junge vom Rijksmus. Leiden (Holland); R. G. van Oont, Zool. Lab. Univ. Utrecht; O. KLeInschmidt, Wittenberg, Forschungsheim; A. v. Jordans, Museum A. Koenig, Bonn; O. Kalela, Zool. Mus. Helsinki; H. Rendahl, Rijksmus. Stockholm; E. Thenius, Pal. Inst. Wien; und E. W. Swinton, Brit. Mus. Nat. Hist. London.

Ferner möchte ich nicht verfehlen, den Angehörigen des Landesmuseums Braunschweig für ihre ständige Hilfsbereitschaft und Unterstützung bei meinen Arbeiten zu danken, ebenso Herrn Kollegen Johannes von der Biologischen Bundesanstalt für die große Hilfe bei schwierigen photographischen Aufnahmen.

\section{Schrift t u m}

Adametz, L.: Lehrbuch der allgemeinen Tierzucht. Wien 1926.

Hartert, E.: Die Vögel der paläarktischen Fauna. II. 1912/21.

KLEINSCHMIDT, A.: Torgos tracheliotus todei form. nova. Ein mitteleuropäischer fossiler Ohrengeier aus dem Diluvium von Salzgitter. - Bonner zool. Beiträge. Im Druck 1953.

Kormos, T.: s. Literatur bei Schreuder, 1940 (dort auch sämtliche Desmana-Literatur bis 1940).

Krause, W.: Die eiszeitlichen Knochenfunde von Meiendorf. - In A. Rust: Das altsteinzeitliche Rentierjägerlager Meiendorf, Neumünster 1937, S. 48-61.

Krause, W. \& Kollau, W.: Die eiszeitlichen Knochenfunde von Stellmoor in Holstein. In A. Rust: Die alt- und mittelsteinzeitlichen Funde von Stellmoor. Neumünster 1943.

Kronacher, C.: Haustierwerdung, Abstammung und Entwicklung der Haustiere. (Allgemeine Tierzucht I. Abteilung). Berlin 1921.

LAmprecht, K.: Handibuch der Paläornithologie. Berlin 1933.

Lundholm, B.: Abstammung und Domestikation des Hauspferdes. - Zool. Bidrag Uppsala 27, 1949.

MilleR, G.: List of North American recent Mammals. - Smiths. Inst. Bull. 128. Washington 1924. 
Ognev, S, I.: The Mammals in the eastern Europa and of the northern Asia. Vol. I. Moskau.

Reichenau v., W.: Beiträge zur näheren Kenntnis fossiler Pferde usw. - Abh. geol. Landesanst. Darmstadt. $7 / 1,1915 / 25$.

Schmidtgen, O.: Myogale moschata Pall. aus dem Mosbacher Sand. - Notizbl. Ver. f. Erdk. u. hess. geol. Landesanst. 5, S. 132, Darmstadt 1925.

Schreuder, A.: A Revision of the fossil Water-Moles (Desmaninae). - Arch. Neerl. Zool. 4, S. 201, Leiden 1940. - Fossil voles and other mammals (Desmana, Talpa, Equus etc.) out of well-borings in the Netherlands. - Verh. Geol. Mijnbouw. Genootsch. Nederland, Geol. Ser. 13. s'Gravenhage 1945.

Thenius, E.: Fischotter und Bisamspitzmaus aus dem Altquartär von Hundsheim in Niederösterreich. - Sber. öster. Akad. Wiss. math.-nat. Kl. I, 15\%, S. 187, Wien 1948.

Weigelt, J.: Rezente Wirbeltierleichen und ihre paläobiologische Bedeutung. Leipzig 1927. - Vom Sterben der Wirbeltiere. Nachtrag. - Leopoldina 6 (WALTHERFestschrift) S. 281. Halle/Saale 1936. - Die Biostratonomie der 1932 auf der Grube Caecilie im mittleren Geiseltal ausgegrabenen Leichenfelder. - Nova Acta Leop. N. F. 1, S. 156. Halle 1933.

Wetmore, A.: Recent Additions to our Knowledge of Prehistoric Birds 1933-1949. Proc. X. Intern. Orn. Congr. Uppsala, S. 151. Stockholm 1951.

Manuskr. eingeg. 18. 3. 1953.

Anschr. d. Verf.: Dr. Adolf Kleinschmidt, Braunschweig, Naturhist. Museum, Pockelsstraße $10 \mathrm{a}$. 


\title{
7. Die bei der Grabung in Salzgitter-Lebenstedt geborgenen Backenzähne von Elefanten
}

\author{
(Ekke W. Guen ther, Kiel)
}

\section{Die Zähne und ihr Erhaltungszustand}

Bei der Grabung in Salzgitter-Lebenstedt wurden 24 einzelne, z. T. sehr gut erhaltene Backenzähne von Elefanten gefunden. Dazu kommen die Unterkiefer von 2 sehr jungen Tieren sowie ein weiterer Kieferrest, die noch nicht aus dem Gips, in den sie bei der Bergung eingebettet wurden, freigelegt sind. ${ }^{1}$ )

An den Backenzähnen ist keine Abrollung zu beobachten, und selbst ein aus $3,10 \mathrm{~m}$ Tiefe aus groben Flußschottern geborgener Unterkiefermolar hat noch gut erhaltene Wurzeln; eine irgendwie beträchtlicher Transport im Wasser hat also nicht stattgefunden. Durch Abbruch verlorene Lamellen fehlen 7 Zähnen, darunter 4 letzten Molaren. Mehrere Zähne sind infolge Abkauung z. T. erheblich verkleinert, drei davon so stark, daß jeweils nur ein kleiner Abkauungsrest übrig blieb. Von diesen gehörten 2 zum Unterkiefer desselben Elefanten, sie wurden also nicht zu dessen Lebzeiten ausgeworfen, sondern fielen erst nach seinem Tode aus dem Kiefer.

\section{Die Anzahl der Elefanten und ihr Alter}

Backenzähne, die aus demselben Elefantengebiß stammen, zeigen meist eine weitgehende Ähnlichkeit. Es ist daher oft möglich, verschiedenen Kieferpartien eines Elefanten entstammende, gleich alte Zähne wieder zusammen zu ordnen. Schwieriger ist die Untersuchung, ob zwei in der Zahnfolge nicht gleiche Zähne demselben Gebiß zugehören. Einander entsprechende Pressionsmarken auf der Rückseite des vorausgehenden und auf der Vorderseite des folgenden Zahnes sowie die Untersuchung des Abkauungsgrades können hierbei wertvolle Hinweise geben.

Nach den bisherigen Untersuchungen lassen sich die Backenzähne 10 bis 16 Elefanten (es wird mit 12 gerechnet) zuordnen. Nach ihrer Dentition ergibt sich diese Altersgliederung:

\begin{tabular}{c|c|c|c}
\hline Anzahl der Elefanten & Alter & Altersklasser & Prozentsätze \\
\hline $2-3$ & 4-7 Jahre & 1/4-6 Jahre & ca. $23 \%$ \\
1 & 5-10 Jahre & & \\
1 & 6-20 Jahre & 6-20 Jahre & ca. $31 \%$ \\
2 & 10-25 Jahre & ca. $23 \%$ \\
1 & 20-50 Jahre & 20-50 Jahre & c-60 Jahre \\
1 & nahe an 50 Jahren oder & ca. $23 \%$ \\
$3-4$ & \multicolumn{2}{|c}{ darüber }
\end{tabular}

1) Für die Überlassung des Materials zur Bearbeitung bin ich den Herren Dr. Tode und Dr. KLEINSCHMIDT aus Braunschweig zu Dank verpflichtet. 
Unter den Elefanten befindet sich nur ein älteres Tier, und gerade dieses ist ein Mammut mit auffallend kleinen Zähnen. Damit fehlen die zahlreichen alten Proboscidier, die z. B. für die Fauna von Hemmingen bei Hannover oder Landesbergen bei Nienburg typisch sind. Der verhältnismäßig hohe Prozentsatz an jungen Tieren in Lebenstedt - Elefanten sind ungefähr vom 20. Lebensjahr ab fortpflanzungsfähig - ist auffallend und entspricht etwa der Altersverteilung von Taubach, deren Zusammensetzung Soerger (1922) auf Jagd des diluvialen Menschen zurückführte.

\section{Die Umlagerung der Zähne}

In mindestens 6 Fällen läßt sich zeigen, daß mehrere Zähne demselben Gebiß entstammen. Dies ist z. B. der Fall bei einem 1. linken Unterkiefermolaren (M 23) und einem 1. rechten Oberkiefermolaren (M 10). Beide Zähne entsprechen einander nicht nur in der äußeren Form - sie sind beide ganz besonders hoch -, sondern auch in der Wurzelbildung, dem Längen-Lamellen-Quotienten, dem Längen-Breiten-Quotienten, dem Aufbau der Lamellen, der Ausbildung des Schmelzes und dem Abkauungsgrad. Der Oberkiefermolar wurde in einer Tiefe von $1,95 \mathrm{~m}$, der Unterkiefermolar in $3,10 \mathrm{~m}$ in groben Flußschottern gefunden. $\mathrm{Da}$ auch andere ursprünglich zusammengehörende Zähne nicht in derselben Fundschicht lagen, muß vor der endgültigen Einbettung eine Umlagerung stattgefunden haben. Aus der Fundtiefe kann also weder auf das relative Alter von Funden noch auf Zusammengehörigkeit geschlossen werden.

4. Artzugehörigkeit und geologisches Alter der Zähne

M. primigenius Blumenb. und $M$. trogontherii PoHL. werden in erster Linie (Wüst 1900, Soergel 1913) mit Hilfe des Längen-Lamellen-Quotienten (Zahnlänge pro Anzahl der Lamellen) voneinander abgegliedert. In einem Diagramm, das diese beiden Werte zueinander in Beziehung setzt, zeigte KFLLER (1939), wie sich die Backenzähne von $M$. trogontherii und $M$. primigenius an einer Grenzlinie trennen lassen, indem von einer bestimmten geringeren Lamellenzahl je Zahnlänge an $M$. trogontherii beginnt. Wenn man die Lebenstedter Elefanten in der Weise aufgliederte, so würde die Grenzlinie Zähne desselben Gebisses trennen.

Der Längen-Lamellen-Quotient allein ist kein sicheres Mittel, diese Trennung durchzuführen, denn er ist in vielen Fällen von der Abkauung abhängig. Schreitet diese fort, so nimmt - vor allem häufig bei Unterkiefermolaren der trogontheroide Charakter zu. Weiter ist bei gleichen Molaren die Zahnlänge größeren Schwankungen unterworfen als die Lamellenzahl (Guenther 1953, 1953a). Größer entwickelte Zähne derselben Elefantenart laufen daher Gefahr, bei gleicher Lamellenzahl zu M. trogontherii, kleinere Zähne zu M. primigenius gestellt zu werden.

Einer bestimmten Lamellenzahl entspricht bei den ersten Zähnen - nur mit geringeren Abweichungen - eine bestimmte Länge. Bereits bei den 2. Molaren ist bei gleicher Lamellenzahl eine Aufspaltung in größere und kleinere Zähne zu erkennen, bei den 3. Molaren wird sie deutlich.

Dies ist auch bei den Lebenstedter 3. Molaren zu erkennen. Es wird jedoch darauf verzichtet, eine kleinwüchsige von einer normalwüchsigen Elefantenform abzugliedern, wie dies RüHL (1940) vorschlug. Besonders kleine ebenso wie abnorm große 3. Molaren finden sich nicht nur bei M. primigenius BlumenB., sondern auch bei $M$. trogontherii PoHL. und $H$. antiquus FALC. Alle diese vom Durchschnittsmaß abweichenden Größen liegen jedoch, soweit sich bisher er- 
kennen ließ, innerhalb der Variationsbreite einer Art. Abweichungen lassen sich vielleicht bis $\mathrm{zu}$ einem gewissen Grade durch Geschlechtsdimorphismus erklären. Dies bezieht sich natürlich nicht auf wirkliche Kümmerformen, wie sie $H$. antiquus auf Mittelmeerinseln oder $M$. primigenius gegen Ende der letzten Vereisung entwickelten.

Der Längen-Lamellen-Quotient bei 17 Lebenstedter Elefanten-Molaren schwankt zwischen 8,5 und 13,5. Er liegt also bei einigen Exemplaren so hoch, daß man diese nach der üblichen Bestimmung $M$. trogontherii oder $M$. trogontherii-primigenius zugliedern müßte. Eine Verteilungskurve, die die Häufigkeit der einzelnen Längen-Lamellen-Quotienten zeigen soll, läßt ein kleineres Maximum bei etwa 9 und ein stärkeres Maximum bei 11 erkennen. Ein LängenLamellen-Quotient über 12 ist nur bei 4 Molaren zu finden. Es zeigt sich also, daß der größte Teil der Zähne ohne Einschränkung zu M. primigenius Blumenb. gestellt werden kann, einige Molaren zeichnen sich jedoch durch trogontheroide Merkmale aus. Vielleicht hängt es mit der Umlagerung zusammen, vielleicht ist es Zufall, daß die Zähne mit den stärksten trogontheroiden Merkmalen in den höchsten, die deutlichsten Primigenius-Zähne in den untersten Schichten gefunden wurden.

Die Zähne aus Salzgitter-Lebenstedt passen in ihrer Entwicklungsstufe recht gut zu einer Fauna, die beim Bau des Rhein-Herne-Kanals an der Basis der Niederterrasse gefunden wurden. KELLER (1939) stellt diese trotz ihres in der Hauptsache kalten Charakters - außer Elefanten enthält sie wollhaariges Nashorn, Ren, Elch, Ur, Wisent, Pferd, Edelhirsch, Löwe und Wildschwein - in das Riß-Würm-Interglazial.

Ein rechter, besonders klein entwickelter 3. Oberkiefermolar zeigt weitgehende Ähnlichkeit mit einem aus dem Nord-Ostsee-Kanal geborgenen Zahn, der wahrscheinlich aus Eemschichten stammt. Damit soll nicht gesagt werden, daß die Elefantenzähne von Salzgitter-Lebenstedt diesem Interglazial zuzugliedern sind. Die Elefanten aus der Stammlinie trogontherii-primigenius haben in der Zeit von oberem Riß bis unterem Würm keine so entscheidende Entwicklung erfahren, daß mit unserer bisherigen Kenntnis eine genauere Eingliederung innerhalb dieses Zeitraums möglich wäre.

\section{Angeführte Schriften}

Guenther, E. W.: Fossile Elefantenfunde aus Schleswig-Holstein. - Schr. d. naturw. Ver. f. Schlesw.-Holst. 26. 1953. - Die diluvialen Elefantenzähne aus dem Nord-Ostsee-Kanal. - Meyniana 2. 1953 (in Vorbereitung). [1953a].

KELLER, G.: Untersuchung über Artzugehörigkeit und Altersaufbau an einer ElephasMolaren-Fauna aus dem Emschertal. - Paläontol. Zeitschr. 21. 1939.

RüHL, W.: Die Raubtiere und Elefanten des sächsischen Diluviums. - Paläontographica 41. A. 1940 .

Soergel, W.: Elephas trogontherii Pohl. und E. antiquus Falc., ihre Stammesgeschichte und ihre Bedeutung für die Gliederung des deutschen Diluviums. - Paläontographica 60. 1913. - Die Jagd der Vorzeit. Jena 1922.

Ms. eingeg.: 6. 3. 1953.

Anschr. d. Verf.: Dr. E. W. Guenther, Geol. Institut d. Univ. Kiel, Olshausenstr. 40/60. 


\title{
8. Einige archäologische Erkenntnisse aus der paläolithischen Freiland- station von Salzgitter-Lebenstedt
}

\author{
(A. Tod e). Mit 19 Abbildungen ${ }^{1}$ )
}

Angesichts des in vier Monaten intensiver Geländearbeit bei der Ausgrabung in Salzgitter-Lebenstedt gewonnenen umfangreichen Materials an Fundstücken, Fotos, Gesamt- und Detailplänen der einzelnen Grabungsschichten (Buntplanreihe, Grundpläne, Profile usw.) können mehrere Monate nach Abschluß der eigentlichen Grabung nur einige erste Eindrücke und Erkenntnisse zum archäologischen Stoff mitgeteilt werden, und zwar mit allem Vorbehalt, da die rein technische Aufarbeitung vor allem des Fundmaterials noch im Gange ist und die eigentliche wissenschaftliche Bearbeitung erst gerade begonnen hat. Es mag aber soviel aus diesem vorläufigen Bericht entnommen werden, daß bestimmte Aussicht besteht, aus dem überreichen Fundstoff noch manche wertvolle Erkenntnis herauszuholen. Insofern wird auf die geplante Monographie des Amtes für Bodenforschung verwiesen.

\section{A. Fundschichten, Fundmilieu und Deutung}

Die systematische Grabung bestätigte die schon im Probeschnitt gemachte Beobachtung, daß die oberen Erdschichten bis etwa $4 \mathrm{~m}$ Tiefe völlig frei von irgendwelchen paläolithischen Knochen- oder Artefaktfunden waren. Die Funde begannen erst in etwa 4,25 m Tiefe, und zwar durchweg in einer unter den feineren Schluff- und Sandschichten auftretenden, stark rostbraun gefärbten Schicht groben Kieses, der die eigentlichen Fundschichten fast überall nach oben hin klar und unvermittelt abschloß.

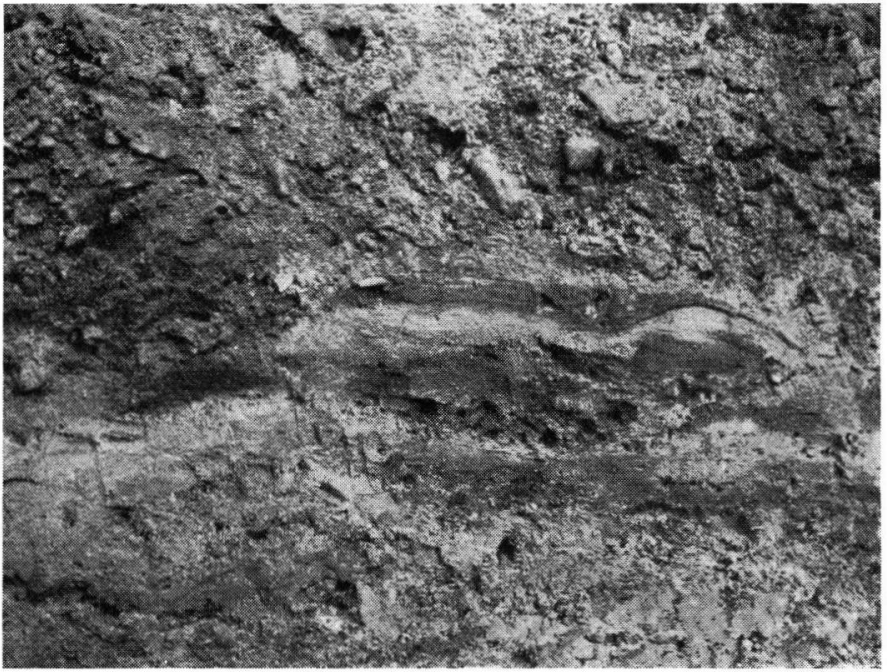

Abb. 1. Profil West-Ost an der Nordwand des Versuchsschnittes. Humase Fundschichten werden von rostfarbenen Kiesschichten diskordant überlagert.

1) Fotos von W. Rennau, Landesmuseum Braunschweig, Pläne von O. Rothenstein, Landesmuseum Braunschweig, Fundzeichnungen von Graphiker R. Fricke, Braunschweig. 
Bei den Fundstücken in dieser Schotterschicht handelte es sich zumeist um widerstandsfähigere, z. T. etwas kantengerundete größere Knochen und Zähne von Mammut und Ren sowie einzelne z.T. ebenfalls wenig kantengerundete Artefakte mit Rostpatina. Der rostbraune und darunter folgende graue Kies scheint demnach ein Umlagerungsprodukt darzustellen, in dem auch Teile von vorher abgelagerten humosen Fundschichten aufgegangen sind. An mehreren Profilstellen war klar zu erkennen, daß Fundschichten in ihrem oberen Teil abgetragen und diskordant von diesen Kiesen überlagert waren (Abb. 1). Für die Fundstücke aus dem Kies ergab sich eine eindeutig s e k u n d ä r e Lagerung.

Der Befund kann nach dem jetzigen Eindruck wohl nur so gedeutet werden, daß nach der letztmaligen Besetzung des Platzes durch Menschen infolge einer erheblichen Verstärkung der Wasserführung des Tales der Lagerplatz unter teilweiser Zerstörung letztgebildeter Schichten mit grobem Kies zugedeckt wurde. Der hohe Humusgehalt des Kieses ist vielleicht die Ursache der starken Eisenausfällung und dadurch der intensiven Braunfärbung besonders der oberen Kiesschichten. Von der Zeit der Kiesschichtablagerung an scheinen die Fundschichten bis heute wasserbedeckt geblieben zu sein, was der guten Erhaltung aller organischen Bestandteile der Fundschicht äußerst dienlich war.

Unter der besprochenen Kiesschicht, die z. T. gröbste Schotter enthielt, folgten die eigentlichen Fundschichten, und zwar in einer Gesamtmächtigkeit von zumeist etwa $1 \mathrm{~m}$, allerdings unter Auskeilen zum Hange (NO) hin. Die Fundschichten reichten also von etwa $4,25 / 4,50$ bis etwa $5,25 \mathrm{~m}$ Tiefe, stellenweise bis $5,75 \mathrm{~m}$ und vereinzelt - in der noch zu besprechenden Steinsohle an der Basis der Fundschichten - bis etwas über $6 \mathrm{~m}$ Tiefe. Eine besondere Häufung der Funde zeigte sich in der Tiefenlage von etwa 4,70 bis $5,10 \mathrm{~m}$.

Durch die Eintragung sämtlicher Funde in Schichtpläne 1:20 und die Anfertigung von zwölf Buntplänen der Fundschichten mit z. T. nur $10 \mathrm{~cm}$ Höhendifferenz besteht die Hoffnung, daß trotz Frostbodenveränderungen und häufiger Übersandung des Lagerplatzes vom Hange her die Rekonstruktion der Fundschichtablagerung in den wesentlichen Zügen gelingen wird. Den Schlüssel dazu bietet die Verteilung der sehr verschiedenartigen fundführenden Bodenarten, eine Verteilung, die uns zunächst völlig regellos erschien.

Als Hauptbodenarten mit Fundführung kommen innerhalb des Fundschichtpaketes vor: schwarzgrauer, stark humoser Feinsand bis schmutziggrauer Kies einerseits und tonig-schwarz-humoser Boden, z. T. ausgesprochener GyttjaBoden andererseits, dazu flache Torflinsen, diese z. T. auch in kleineren Schollen. Zwischen den genannten stark fundführenden Bodenschichten zeigten sich immer wieder saubere, fast fundfreie Streifen Sandes oder Kieses. In den schwärzlichen Sanden und Kiesen fanden sich nur wenige Knochen, dafür aber vor allem Feuersteinabschläge und -Werkstücke. In den tonig-humosen Wasserabsätzen dagegen lagen Knochen neben Knochen, z. T. in dicker Schicht, dazwischen auch Feuersteinabschläge und beste Werkstücke, wenn auch nicht so gehäuft wie in den Sanden und Kiesen.

Die Verteilung der verschiedenen Bodenarten war in der horizontal geschnittenen Fläche und auch im Profil zunächst fast unentwirrbar. Wohl ließ sich erkennen, daß einer größeren Fläche von dunklen Absätzen eines offenbar flachen Wassers mit den zahllosen hineingeworfenen Knochen sandig-kiesige „Ufer"Zonen gegenüberstanden, auf denen der Mensch gelebt und seine Zeltlager errichtet haben mußte. Aber sonst blieben viele Rätsel in der Verteilung, da während des Bestehens des Lagerplatzes der Bodenfrost einen Teil der damaligen Oberflächenschichten völlig verbrodelt hat, und da ferner — wahrscheinlich im 
Gefolge der Frühjahrsschneeschmelze und schwerer Sommerniederschläge -- immer wieder vom Hang her Sand- und Kiesschichten über den Lagerplatz oder einen Teil des Platzes gekommen waren, die Teile der primär lagernden Fundschichten zerstörten, umlagerten oder überdeckten.

Eines scheint sich aber schon jetzt immer deutlicher herauszustellen: In der Hauptzeit des Lagerplatzes muß eine längliche, in Richtung des Hanges (SONW) verlaufende, seichte Wasserfläche von etwa $12 \mathrm{zu} 8 \mathrm{~m}$ bestanden haben, deren Grenzen im Nordwesten durch die Erweiterung der Grabungsfläche in den

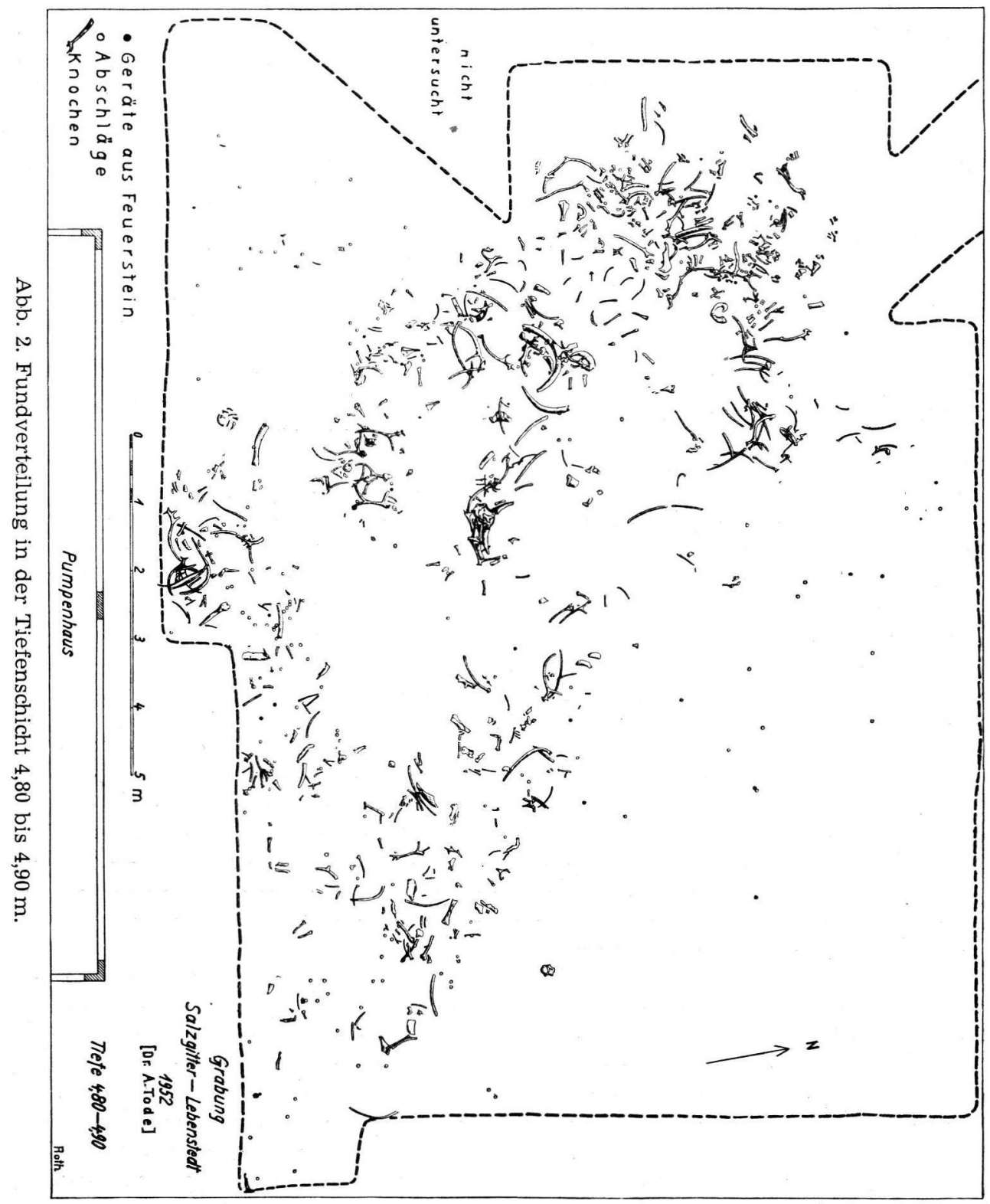


letzten Wochen der Grabung noch gerade erfaßt wurden. Der äußere Umfang dieser Wasserfläche in ihrer größten Ausdehnung ist vielleicht am besten durch die Knochenverteilung in der Tiefenschicht von 4,80 bis $4,90 \mathrm{~m} \mathrm{zu}$ erkennen (Abb. 2). In den Schichten unter $5,00 \mathrm{~m}$, besonders in denen von 5,10 bis $5,40 \mathrm{~m}$ Tiefe erkennt man die tieferen Partien des Wassers, die tiefste zuletzt nur noch im Nordwesten. Hier muß schon ein Tümpel bestanden haben, als der Ostteil der späteren, sehr seichten Wasserfläche noch bewohnbar war, vielleicht schon etwas feucht geworden war (Tiefe 5,10 bis $5,20 \mathrm{~m}$ ). Diese Oberflächenschicht mit ihren stark humosen Bildungen war besonders deutlich in ihrer Frostverbrodelung zu erkennen (Abb. 3). Am Rande dieser flach auskeilenden, an der tiefsten Stelle beim Höchststand des Wassers nur etwa $1 \mathrm{~m}$ Tiefe messenden Wasserfläche sind anscheinend ausgesprochene randliche Moorbildungen vorgekommen. Wenn auch die Frostverbrodelungen den gesamten Wasserboden erfaßt haben, so waren sie doch an der sehr flach auskeilenden moorigen Randzone besonders instruktiv.

Der größere Tümpel muß sehr bald durch starke, von Nordosten, also vom Hang her kommende Wässer, und zwar vor allem in der Mittelpartie, übersandet worden sein. Die in den Tümpel geworfenen Knochen scheinen dabei in der Mitte des Wasserbeckens nach Süden bzw. Südwesten verfrachtet und z. T. in streifenartigen Partien zusammengeschoben zu sein (vgl. die Knochenkonzentrierungen in der Mitte und besonders im Südwesten des ursprünglichen Wassers auf Abb. 2). Einige größere Knochen, die schwer beweglich waren, wie etwa große Rengeweihstangen oder der große Bisonkopf (Abb. 2, Mitte) scheinen An-

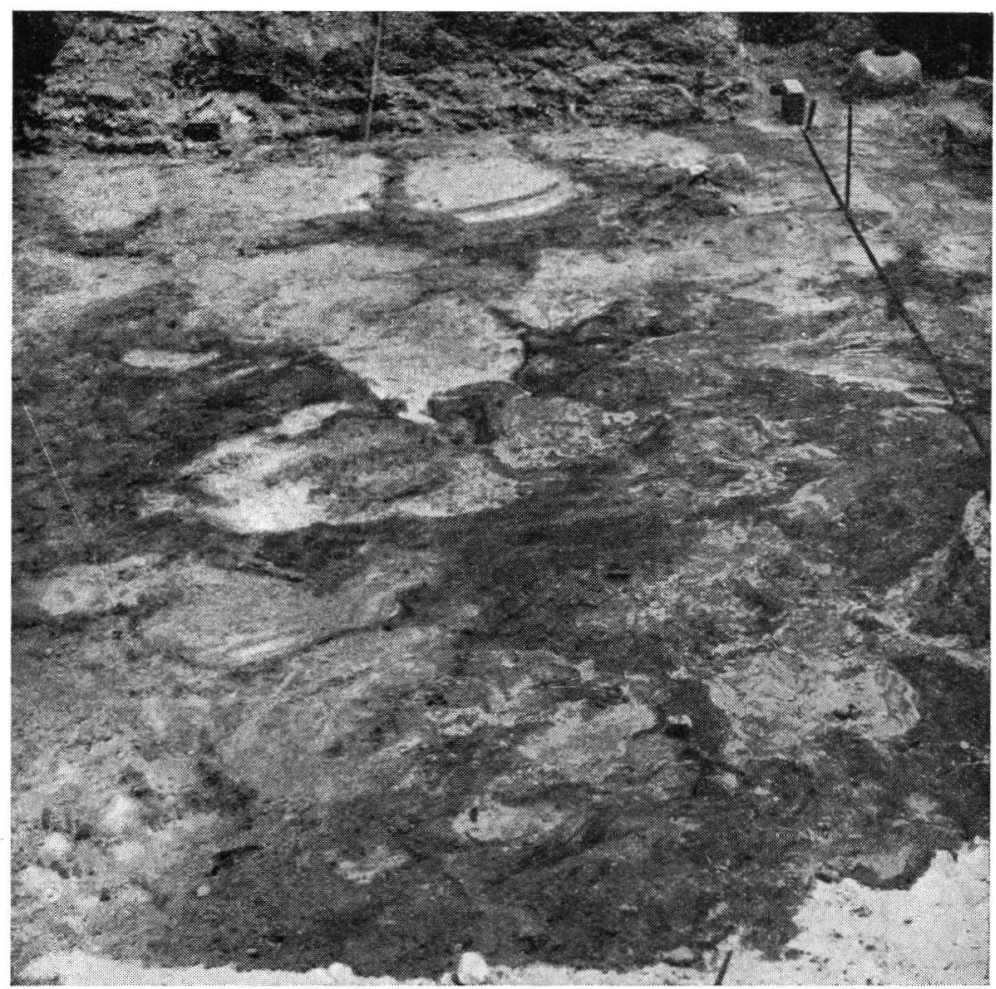

Abb. 3. „Brodelboden“ (Tiefe $\mathbf{5 , 1 0} \mathrm{m}$ ). 
laß von Knochenzusammenschiebungen gewesen zu sein. So erklärt sich auch die immer wieder von unserem Zoologen Dr. KLEINSchmidt in der Knocheneinbettung im Kleinen gemachte Beobachtung, daß ein Teil der Knochen durch Wasser umgelagert sein muß (vgl. den Beitrag KLeinschmidT). Aus den nordöstlichen Randpartien des Tümpels müssen im übrigen die verfrachteten Torffetzen stammen, die südwestlich davon im Sand eingelagert angetroffen wurden.

An mehreren Stellen um die geschilderte flache Wasserfläche herum sind so starke Anhäufungen von Feuersteinabschlägen festgestellt, daß man den unmittelbaren Eindruck gewinnt, daß hier Menschen am Wasser nicht nur die Jagdbeute zerlegt und ihre Mahlzeiten gehalten, sondern auch ihre Geräte geschlagen haben. Ein besonders dicht mit Artefakten belegter Platz war auch der Platz in Tiefe 5,10/5,20 m östlich des ältesten, kleineren Tümpels. Mehrfach lagen in der nordöstlichen Randzone des Tümpels völlig unvermittelt größere Steine (bis 0,5 m Durchmesser) - einmal mehrere in einem Kreis von $5 \mathrm{~m}$ Durchmesser in einer Schicht - sodaß man an Beschwersteine von Zelten denken möchte. Feuerstellen konnten auf der Grabungsfläche nicht eindeutig bestimmt werden.

$\mathrm{Da}$ im übrigen auch in einer weiter westlich gelegenen Baugrube in entsprechend tiefen Sandschichten Feuersteinartefakte gefunden werden konnten, muß sich das Jägerlager von den in der Grabungsfläche erfaßten Teilen am Hange des Tales entlang mindestens noch etwa $20 \mathrm{~m}$ weiter nach Westen ausgedehnt haben, während die Ausdehnung nach Osten nicht bestimmt werden konnte. Nachgewiesen ist also ein Lager von mindestens $30-40 \mathrm{~m}$ Länge. Die Ausdehnung des Lagers ins Tal hinein ist eher zu schätzen: Die Südwestgrenze des flachen Wassers scheint gerade die Nordwestecke des heutigen Pumpenhauses erreicht zu haben, da nur hier von den Schachtarbeitern Knochen angetroffen wurden. Es waren diejenigen, die zur Entdeckung des Gesamtfundes führten. Im übrigen Baugrund wurde nur Sand festgestellt, allerdings im Nordosten des Pumpenhauses von sehr schmutziger Färbung. Im Baggerabraum aus

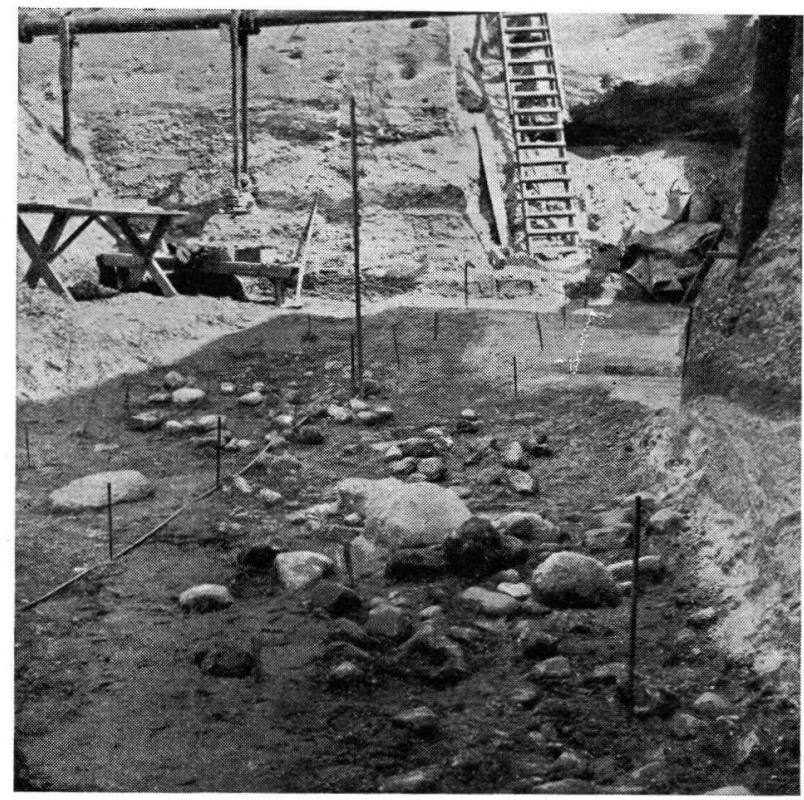

Abb. 4. Die Steinsohle an der Basis der Fundschichten (Tiefe $6 \mathrm{~m}$ ). 
diesem Teil des Baugrundes fanden wir bezeichnenderweise noch nachträglich Abschläge und herrlichste Werkstücke in größerer Zahl, im sauberen Abraum aus dem südlichen Baugrund des Pumpenhauses jedoch so gut wie keinerlei Artefakte oder Knochen. So scheint der Lagerplatz vom Hang ins Tal hinein nur etwa 15 bis $20 \mathrm{~m}$ Breite erreicht zu haben.

An der Basis der Fundschichten wurde im Süd-Osten unserer Fläche ein in Richtung nach SW stark fließendes Wasser mit einer ausgesprochenen $\mathbf{S}$ t e in s o h l e festgestellt (Abb. 4), die nach Aussage der Baggerarbeiter sich noch weiter durch die NW-Ecke des Pumpenhauses nach Südwesten hatte verfolgen lassen. In der Steinsohle und am Südostufer des hier einmal fließenden Wassers lagen verstreut Artefakte und Knochenabfälle. In welche Zeit unseres Lagerplatzes - wahrscheinlich doch an den äußersten Anfang - diese Lagerspuren zu setzen sind, muß noch untersucht werden. Die in der Steinsohle und an ihrem Südrand im Sand und Kies angetroffenen Werkstücke und Knochen könnten auch sekundär in diese Lagerung gekommen sein.

Insgesamt mag es sich um eine g $\mathrm{r}$ ö Bere $\mathrm{H}$ orde paläolithischer Jäger gehandelt haben, die hier in der Talaue am sonnenbegünstigten Hange am Rande von flachen Wasserbecken einen Lagerplatz unterhielt. Ihre Zahl aber auch nur ungefähr, etwa nach dem verzehrten Wild, bestimmen zu wollen, wäre müßig. Man wird nach den Beobachtungen bei primitiven Jägerhorden nur sagen können, daß Horden, die zu groß werden, sich stets wieder in normale Gemeinschaften spalten, bei denen eine Größe von etwa 40 bis 50 Personen oder weniger vorherrschend ist. Hätte man durch weitere Fortführung unserer Grabung etwa noch Versuchsschnitte nach Westen, Osten und Süden führen können, wäre auch die genauere Ausdehnung des Lagerplatzes zu bestimmen und eine ungefähre Schätzung der Hordengröße zu versuchen gewesen.

Die Lage des Fundplatzes im Gelände, und zwar am Ostrande des breiten, südnördlich verlaufenden $\mathrm{Ha}$ a pttales - heute von der Fuhse durchflossen - erhält dadurch eine weitere Kennzeichnung, daß an dieser Stelle (vgl. den Meßtischblatt-Ausschnitt in der Einleitung) ein S e i t e n t a l von Südosten her einmündet. Der Platz lag also in der Talaue am Südwesthang der Hochfläche, dadurch geschützt gegen Nordostwinde, mit weitem Blick über beide Talzüge. Die W a h l d e s L a g e r p la t z e s mag insgesamt also durch die Südhanglage und durch die gute Weitsicht über beide Täler, vielleicht aber auch durch eine oder mehrere in günstiger Entfernung liegende Wildwechsel- oder Furtstellen bedingt gewesen sein: Am Haupttal entlang ziehendes Wild wurde durch das Seitental auf alle Fälle verzögert. Es entschloß sich zum Übergang über das Seitental, falls eine passende Furt es gestattete, oder mußte ostwärts ausweichen, um das Seitental zu umgehen. Beides gab gute Jagdmöglichkeiten.

Man wird bei dem paläolithischen Jägerlager von Salzgitter-Lebenstedt, das in manchen Dingen an die sehr viel jüngeren späteiszeitlichen Sommerlager von Renjägern bei Meiendorf und Stellmoor (Bez. Hamburg) erinnert, wohl ebenfalls annehmen dürfen, daß es nur im Sommer besetzt war. In arktischen Zeiten dürfte die im Winter tiefverschneite Tundra dieser Gegend für Mensch und Tier keine Existenzmöglichkeiten geboten haben. Was die Da u e r der B es e tzung des Jägerlagers von Salzgitter-Lebenstedt betrifft, so spricht das Milieu, das sich uns für einen wesentlichen Teil der Besetzung des Lagers in der Talaue gezeigt hat, nur für eine recht kurze Zeit, also für eine nicht zu große Zahl von Sommern. Auch die Zahl der erlegten Tiere (aus der Grabungsfläche insgesamt nur etwa 80 Rentiere, vergl. Beitrag KLEINschmidT) deutet auf eine nur kurze Zeit. 
B. Funde, Kulturstellung und Datierung

Es wird verständlich sein, daß gerade über die kaum inventarisierten Artefaktfunde der Ausgrabung Salzgitter-Lebenstedt, also über die vorkommenden paläolithischen Fundtypen und ihr Zahlenverhältnis untereinander, noch am wenigsten Verbindliches gesagt werden kann, und daß hier daher nur einige

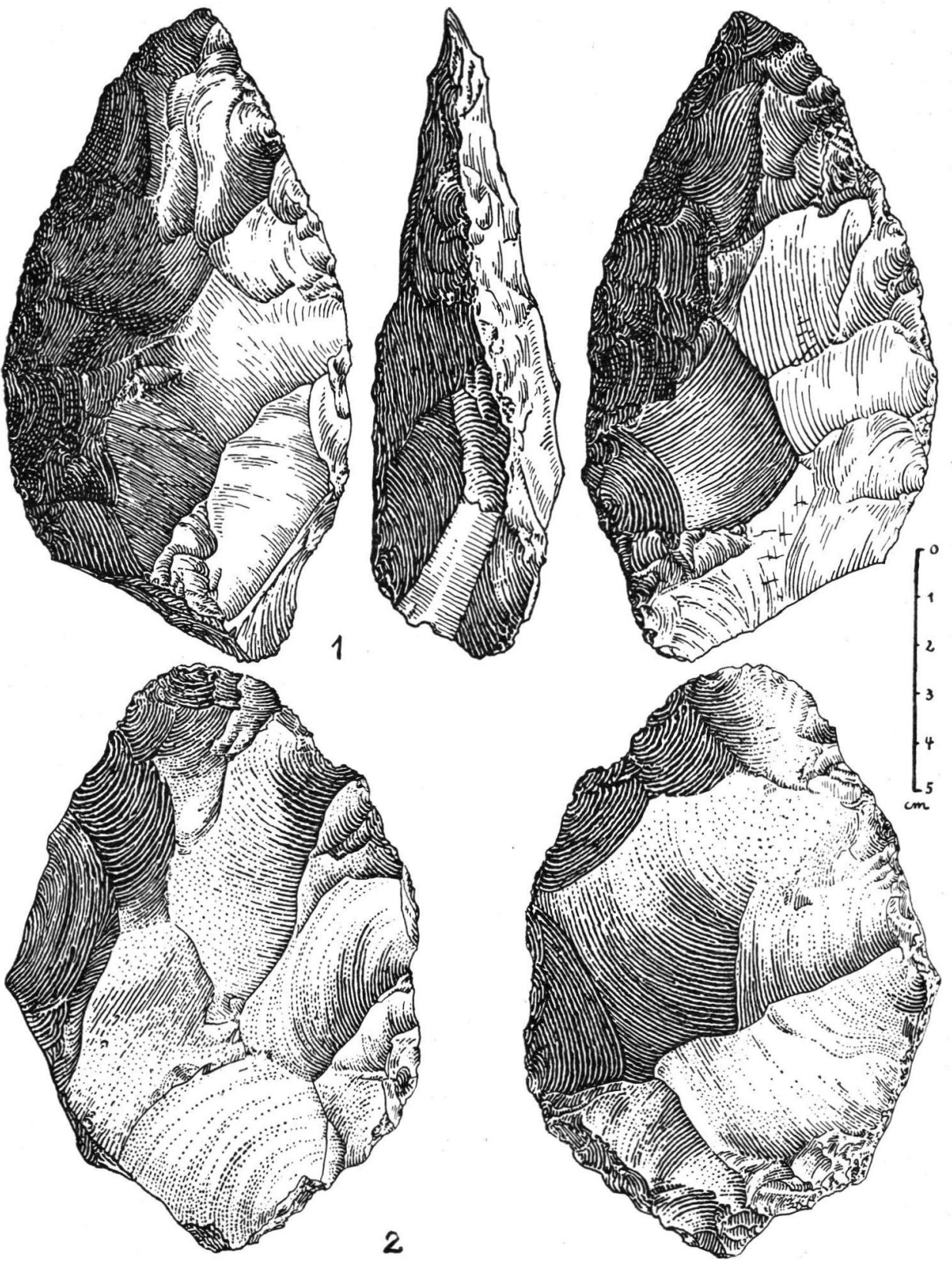

Abb. 5. Faustkeile von Salzgitter-Lebenstedt. 1: Leb. IV. 21, 2: Leb. S. 15. [Ldsmus. Brschw.] $2 / 3$ nat. Gr. 

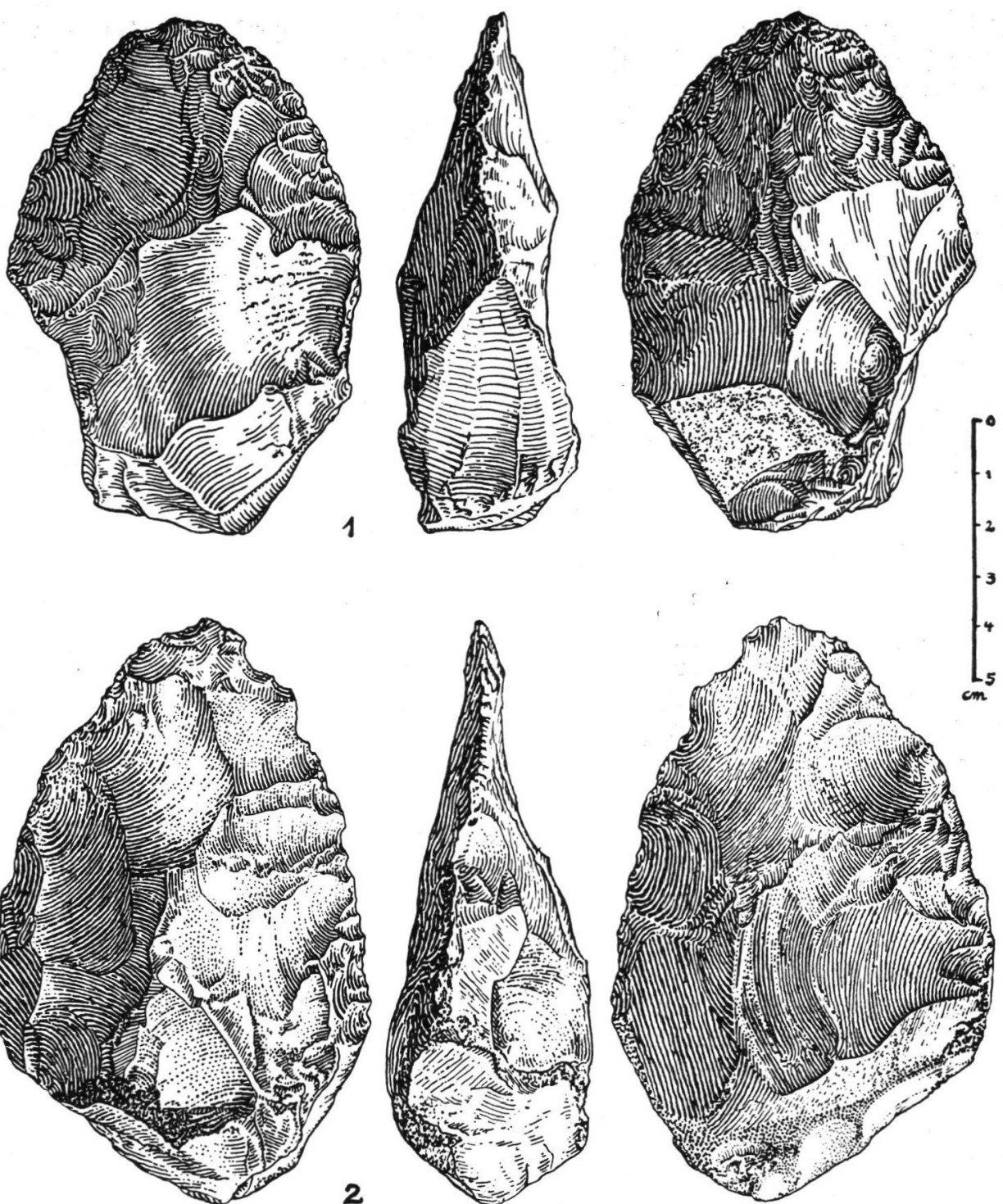

2
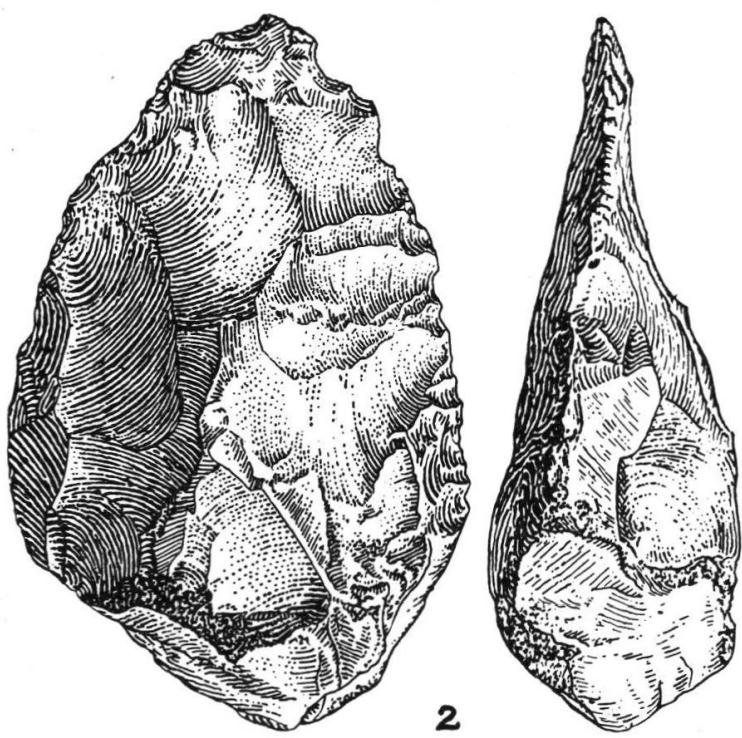

Abb. 6. Faustkeile von Salzgitter-Lebenstedt. 1: Leb. IV. 18, 2: Leb. IV. 100

[Ldsmus. Brschw.] \%/3 nat. Gr.

erste Mitteilungen über das Fundmaterial veranwortet werden können. Gerade bei der kulturellen Einordnung größerer Fundplätze sind, wie die Geschichte der Altsteinzeit-Forschung gezeigt hat, „erste Eindrücke“ häufig recht trügerisch gewesen. Mit Recht ist wiederholt darauf hingewiesen worden, daß erst die vollständige und sorgfältige Aufnahme und Vorlage des jeweiligen Gesamtfundstoffes eine wirkliche Beurteilung und kulturelle Einordnung eines Fundplatzes ermöglichten ${ }^{2}$ ). Diese Gesamtvorlage der Funde wird unter sauberer

$\left.{ }^{2}\right)$ Vgl. die letzte überzeugende Äußerung in dieser Richtung von A. Bormers 1951 , S. 28. 
Trennung von Materialdarbietung und Deutung in der geplanten Monographie über Salzgitter-Lebenstedt erfolgen, auf die hier anläßlich des ersten Vorberichtes verwiesen sei.

\section{Die Funde}

Außer einigen Funden bearbeiteter $\mathrm{Knochen}$, über die kurz am Schluß berichtet wird, bestehen alle übrigen Artefaktfunde ausschließlich aus Feuersteingeräten, - knollen und - a b schlägen, und zwar sind insgesamt aus der Ausgrabungsstelle über 2000 Stücke geborgen, davon fast 200 gute und charakteristische Artefakte. Der W e r k s t of $\mathrm{f}$ ist baltischer Feuerstein, der sich am Talhang und in der Talsohle als Auswaschungsprodukt aus den älteren Moränen reichlich vorfindet. Die Farbe des Feuersteins ist hellgrau bis schwarzgrau, häufig tiefschwarz mit herrlicher, mattglänzender Patina. Braungelbe Töne treten demgegenüber stark zurück, und zwar wurden fast nur aus der obersten Kiesschicht Stücke von braungelber Färbung und z. T. etwas Kantenrundung geborgen. Seltener kommt auch stark kalkiger Feuerstein vor, aus dem besonders gern größere Werkstücke gearbeitet waren.

Über die zahlreichen Rohknollen, z. T. angeschlagenes, z. T. unbearbeitetes Material, die ungezählten unbearbeiteten Abschlagstücke und das atypische Material, das in den Fundschichten zutage trat, kann noch gar nichts gesagt werden. Viele angefangene und halbfertige Werkstücke, Stücke insbesondere mit unerwünschten $\mathrm{K}$ a lk k onkreti on en darin, die eine weitere erfolgreiche Bearbeitung verhindert hatten, und das reichliche „Negativ“-Material zu den fertigen Geräten stellen ein wichtiges Studienmaterial besonders für die $\mathrm{Ab}-$ schlagtechnik und den Herstellungsvorgang bestimmter Ger ät y pen dar. Auch hierin erkennt man die große Überlegenheit eines vollständig registrierten, in der Lagerung festgelegten Grabungs-Fundmaterials gegenüber einem ungeregelt abgesammelten Material eines Fundplatzes o h n e Grabung.

Der tadellose Erhaltung z u s t a n d fast sämtlicher Feuersteinartefakte, das Fehlen einer Rollung sowie einer tiefgründigen Patina, wie sie unter langwirkendem Einfluß von Luft, Wind und Niederschlägen auf der Erdoberfläche entstanden wäre, beweist eine Einbettung der Stücke in schützende Erdschichten bald nach der Herstellung bzw. nach dem Gebrauch. Der S c h la g t e c h n i k nach ist ein Teil der Abschläge in altertümlicher Weise durch Anschlagen des Werkstückes gegen einen Amboß, also in ,C 1 a ct on-Art", ausgeführt, der weitaus größere Teil aber in der Art der sogenannten „L e v a 11 o is - Technik“, bei der mit weicherem direktem Schlag (z. T. mit Holz oder Knochen, wie man annimmt) zumeist längere und dünnere Abschläge erzielt werden als bei dem harten indirekten Schlag der Clacton-Technik. Sehr viele Geräte erhielten eine künstliche Schartung („Retusche“) der Arbeitskanten. Diese Retuschen erreichen vielfach höchste technische Vollendung. Viele Geräte haben Kanten- und Oberflächenretuschen, die ineinander übergehen (Stufenretusche).

Überblickt man die Gesamtheit der eigentlichen Geräte, so erkennt man, $\mathrm{da}$ es sich im Wesentlichen um $\mathrm{Abschlag} g$ e $\mathrm{r}$ ät e handelt. Der Anteil an Geräten, die aus einem $\mathrm{K}$ e r $\mathrm{n}$ gearbeitet sind, ist den guten Abschlaggeräten gegenüber aber doch, grob gesagt, mit etwa $10 \%$ zu veranschlagen. Von den in Salzgitter-Lebenstedt vertretenen Geräten mögen die folgenden $\mathrm{Haupt-}$ g e r ä t y pen kurz aufgeführt werden:

Eine erste wichtige Gruppe von Geräten für die Beurteilung der Kultur von Salzgitter-Lebenstedt stellen die aus der dortigen Fundstelle größtenteils in situ 


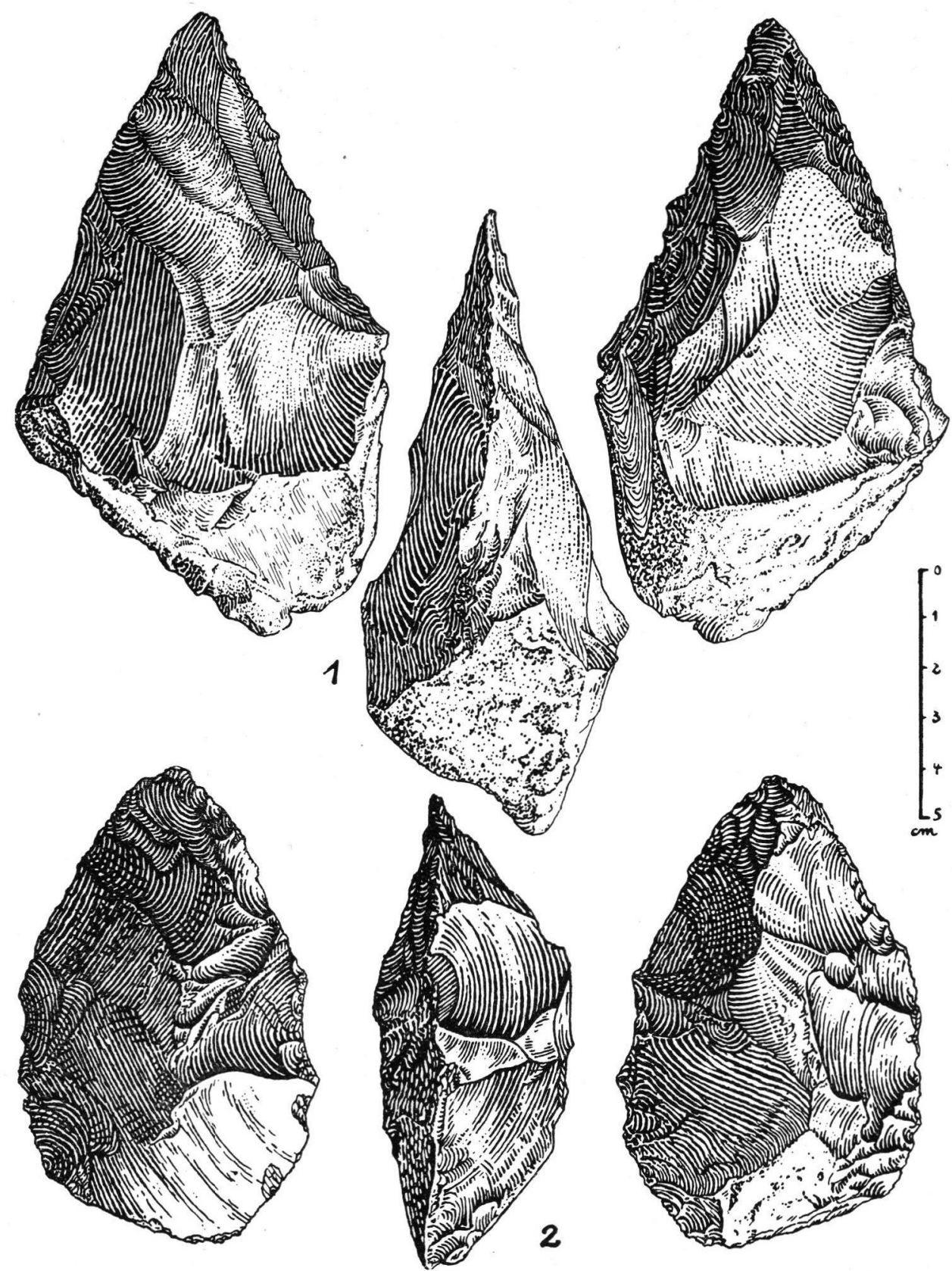

Abb. 7. Faustkeile von Salzgitter-Lebenstedt. 1: Leb. IV. 104, 2: Leb. IV. 91

[Ldsmus. Brschw.] $\%$ nat. Gr.

geborgenen Faustkeile und einige dazugehörige „D op pelseiter “-Typen $\operatorname{dar}^{3}$ ). Es handelt sich um etwa 20 Geräte (einschließlich einiger halbfertiger Stücke). Die Fa ustkeile (Abb. 5-7) sind mittelgroß bis klein (8 bis $12 \mathrm{~cm}$ lang). Einige Stücke stellen ausgesprochen kleine, dabei dicke „Fäustel“ 
dar. Nur wenige Stücke sind länger als $12 \mathrm{~cm}$. Die meisten Faustkeile zeigen ein stumpfes, ungepflegtes Bahnende mit Abschrägung, z. T. mit ursprünglicher Gesteinsrinde am Knaus. Die Oberseite ist bei einigen Stücken stark, die Unterseite kaum gewölbt. Die Spitze ist mehrfach ausgesprochen langgezogen (Abb 5-7). Als eigenartig in seiner Größe muß ein g roßer dreikantiger Pickel von fast $25 \mathrm{~cm}$ Länge aus dunkelgrauem kalkigem Feuerstein erwähnt werden, der mit seinem dicken Griffende und dem dreiseitigen Querschnitt seiner lang ausgezogenen Spitze eine typische Micoque-Erscheinung ist (Abb. 8). Parallelen bieten besonders Funde aus der Bocksteinschmiede (R. WETzEL 1944, Abb. 2-5). Fast alle Merkmale der Faustkeile von Salzgitter-Lebenstedt sind Kennzeichen der späten Faustkeiltypen des ausgehenden Altpaläolithikums von Spätacheuléen- speziell Micoquien-Gepräge ${ }^{4}$ ).

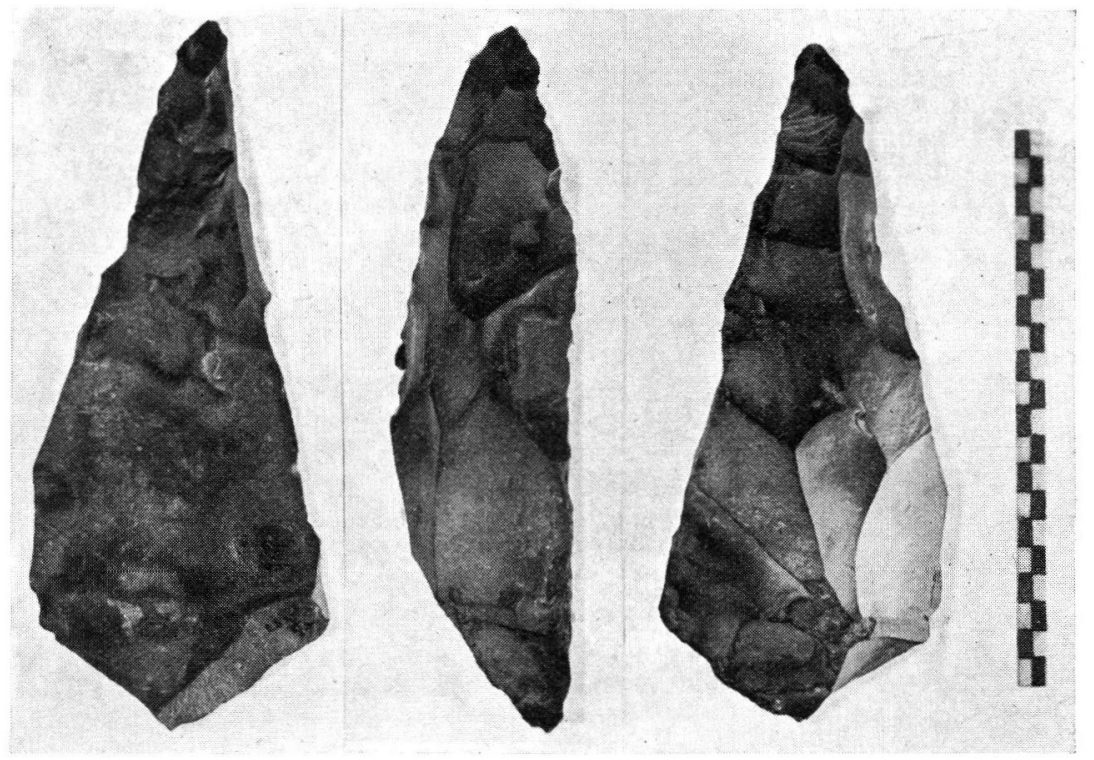

Abb. 8. Großer dreikantiger Faustkeil von Salzgitter-Lebenstedt. Leb. III. 57. [Ldsmus. Brschw.]. Länge des Stückes $25 \mathrm{~cm}$.

Im Anschluß an die Faustkeile können einige "Faustkeils chaber" bzw. "Keilmesser " mit dickem, stumpfen Rücken ${ }^{5}$ ) genannt werden, Stücke, die z. T. aus einem dicken Abschlag doppelseitig gearbeitet sind, dazu Geräte, die man vielleicht als „blattförmig e Fä us t el " bezeichnen kann. Gerade die süddeutschen und mährischen Fundplätze (z. B. Bocksteinschmiede, Klausennische u. a.) haben uns gezeigt, wie fließend die Übergänge zwischen den zweiseitig bearbeiteten Gerättypen sind. Von den Faustkeilen bis hin zu den Vorformen von „Blattspitzen“ gibt es fast lückenlose Formreihen besonders aus

$\left.{ }^{3}\right)$ Da eine konsequente Orientierung der paläolithischen Geräte weder nach dem Arbeitsgang bei der Herstellung, noch nach der (vermutlichen) Handhabung beim Gebrauch möglich ist, sind die Faustkeile in altgewohnter, auch international zumeist angewandter Art auf den Abbildungen mit der Spitze nach oben gezeigt, andere Geräte in möglichst günstiger Darstellung und Raumausnützung.

$\left.{ }^{4}\right)$ Vgl. R. Wetzel, 1944, S. 82ff., L, F. Zotz, 1951, S. 64, A. Bohmers, 1951, S. 44, R. Grahmann, 1952, S. 207.

${ }^{5}$ ) Vgl. K. H. JACOB-Friesen, 1949, S. 128. 

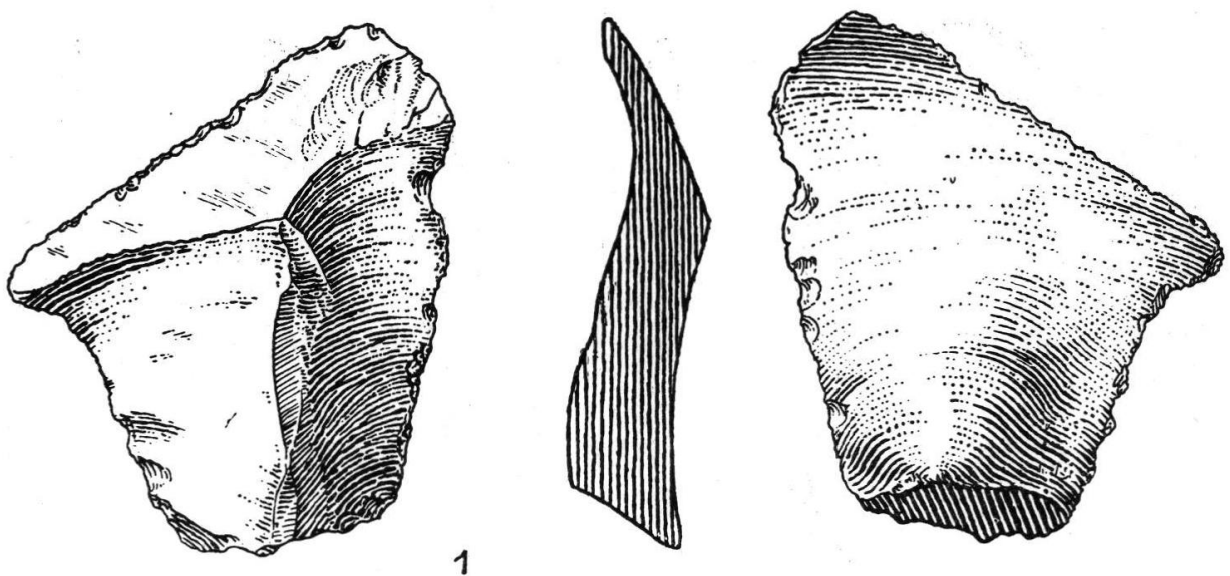

1
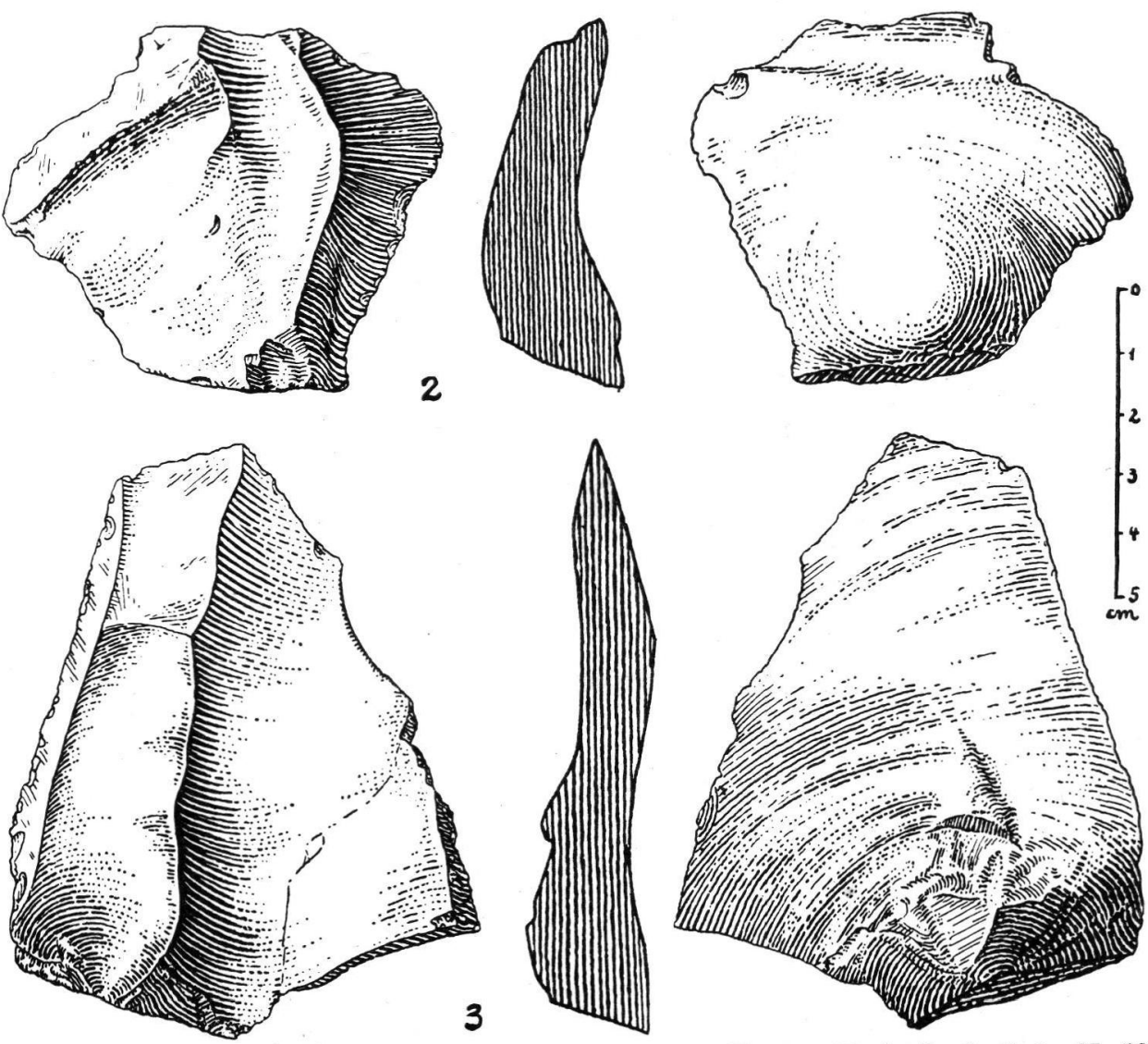

Abb. 9. Abschläge, hergestellt in der Tradition der Clacton-Technik. 1: Leb. II. 29, 2: Leb. IV. 71, 3: Leb. I. 51 [Ldsmus. Brschw.] $2 / 3$ nat. Gr.

dem Kreis des Spätacheuléen, des Micoquien und des faustkeilführenden Moustérien ${ }^{6}$ ).

$\left.{ }^{6}\right)$ Vgl. bes. G. Freund, 1951 an versch. Stellen, z. B. S. 280 u. S. 317. 

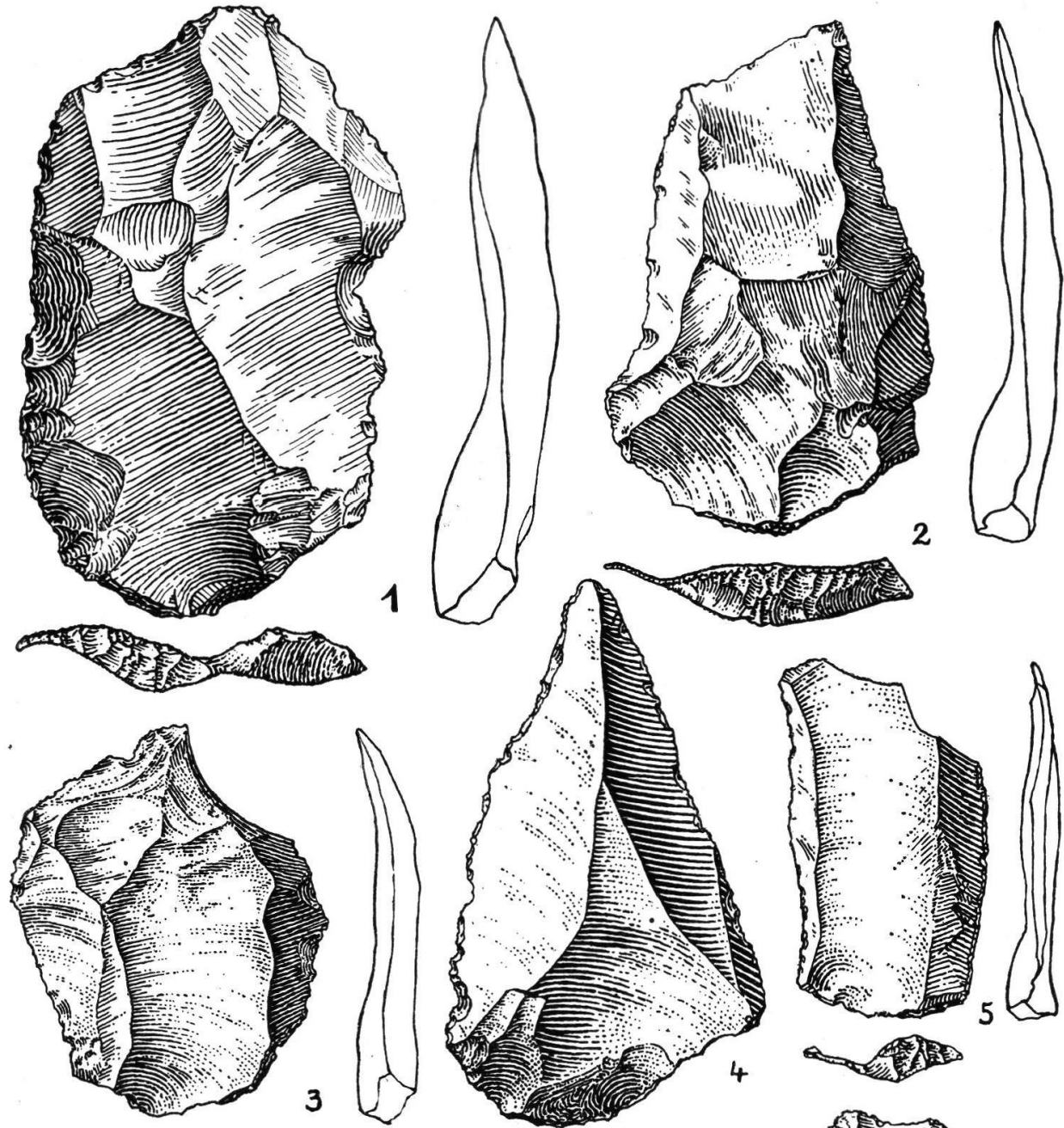

\section{2}
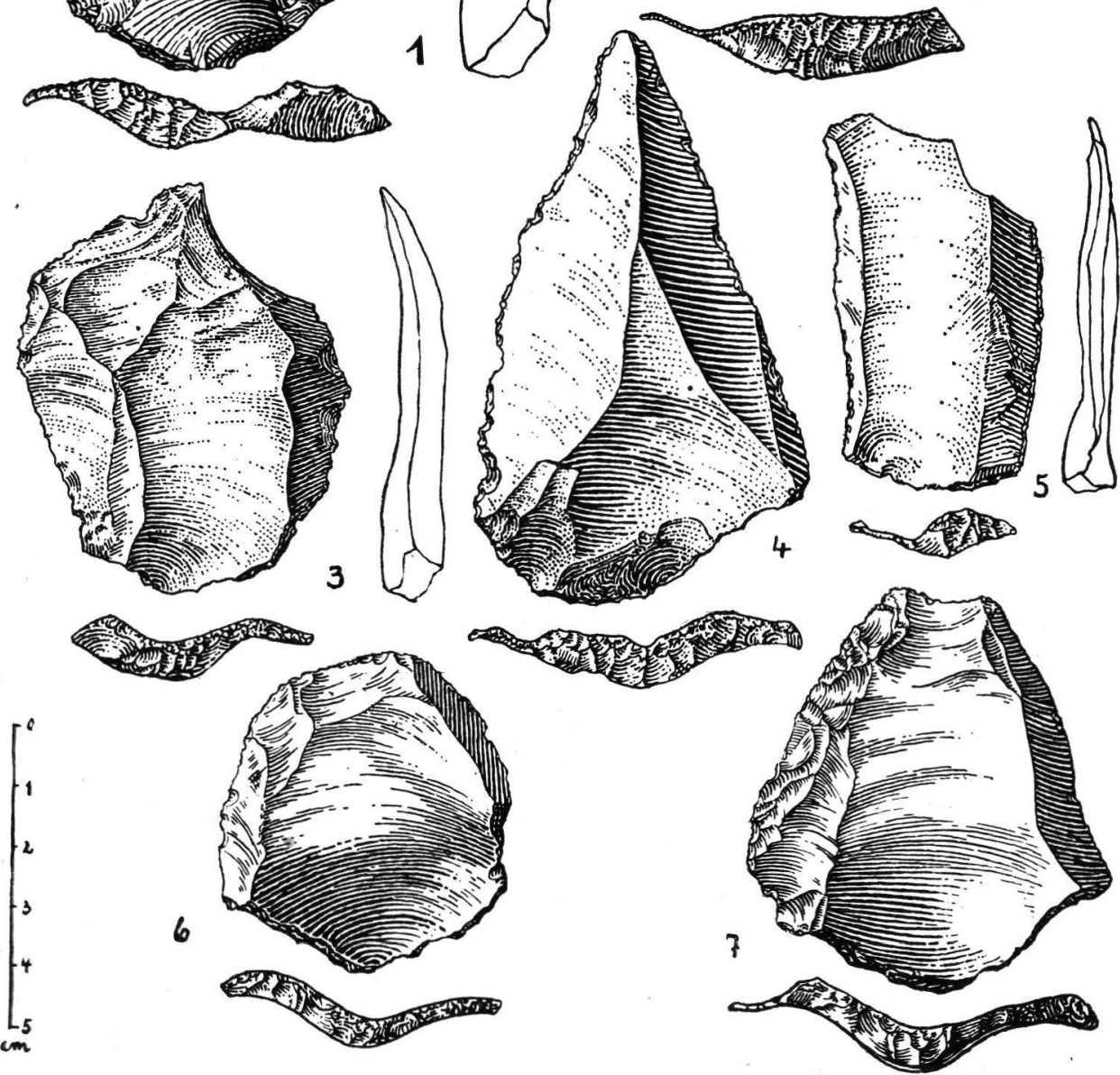

Abb. 10. Abschläge bzw. Klingen verschiedener Form, hergestellt in Levallois-Technik. 1: Leb. S. 16, 2: Leb. IV. 225, 3: Leb. I. 48, 4: Leb. II. 117, 5: Leb. IV. 442, 6: Leb. N.W. 1, 7: Leb. S. 12 [Ldsmus. Brsch.] $\% 3$ nat. Gr. 
Die Abschlaggeräte lassen in vielen Stücken ihre verschiedene Herstellungstechnik deutlich erkennen. So zeigen einige Abschläge (etwa ein Dutzend) noch gewisse Merkmale der uralten $\mathrm{Clact}$ on-Technik, nämlich breite Schlagflächen und große Schlagwinkel, dazu große und stark vortretende Schlagbuckel, sodaß diese Stücke einen sehr primitiven Eindruck machen (Abb. 9). Sie
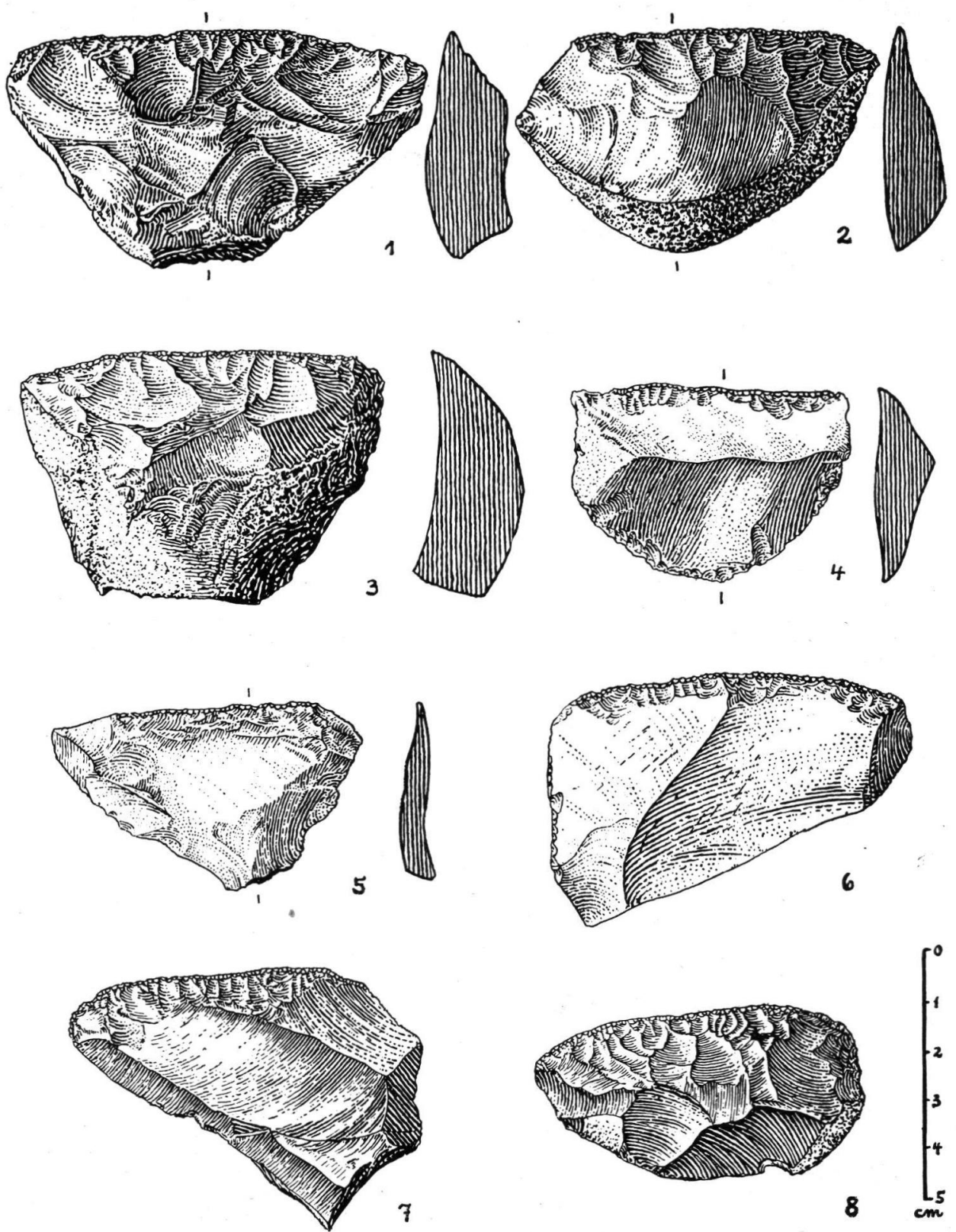

Abb. 11. Schaber mit gerader oder annähernd gerader Schaberkante. 1: Leb. I. 44, 2: Leb. IV. 360, 3: Leb. II. 109, 4: Leb. IV. 67, 5: Leb. Sfg. 35, 6: Leb. Sfg. 10, 7: Leb. IV. 385, 8: Leb. IV. 42 [Ldsmus. Brschw.] 2/3 nat. Gr.. 


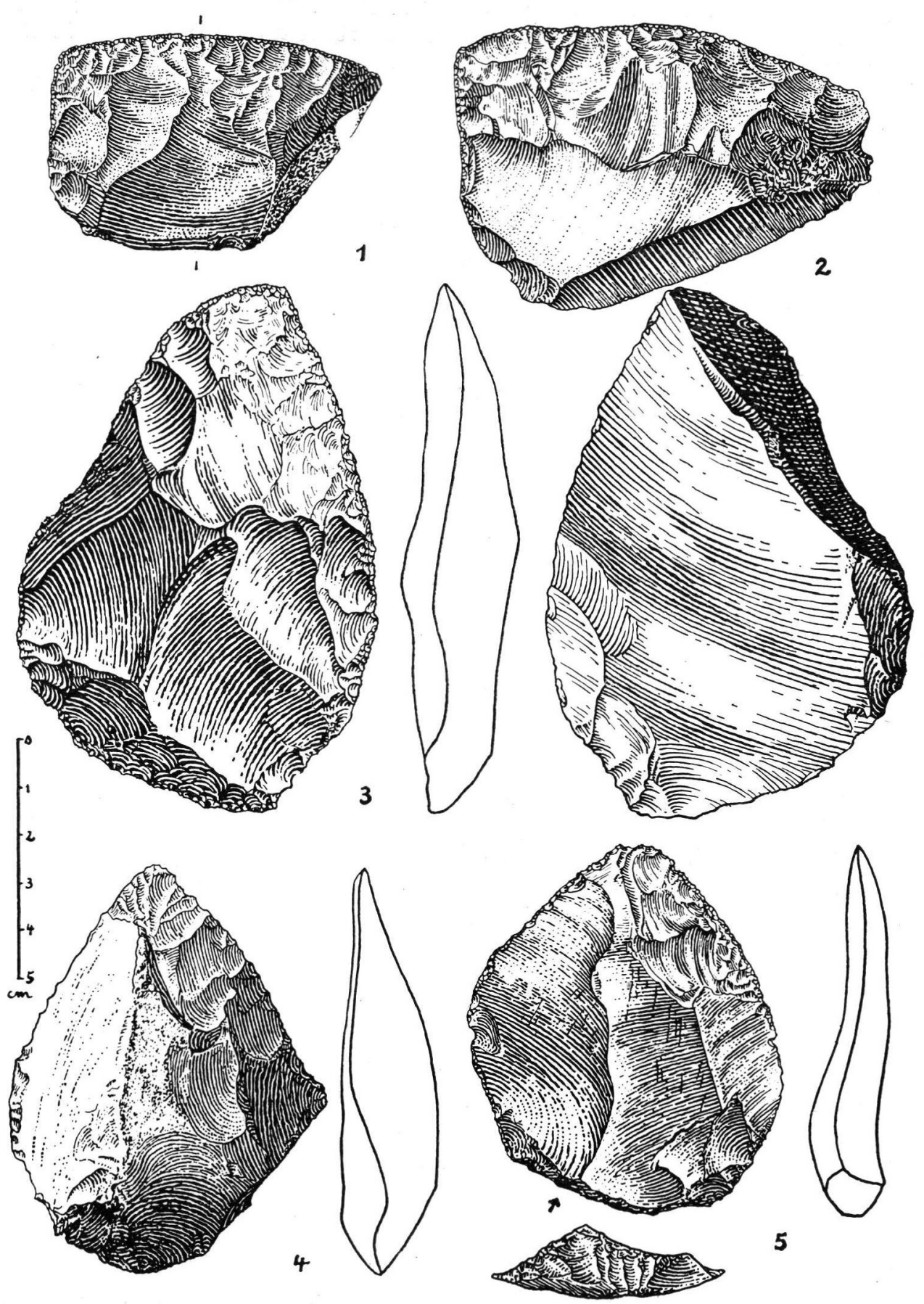

Abb. 12. Winkelschaber, Spitzschaber bzw. Spitzen. 1: Leb. IV. 400, 2: Leb. IV. 306, 3: Leb. S. 2, 4: Leb: S. 18, 5: Leb. I. 42 [Ldsmus. Brschw.] 2/3 nat. Gr. 
sind aber, wie eine genaue Nachprüfung der Fundlagerung ergeben hat, genau wie alle übrigen Fundtypen in ihrer Fundstreuung nicht auf irgendeine Fundschicht oder einen Teil des Fundschichtpaketes beschränkt, sondern kommen in allen Schichten in typischen Exemplaren vor.

Eine wesentlich umfangreichere Gruppe von Abschlaggeräten (mindestens 30 bis 40 Stück) zeigt typische Levallois-Technik (Abb. 10). Es treten B reitklingen verschiedenster Form, Spitzen und $\mathrm{r} u n d$ e Absch 1 äge auf. Die für Levallois-Abschläge so charakteristische Basisretusche ist bei den meisten Stücken in klassischer Weise ausgebildet. Im übrigen kommen auch mehrere typische Levallois-Kernsteine in Form der sogenannten „Schildkerne" vor.

Auch Schmalklingen verschiedener Größe befinden sich unter dem Fundgut von Salzgitter-Lebenstedt (etwa 20), darunter eine Klinge mit fast rundherum geführter Retusche.

Manche Abschläge sind durch sorgfältige Kanten- und auch Stufenretusche zu Schabern (Abb.11) zugerichtet. Die Schaber treten einmal auf als G eradschaber (etwa 20), und zwar als dickere Abschlaggeräte mit ungepflegtem Griffende oder als dünnere Klingengeräte mit einer geraden oder annähernd geraden, z. T. auch in einem Bogen abschließenden Schaberkante (Abb. 11 unten), sodann als sogenannte W in k el s c h a be r (etwa 10) mit zwei spitz- oder rechtwinklig aneinanderstoßenden sauberen Geradretuschen (Abb. 12 oben), die in ganz ähnlicher Art u. a. auch im Fundgut der Bocksteinschmiede in Süddeutschland (R. Werzel 1944), vor allem aber in der von A. Rust (1950) beschriebenen älteren Jabrud-Kultur in Syrien mit Jungacheul- und MicoqueErscheinungen verzahnt auftreten (vgl. R. Grahmann 1952, S. 221). Ferner treten mehrfach Spitzschaber auf, bei denen eine kürzere Geradretusche in einem mehr oder weniger spitzen Winkel mit einer längeren Bogenretusche zusammenstößt (Abb.12). Mehrere dreieckige Spitzschaber weisen Merkmale echter „Handspitzen“ auf (Abb. 12,3) ${ }^{7}$ ).

Viele Schaber gehören dem Typus des B ogenschabers an, der in den verschiedensten Größen und Bogenkrümmungen, u. a. auch als „La Quina“Schaber, Doppel- und Allseitschaber, häufig mit bester Stufenretusche auftritt (Abb. 13). Ein Teil der Doppel- bzw. Allseit-Schaber gehört zu den zumeist doppelseitig bearbeiteten „Blattspitzen-Prototypen (Abb. 14), wie sie besonders L. F. Zotz (1951) und G. Freund (1952) für die "Wurzelkulturen“ der jungpaläolithischen Blattspitzenentwicklung herausgearbeitet haben. Symmetrisch geformte, einseitig bearbeitete Spitzen mit bog e $\mathrm{f}$ örmige m A bs c h $1 \mathrm{u} B$ (Abb. 14 unten) erinnern in Art und Technik an die hochrückigen Doppelspitzen, wie sie u. a. in Ehringsdorf und in Předmost vorkommen. Auch sie gehören in den Formenkreis der „Blattspitzen“-Vorformen. Von den Schabern und schaberähnlichen Geräten kann insgesamt gesagt werden, daß alle vertretenen Typen im s päten Acheuléen und vor allem im Moustérien durchaus bekannte Formen darstellen.

Die im Vorhergehenden aufgeführten Hauptgerättypen sind in SalzgitterLebenstedt über alle Schichten des Fundplatzes gleichmäßig verstreut festgestellt worden. Sie stellen demnach trotz ihrer scheinbaren Verschiedenheit in kultureller Beziehung eine Einheit dar. Wenn auch erst eine genaue Aufnahme, Formenanalyse und Auszählung aller Stücke einen besseren Einblick in die Kultur vermitteln wird, so kann doch zur Kulturstellung und zeit-

$\left.{ }^{7}\right)$ Vgl. die letzte Definition der „Handspitze“ bei A. Bohmers 1951, S. 44 

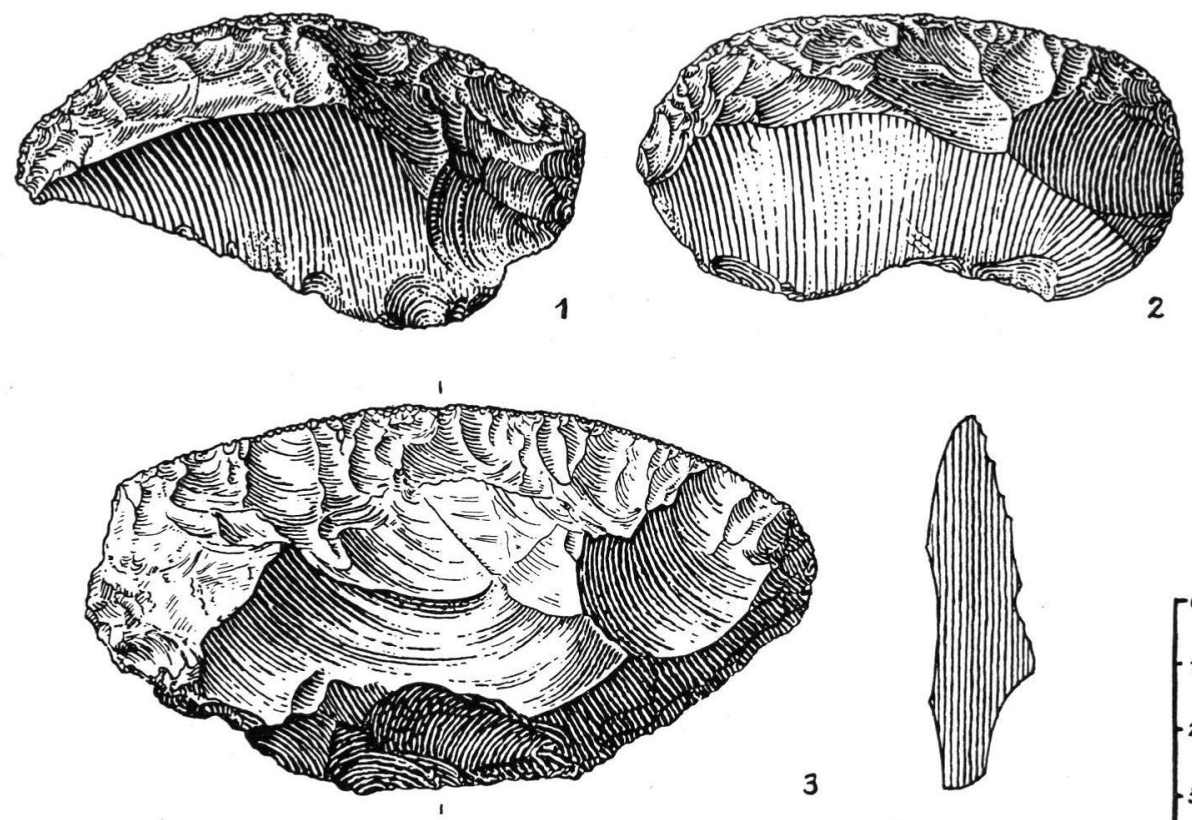

3
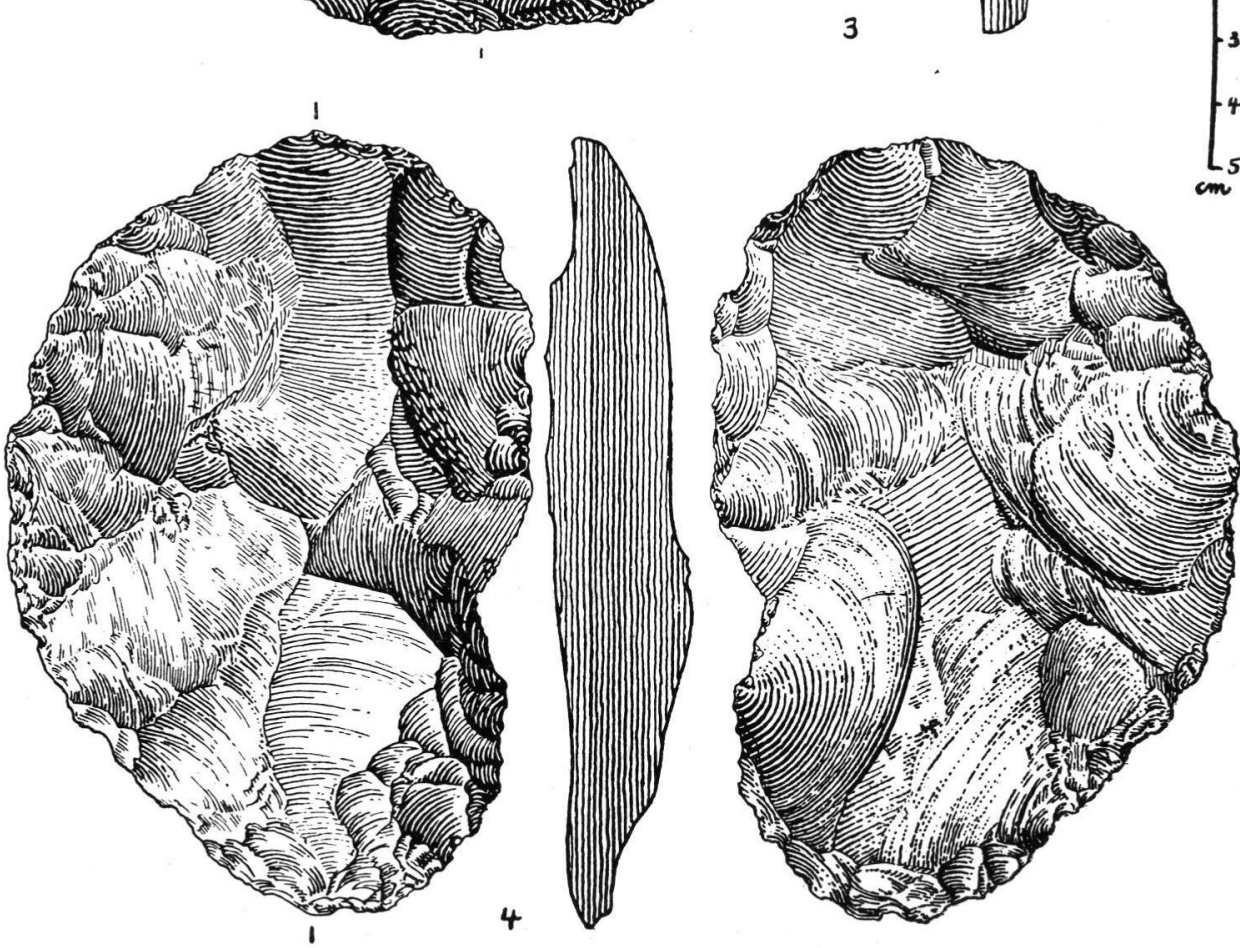

Abb. 13. Bogenschaber, z. T. mit doppelseitiger Oberflächenbearbeitung (Nr. 4). 1: Leb.

S. 21, 2: Leb. IV. 95, 3: Leb. IV. 22, 4: Leb. II. 1 [Ldsmus. Brschw.] $2 / 3$ nat. Gr. 


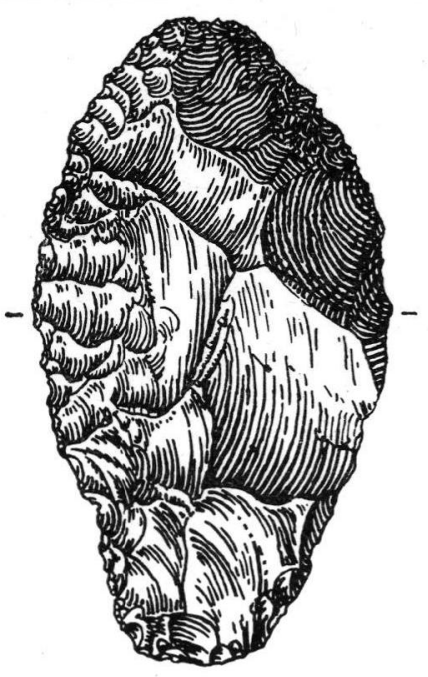

1
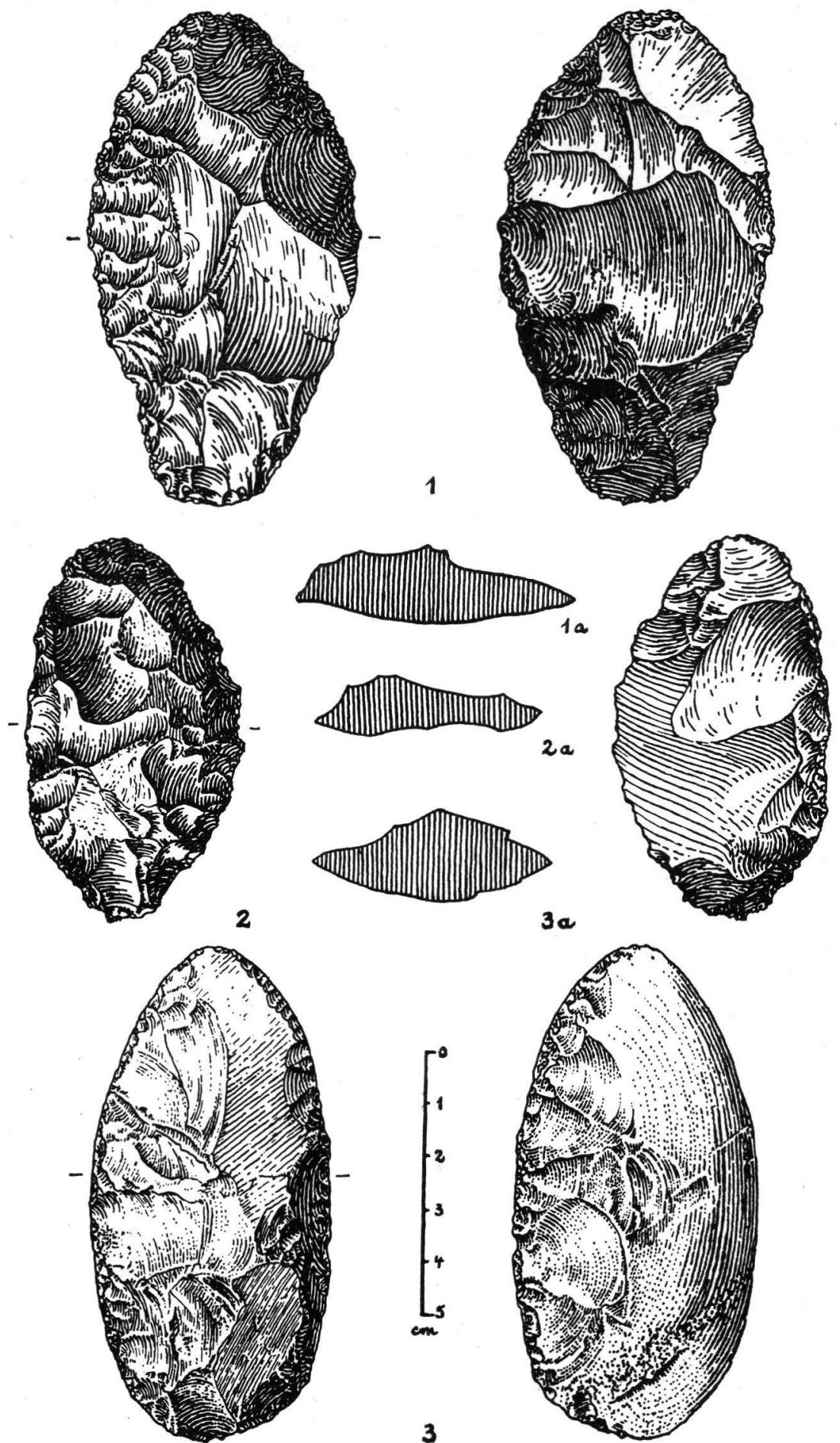

Abb. 14. Doppelseitig bearbeitete „Blattspitzen-Prototypen“ sowie Spitze mit bogenförmigem Abschluß (Nr. 3). 1: Leb. III. 56, 2: Leb. S. 17, 3: Leb. IV. 20 [Ldsmus. 


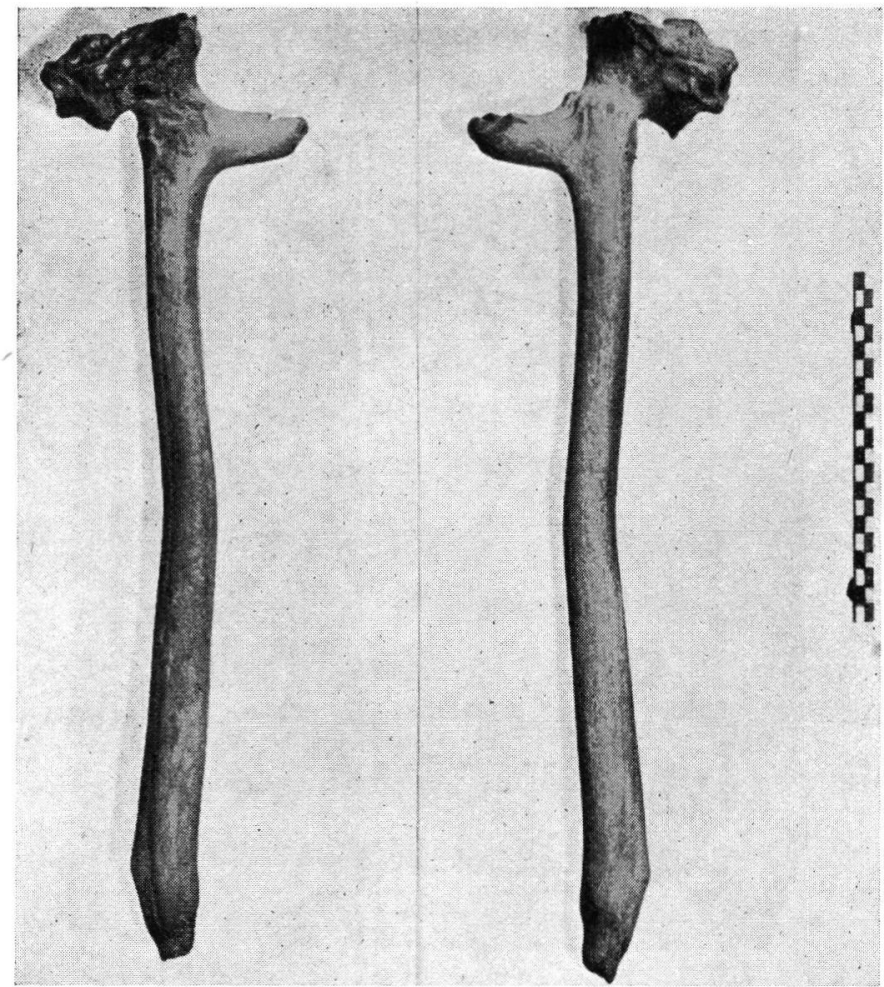

Abb. 15. Bearbeitetes Rengeweih (Beil ?) [Ldsmus. Brschw.] Länge $52 \mathrm{~cm}$.

lichen Einordnung des Ges a m t fundes nach dem erkannten Typenbestand schon jetzt, kurz zusammengefaßt, etwa das Folgende festgestellt werden:

1. Das Fundmaterial von Salzgitter-Lebenstedt zeigt noch klare A c h e u lé e nTradition, die sich auch in den zahlreichen Micoque-Erschein ung en manifestiert.

2. Die starke Mischung von typischen M o u t érie n-Formen mit abklingenden Acheuléen- und Levalloisien-Erscheinungen ist für $\mathrm{Nord-}$ westeurop a auch sonst durchaus charakteristisch. Schon lange wird hier von dem Bestehen eines „Moustérien mit Acheulé en-Morpholo gi e " gesprochen ${ }^{8}$ ).

3. Alle vergleichbaren Funde des Spätacheuléen, Micoquien, Moustérien usw., die geologisch datiert werden konnten, gehören in den A usgang des letzten Interglazials bzw. den frühesten Abschnitt des Würm-Glazials.

Vergleichbare Fundplätze dieser Art sind in Nordwestdeutschland z. B. diejenigen von $\mathrm{Herne}$ und Ternsche in Westfalen ${ }^{9}$ ), Plätze, bei denen auch die ganz gleichartige geologische Lagerung der Fundschichten (an der Basis der Niederterrasse bzw. in den Kiesschichten der Niederterrasse) auffällt ${ }^{10}$ ). Auch

$\left.{ }^{8}\right)$ Vgl. H. Obermaier 1927, S. $314 \mathrm{ff.}$

${ }^{9}$ ) Vgl. E. Kahrs 1925, S. 93ff., L. F. Zotz 1938, S. 183/184, L. F. Zotz 1951, S. 41/42, A. Bohmers 1951, S. $50 \mathrm{ff}$.

10) P. Woldstedt 1950, S. 177 u. S. 350. 
die Leinetalfunde ${ }^{11}$ ) zeigen in einer Reihe von Fundtypen - durchaus nicht in allen - ausgezeichnete Parallelen zu Salzgitter-Lebenstedt. Es wird sich zu erweisen haben, ob nicht ein Teil der Funde überhaupt der Niederterrasse der Leine entstammt und sowohl die typologische Einheitlichkeit der Leinetalfunde als auch ihre geschlossene Einordnung in die Zeit der Riß-Eiszeit, die F. HАMm (1949) und K. H. Jacob-Friesen (1949) vertreten, berichtigt werden muß.

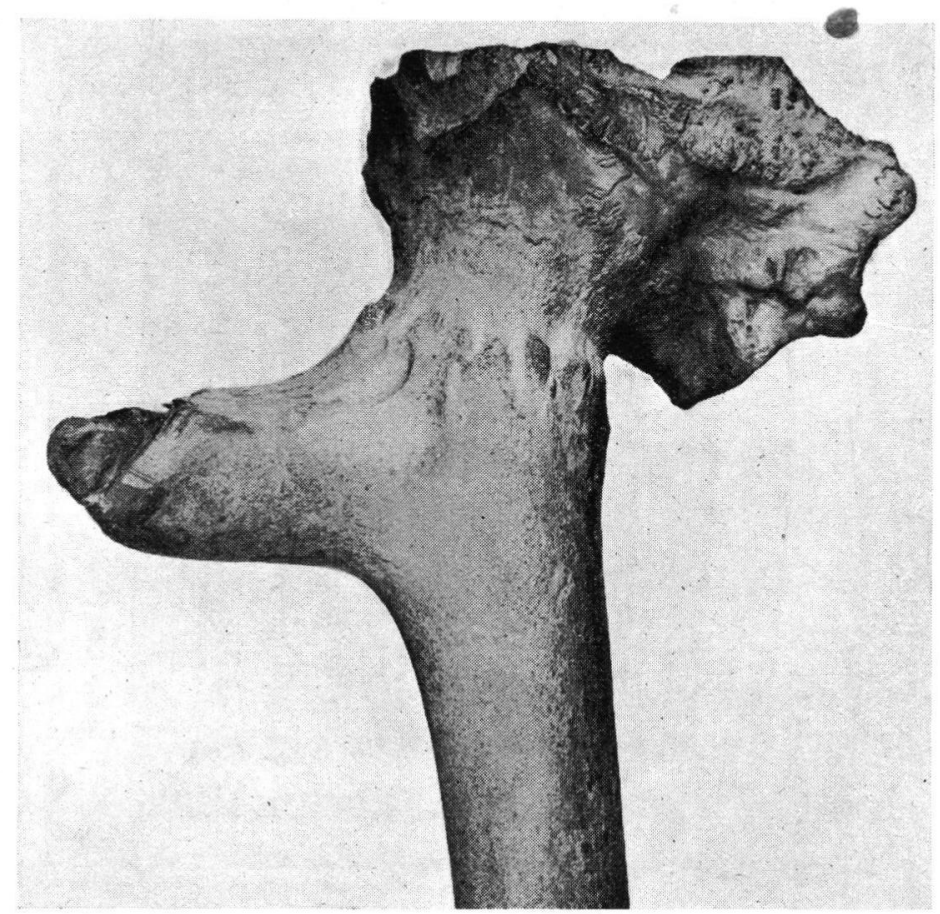

Abb. 16. Rengeweihrose mit abgeschnittener Eissprosse (vgl. Abb. 15)

[Ldsmus. Brschw.]

Einen neuen Akzent bringen nun in die Kultur von Salzgitter-Lebenstedt die bei unserer Grabung zutage getretenen $\mathrm{Kn}$ ochengeräte hinein, die zum Schluß noch kurz besprochen werden sollen. Sie werden an anderer Stelle eine besondere Darstellung erfahren. Unter den zahlreichen Rengeweihst a ngen, die unsere Ausgrabung erbracht hat, befindet sich einstweilen nur ein einziges Stück mit umfangreicheren, deutlichen Schnittspuren (Abb. 15). Es handelt sich um eine schädelechte Stange, die $52 \mathrm{~cm}$ von der Rose nach kerbenförmig ringsum ausgeführten Schnitten abgebrochen ist. Auch die Augensprosse wurde $-6 \mathrm{~cm}$ von der Hauptstange --, wenn auch ziemlich ungeschickt, mit Schnitten abgetrennt (Abb.16). Die abgebrochenen Enden scheinen noch etwas nachgearbeitet zu sein. Außerdem befinden sich noch Schnittspuren an der Geweihrose.

Da Schnittspuren an Geweihstangen unseres Fundplatzes sonst so gut wie gar nicht auftreten, kann es sich bei diesem Stück kaum um Spielerei handeln. Dieser recht beschwerlichen Schneidearbeit an einem frischen Geweih muß vielmehr ein Sinn beigemessen werden: Das Stück muß m. E. als Gerät der da-

11) K. H. JАCOB-Friesen 1949. 
maligen Menschen betrachtet werden, und zwar kann es, wenn es überhaupt angefaßt worden ist, nur wie ein $\mathrm{Beil}$ geschwungen worden sein. Auch wenn man diese Handhabung für eine so frühe Zeit zunächst bezweifeln möchte, weil wir die Entstehung des Beiles als menschliches Gerät nach den bisherigen Funden erst in das Spätpaläolithikum zu setzen gewohnt sind, so müssen wir diesen Fund aus der beginnenden letzten Eiszeit doch wohl zur Kenntnis nehmen. Selbst wenn man annehmen will, daß das Abschneiden der Stange und der Augensprosse -übrigens beide in sehr günstiger Länge und ähnlich wie bei den bisher bekannten späteren Geweihbeilen - ohne bestimmte Überlegung geschehen sei, müßte gefragt werden, ob man glauben soll, daß das Stück nicht wenigstens nachträglich als Schlagwaffe erkannt sei. Wir müssen also mit der Möglichkeit rechnen, daß hier ein Schlaggerät des a usklingenden Altpaläolithikums gefunden ist.

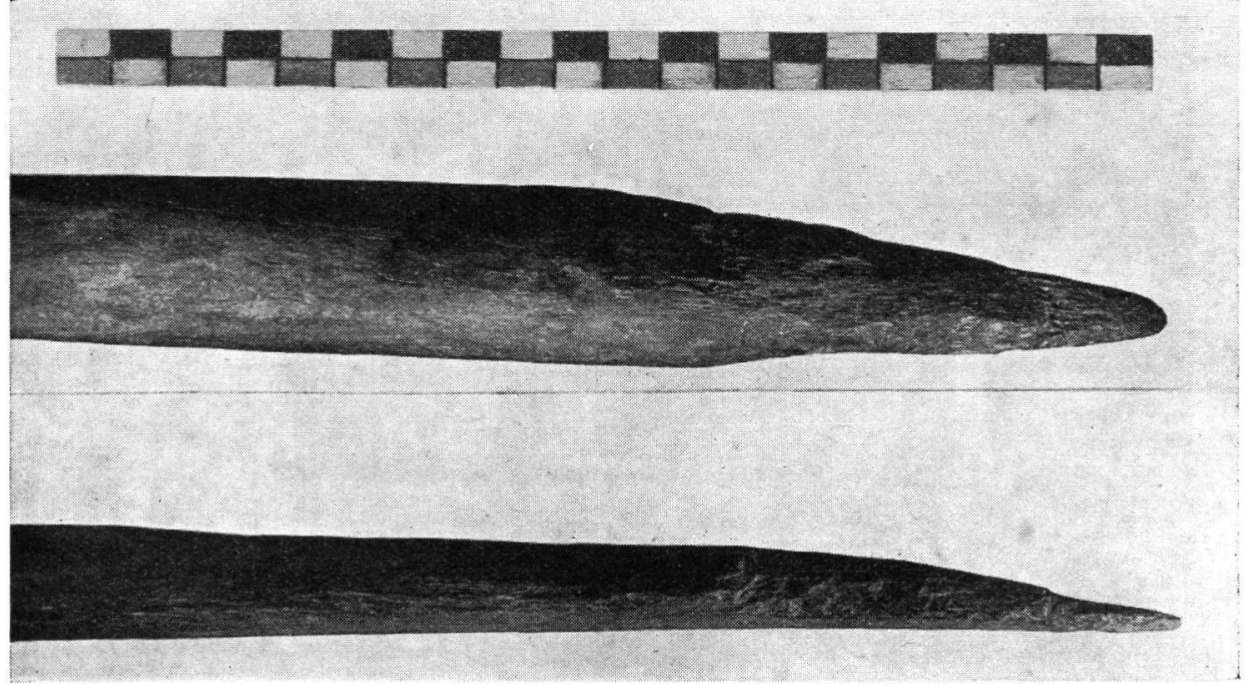

Abb. 17. Knochenspitze (Dolch ?) aus einer Dickhäuter-Rippe, wahrscheinlich vom Mammut [Ldsmus. Brschw.]

Eine weitere Überraschung stellt nun die Auffindung von angespitzte $\mathrm{n}$ $\mathrm{R}$ ippenknochen dar. Es handelt sich um etwa 10 Knochenstücke mit verschiedenartig ausgefühter Anspitzung. Sämtliche Stücke sind Dickhäuter-Rippen, wahrscheinlich Mammutrippen, die z. T. eine Länge von etwa 60 bis $70 \mathrm{~cm}$ haben. Die kürzeren Stücke dürften abgebrochene Enden ursprünglich ähnlich langer Geräte darstellen. Die Anspitzung betrifft ein Ende von etwa $10 \mathrm{~cm}$, in einigen Fällen ein etwas kürzeres Ende der Rippe. Es kommt eine sehr sorgfältig ausgeführte allseitige Anspitzung vor (vgl. bes. Abb. 17), mehrfach eine meißelförmige und schließlich eine sehr einfache schräge Anspitzung. In jedem Falle ist das künstlich ausgeführte Anspitzen, teilweise mit den einzelnen Schnitten, deutlich erkennbar (Abb. 18).

Gerade die sorgfältige allseitige Anspitzung macht es sehr unwahrscheinlich, daß es sich bei diesen leicht gekrümmten Rippen um „Grabstöcke“ gehandelt hat, mit denen man damals in der Tundra gegraben haben soll. Die Tundra hat keine Knollen- und Wurzelgewächse zu bieten, und etwaige Wildgruben dürfte man nicht gerade mit längeren, gekrümmten, spitzen Rippen, sondern mit flachen Steinscheiben oder breiteren Geweihstücken ausgetieft haben. Diese ange- 


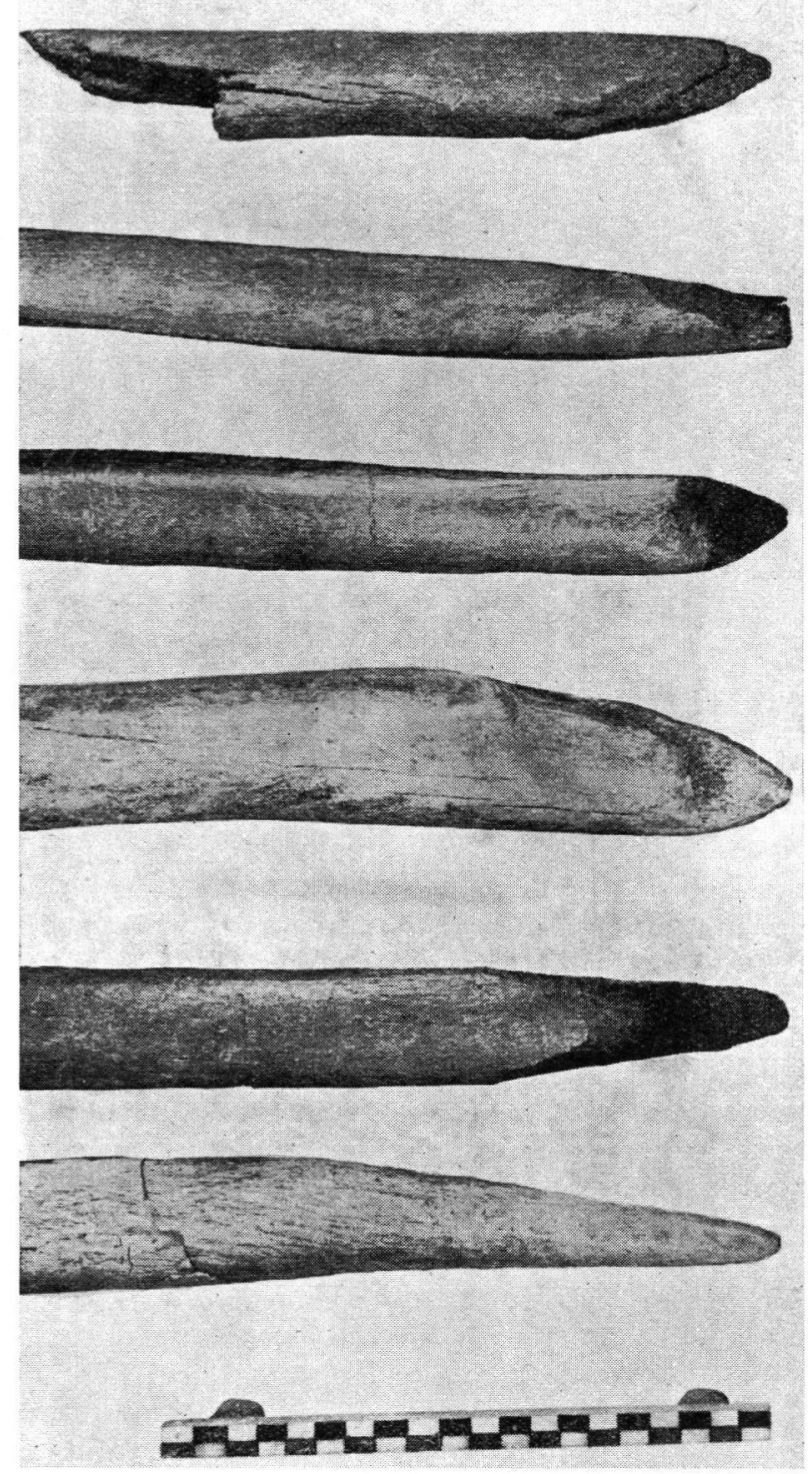

Abb. 18. Angespitzte Dickhäuter-Rippen (Knochendolche ?), zumeist wohl vom Mammut [Ldsmus. Brschw.]

spitzten Rippenknochen müssen $\mathrm{m}$. E. vielmehr als $\mathrm{K} n$ ochendol che angesprochen werden, die als äußerst wirksame Waffe im Nahkampf und als ausgezeichnete Jagdwaffe etwa zum Erlegen von Rentieren verwendet sein müssen. Noch heute werden nach freundlicher Mitteilung des Lapplandforschers G. HAGEMANN ${ }^{12}$ ) grundsätzlich Rentiere nicht geschossen, sondern durch einen Stich in den Brustkorb getötet. Da es auf die Schärfe der Spitze ankam, mögen öfter

12) Gustav Hagemann, Lappen zeichnen ihr Leben. L. Schwann, Düsseldorf. 


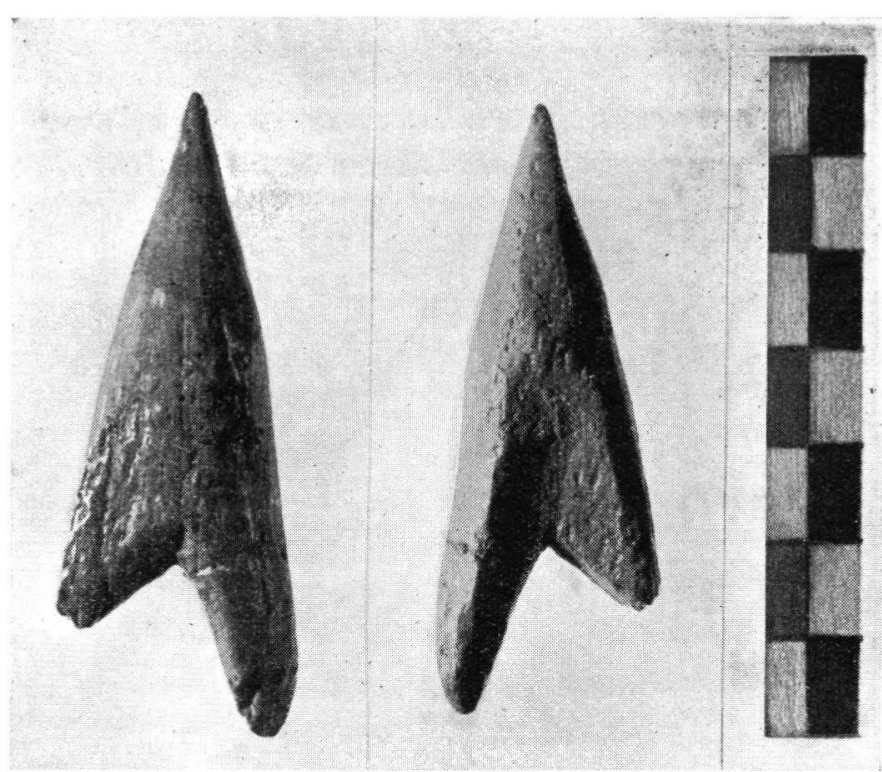

Abb. 19. Kleine Knochenspitze mit Flügeln [Ldsmus. Brschw.] nat. Gr.

derartige Rippendolche angefertigt sein, sodaß aus dem Platz der Grabung zehn einwandfreie Rippenspitzen gefunden werden konnten.

Aus der Fundstelle, allerdings aus nicht gesicherter Lagerung, stammt schließlich eine kleine $6,5 \mathrm{~cm}$ lange $\mathrm{Kn}$ och enspitze $\mathrm{mit} F \mathrm{Füg}$ eln (Abb. 19), die nach Feststellung von Dr. KLEINSchmidt ebenfalls aus Rippenknochen (vom Mammut ?) gefertigt worden ist. Diese sorgfältig geschnitzte Spitze, die auf einer Seite eingedellt ist und außerordentlich spitz zuläuft, könnte, mit Tiersehnen befestigt, vorn auf einer Holzlanze oder einem Holzspeer gesessen haben. Sie ist wohl die älteste Widerhakenspitze des Paläolithikums. Der Verfasser wäre für die Angabe von Parallelen für diese Knochenspitze und auch für die „Rippendolche“ sehr dankbar. Im übrigen können unter dem reichlichen Knochenmaterial der Fundstelle durchaus noch weitere Knochenbearbeitungen entdeckt werden.

Was den Menschen betrifft, den wir mangels direkter Funde als Träger dieser Kultur erschließen müssen, so ist die Frage zu stellen, ob wirklich nur der $\mathrm{Neandertaler}$ infrage kommt, der nach der bisherigen Anschauung Träger der Moustérien-Kulturen gewesen ist, oder ob man nicht auf Grund der fortschrittlichen Erscheinungen, insbesondere auch in der Knochenbearbeitung, annehmen könnte, daß wir hier „Prä-s a piens"-Formen (nach Heberer 1951) bzw. "Proto-homo- s a piens"-Formen (nach G. Asmus 1951) als Träger der Kultur von Salzgitter-Lebenstedt vor uns haben. Das wird einstweilen noch nicht entschieden werden können.

Angeführtes Schriftum:

Asmus, G.: Zur Stellung des Neandertalers in der Menschheitsgeschichte. - Eiszeitalter und Gegenwart 1, 1951.

Bohmers, A.: Die Mauerner Höhlen und ihre Bedeutung für die Einteilung der Altsteinzeit. - Bericht über die Kieler Tagung 1939. Neumünster 1944. - Die Höhlen von Mauern, Teil I. Kulturgeschichte der altsteinzeitlichen Besiedlung. - Palaeohistoria, herausgeg. von A. E. van Giffen, 1, 1951. 
Freund, G.: Die Blattspitzen des Paläolithikums in Europa. Bonn 1952.

Grahmann, R.: Urgeschichte der Menschheit. Stuttgart 1952.

Hamm, F.: Über die eiszeitlichen Ablagerungen im Leinetal.... in: K. H. JACoBFriesen 1949.

Heberer, G.: Das Präsapiens-Problem. 1951.

JACob-Friesen, K. H.: Die Altsteinzeitfunde aus dem Leinetal bei Hannover. Hildesheim 1949.

Kahrs, E.: Paläolithische Funde aus dem Diluvium des Emschertales. - Prähist. Zeitschr. 16, 1925.

Obermaier, H.: Moustérien, in: M. Ebert, Reallexikon der Vorgeschichte Bd. 8. 1927.

Wetzel, R.: Die Faustkeilfunde der Grabung Bocksteinschmiede. - Bericht über die Kieler Tagung 1939. Neumünster 1944.

Woldstedt, P.: Norddeutschland u. angrenzende Gebiete im Eiszeitalter. Stuttgart 1950.

ZотZ, L. F.: Zum gegenwärtigen Stand der Altsteinzeitforschung in Deutschland. Quartär 1. 1938. — Altsteinzeitkunde Mitteleuropas. Stuttgart 1951.

Manuskr. eingeg. 31. 3. 1953.

Anschr. d. Verf.: Dr. A. Tode, Braunschweig, Landesmuseum für Geschichte und Volkstum, Mönchstraße 1. 


\title{
Anhang: Geomikrobiologische Untersuchungen II. Bakteriologische Untersuchungen an Sedimenten aus der paläolithischen Grabung in Salzgitter-Lebenstedt
}

\author{
(Adelheid M üller und W. S chwar tz)
}

Nachdem das Landesmuseum Braunschweig etwa ein Vierteljahr mit der Freilegung der palaeolithischen Fundstelle in den glazialen Ablagerungen von Lebenstedt beschäftigt gewesen war, hatten wir durch das freundliche Entgegenkommen von Herrn Dr. ToDE Gelegenheit, die durch einen glücklichen $\mathrm{Zu}-$ fall freigelegten Schichten in die in unserem Laboratorium laufenden geomikrobiologischen Untersuchungen einzubeziehen. Es handelte sich darum, festzustellen, ob und gegebenenfalls in welcher Menge die glazialen Sedimente, die ursprünglich etwa $6 \mathrm{~m}$ unter der heutigen Bodenoberfläche gelegen waren, lebende Mikroorganismen führten und ob sich in Beziehung $\mathrm{zu}$ den eingeschlossenen palaeolithischen Resten irgendwelche Besonderheiten in den mikrobiologischen Verhältnissen nachweisen ließen.

Wir besuchten die Fundstelle am 19. 6. 52 zu einem Zeitpunkt, da die Arbeit des Landesmuseums dort nahezu abgeschlossen war. In der großen neben dem Pumpenhaus und der im Bau befindlichen Kläranlage gelegenen Ausschachtung wurde nur noch in der NW-Ecke gearbeitet in einer kleinen Grube von etwa 5,30 $\mathrm{m}$ Tiefe und einer Länge und Breite von je etwa 5--6 m. In dieser Grube fanden sich palaeolithische Reste nur in ihrem südöstlichen Teil in sandig-kiesigen Ablagerungen, die sorgfätig in jeweils etwa $10 \mathrm{~cm}$ dicken Schichten abgetragen wurden, wobei die Bergung der eingeschlossenen Knochen und sonstigen Reste durch die Mitarbeiter des Landesmuseums erfolgte. Im Hinblick auf den kurz bevorstehenden Abschluß der Grabung wurden täglich bis zu 5 Schichten abgetragen, ein Umstand der für unsere Untersuchungen als günstig zu bezeichnen war, da durch den schnellen Vortrieb die Gefahr einer Infektion, d. h. einer Einwanderung von Mikroorganismen in die Ablagerungen von oben her weitgehend herabgesetzt war. Die Sohle, die wir bei der Entnahme unserer Proben vorfanden, konnte wohl als unbeeinflußt von den Grabungsarbeiten angesehen werden.

Zur Entnahme von Proben standen uns einerseits die sandig-kiesigen, nährstoffarmen, glazialen Ablagerungen in der NW-Ecke der erwähnten Grube zur Verfügung, die frei von sichtbaren organischen Resten waren, andererseits im SO-Teil die Abschnitte mit eingeschlossenen palaeolithischen Resten. Hier wechselten bräunlich verfärbte humose Partien, wohl letzte Anzeichen völlig zersetzter organischer Substanzen (Fleisch, Jagdabfälle, Pflanzenreste) mit unveränderten Partien ab. Auch um die gut erhaltenen Knochen hatte sich das Sediment in einer mehr oder weniger breiten Zone bräunlich-humos verändert. Unsere Aufgabe bestand nun darin zu untersuchen, ob sich die angedeuteten lokalen Unterschiede in der chemischen Beschaffenheit des Sedimentes irgendwie auf Art und Menge der etwa vorhandenen Mikroorganismen ausgewirkt hatten. $\mathrm{Zu}$ diesem Zweck entnahmen wir am Spätnachmittag des 19. 6. 52 verschiedene Proben: drei Proben aus der humosen Zone in der Nachbarschaft eines Knochens, wobei getrennte Proben aus der Region über, neben und unter dem Knochen eingesammelt wurden und zwei Proben aus dem reinen sandig-kiesigen 
Sediment, Die Entnahmestellen waren etwa $4 \mathrm{~m}$ voneinander entfernt. Es wurde ferner ein Knochenrest, das Stück einer Rippe, geborgen. Die Probenahme erfolgte unter aseptischen Bedingungen: Von der gerade freigelegten frischen Oberfläche trugen wir mit sterilen Instrumenten (Spateln) an den vorgesehenen Stellen nach Abdecken der Umgebung mit sterilen Tüchern nochmals mehrere cm $\mathrm{ab}$, wobei die Rippe sichtbar wurde, und füllten erst dann mit frischen Instrumenten die sterilen Probegefäße. Die Rippe wurde mit sterilen Pinzetten herausgehoben und in mehrere Lagen von sterilen Tüchern und Papier verpackt. Die bakteriologische Untersuchung erfolgte in unserem Laboratorium am Tag nach Entnahme der Proben.

Keimgehaltsbestimmungen wurden nach dem Koch'schen Plattenverfahren durchgeführt mit Aussaatmengen zwischen 1 und 0,01 g Sediment nach sorgfältigem Ausschütteln abgewogener Mengen in sterilem Wasser. Die Bestimmung wurde in zwei parallelen Reihen durchgeführt, einmal mit Fleischbouillonagar und Würzeagar von normaler, in bakteriologischen Laboratorien üblicher Konzentration, ferner mit den gleichen mit Leitungswasseragar im Verhältnis $1: 2$ verdünnten Medien. Die Kulturen standen 1 Woche bei $30^{\circ} \mathrm{C} \mathrm{im}$ Brutschrank und wurden dann ausgezählt und nochmals einige Tage beobachtet. Es zeigte sich, daß Pilze überhaupt nicht zur Entwicklung kamen; die Bakterienzahlen waren in allen Fällen auf dem mit zwei Teilen Wasseragar verdünnten Fleischmedium höher als auf FBAg normaler Konzentration, eine Tatsache, die wir bereits früher bei ähnlichen Untersuchungen beobachtet hatten. Die Keimzahlen sind in Tab. 1 zusammengestellt, wobei wir die höheren Zahlen des verdünnten Fleischnährbodens zugrunde gelegt haben. Vergleicht man die Zahlen miteinander, so fällt auf, daß die Proben der ersten Gruppe $(1 \mathrm{a}-\mathrm{c})$ be-

Tab. 1. Ergebnis der Keingehalts-Bestimmungen

\section{Beschaffenheit der Proben}

1. Bräunlich verfärbtes sandig-kiesiges Sediment mit humosen Resten
a) über
b) unter
c) neben
eingeschlossenen Knochenresten

2. Sandig-kiesiges Sediment ohne organische Reste

a) erste Probe

b) zweite Probe

3. Reste aus dem Inneren einer Rippe
Keimzahlen (aerobe Bakterien je $g$ der feuchten Probe)

trächtlich höhere Keimzahlen aufweisen als die Vergleichsproben $(2 a, b)$; es stehen sich Werte mit einer Differenz von fast 2 Zehnerpotenzen in den beiden Gruppen gegenüber. Die Keimzahl aus dem Mark der Rippe lag nahe bei Gruppe (2); Reste aus dem Inneren angeschlagener Röhrenknochen, die hier nicht erwähnt sind, verhielten sich ebenso. Das gleiche Verhalten zeigten schließlich auch die Anaerobier, bei denen bei Kultur in hoher Schicht im verdünnten FBAg-Medium die Keimzahlen bei (1) um ein Vielfaches höher waren als bei (2).

Der Nachweis spezifis cher Keime erstreckte sich auf desulfurizierende Bakterien der Gattung Desulfovibrio, deren Vertreter uns wiederholt bei geomikrobiologischen Untersuchungen begegnet sind ${ }^{1}$ ). Desulfurizierer entwickeln sich unter anaeroben Bedingungen in Substraten, die Sulfate enthalten, da ihr Stoffwechsel auf die Verwertung des Sauerstoffs der Sulfate einge-

1) Desulfovibrio desulfuricans BeIJERINCK in Erdböden, Schlamm, Süßwasser, $D$. aestuarii VAN DELDEN in Meerwasser, marinem Schlamm, Olwasser; Vibrio thermodesulfuricans ELION = Sporovibrio desulfuricans STARKEY in Sedimenten, Erdölprodukten. 
stellt ist. Sämtliche Proben wurden den von Stapkey (1938) für diese Bakterien angegebenen Kulturbedingungen unterworfen: Kultur in Glasstopfenflaschen, die bis zum Stopfen mit einer Nährlösung folgender Zusammensetzung gefüllt waren: $\mathrm{K}_{2} \mathrm{HPO}_{4}$ 0,5 g, $\mathrm{NH}_{4} \mathrm{Cl} 1,0 \mathrm{~g}, \mathrm{Na}_{2} \mathrm{SO}_{4} 1,0 \mathrm{~g}, \mathrm{MgSO}_{4}$. $7 \mathrm{aq} 2,0 \mathrm{~g}, \mathrm{Ca} \mathrm{Cl}_{2} .2 \mathrm{aq}$ $0,1 \mathrm{~g}$, Natriumlakat 3,5 g, Mohrsches Salz 0,01 g, Leitungswasser $1000 \mathrm{ccm}$; Kulturtemperatur 30 und $55^{\circ} \mathrm{C}$.

Es traten zwar bei $30^{\circ} \mathrm{C}$ in allen Fällen bakteriell bedingte Trübungen und Hautbildungen auf, da die Nährlösung nach STARKEy auch für andere anspruchslose Bakterien Entwicklungsmöglichkeiten bietet, - Desulfurikation mit Schwefelwasserstoff-Bildung und Fällung von schwarzem Eisensulfid zeigte sich jedoch nur bei den Proben $1 b$ und $1 c$ aus der humosen Zone unter und neben dem Knochenrest. Die mikroskopische Kontrolle ergab in beiden Fällen das für Desulfovibrio typische Bild eines pleomorphen Gemisches von Spirillen, Vibrionen und wenig gekrümmten Stäbchen. Sporen waren nicht vorhanden. Der Stamm ließ sich in Subkulturen weiterzüchten. Thermophile Bakterien, insbesondere thermophile Desulfurizierer, kamen im Starkey-Medium nicht zur Entwicklung. Die bei $55^{\circ} \mathrm{C}$ angesetzten Kulturen blieben während einer Beobachtungsdauer von 10 Wochen steril.

Der Umstand, daß in einem engen Bereich von nur $4 \mathrm{~m}$ seitlichem Abstand so auffällige Unterschiede im Vorhandensein einer charakteristischen Gattung vorhanden waren, veranlaßte uns, nach den Ursachen zu suchen und zu prüfen, ob sich etwa neben dem sichtbaren Unterschiede in der humosen bzw. rein sandig-kiesigen Beschaffenheit auch Unterschiede in der Wasserstoffionen-Konzentration, im Redoxpotential oder im Sulfatgehalt nachweisen ließen. Die Ergebnisse der hierzu ausgeführten Untersuchungen sind zusammen mit dem bakteriologischen Resultat in Tab. 2 darstellt. Die $\mathrm{p}_{\mathrm{H}}$-Werte wurden mit dem Jonometer der Firma Lautenschläger an wässrigen Auszügen (10 g Probema-

Tab. 2. Auftreten der desulfurizierenden Bakterien

\begin{tabular}{|c|c|c|c|c|c|}
\hline \multirow[t]{2}{*}{ Probe } & \multicolumn{2}{|c|}{ Desulfurikation bei } & \multirow[t]{2}{*}{$\mathrm{p}_{\mathrm{H}}$} & \multirow[t]{2}{*}{$\mathrm{r}_{\mathrm{H}}$} & \multirow[t]{2}{*}{ Sulfatgehal } \\
\hline & $30^{\circ} \mathrm{C}$ & $55^{\circ} \mathrm{C}$ & & & \\
\hline $1 \mathrm{a}$ & - & - & 7,56 & 18 & Spur \\
\hline $1 \mathrm{~b}$ & + & - & 6,16 & 17 & $1,24^{\circ} / 0$ \\
\hline $1 \mathrm{c}$ & + & - & 6,00 & 17,5 & $1,25 \%$ \\
\hline $2 a$ & - & - & 7,45 & 20 & - \\
\hline $2 \mathrm{~b}$ & - & - & 7,50 & 20 & - \\
\hline 3 & - & - & 7,24 & 20 & Spur \\
\hline
\end{tabular}

terial/ $100 \mathrm{ccm}$ dest. Wasser) gemessen und die $\mathrm{r}_{\mathrm{H}}$-Werte mit Hilfe der Indikatoren-Reihe der Chemischen Fabrik Merck kolorimetrisch bestimmt. Die SufatWerte wurden nach dem Trocknen der Proben bei $105^{\circ} \mathrm{C}$ titrimetrisch ermittelt.

Der Vergleich zeigt, daß tatsächlich die beiden positiven Proben mit desulfurizierenden Bakterien in allen Daten von den übrigen Proben abweichen: Nur bei ihnen liegen die $\mathrm{p}_{\mathbf{H}}$-Werte im schwach sauren Bereich gegenüber alkalischem $\mathrm{p}_{\mathrm{H}}$ bei den übrigen Proben; nur sie enthalten quantitativ nachweisbare Sulfatmengen, und ihr Redox-Potential zeigt die niedrigsten Werte.

Diskussion der Ergebnisse. Die Ansicht, daß die überaus hohen Keimzahlen, die man in Böden nahe der Erdoberfläche antrifft, mit zunehmender Tiefe sehr schnell abnehmen und schießlich verschwinden und daß unverwitterte Gesteine keimfrei sind, läßt sich für Sedimentgesteine nicht mehr aufrecht erhalten, nachdem in den letzten 20 Jahren immer wieder mit einwandfreier Methodik vor allem lebende Bakterien noch bis zu erheblichen Tiefen nachgewiesen werden konnten. Allerdings ändern sich in tieferen Schichten 
Individuenzahl und Artenbestand grundlegend, und es bleiben schließlich von dem kaum zu überblickenden Artengemisch aus Bakterien, Actinomyceten, Pilzen und anderen Mikroorganismen nur noch wenige Arten von Bakterien übrig. Sie finden sich in Sedimentgesteinen in geringer Zahl und offenbar in unregelmäßiger Verteilung. Wir dürfen sie wohl als die autochthonen Bewohner dieser Standorte bezeichnen. Das allmähliche Zurückbleiben allochthoner Elemente in horizontaler und vertikaler Richtung haben wir vor kurzem an postglazialen Sedimenten in Wallensen am Hils verfolgt (A. Müller \& W. Schwartz 1952).

Beim Nachweis einer autochthonen Besiedelung erhebt sich bei geomikrobiologischen Untersuchungen immer wieder die Frage nach der Herkunft dieser Keime, und immer wieder stehen sich mindestens zwei Alternativen gegenüber: Die Möglichkeit einer Ableitung von der Bakterienflora, die zur Zeit der Ablagerung des Sedimentes bestanden hat, - das würde also heute das Vorhandensein echter Relikte bedeuten, - und die Möglichkeit einer späteren, jedoch vor der Zeit der Probenahme liegenden und von dieser unabhängigen Einwanderung in das Sediment, ohne daß es bisher in irgendeinem Fall möglich gewesen wäre, eine der beiden Möglichkeiten mit Sicherheit auszuschließen.

Auch für unsere Untersuchungen in Lebenstedt lautet die Frage, ob die heute angetroffenen Keime, besonders die Desulfurizierer, in ununterbrochener Folge auf das Palaeolithikum zurückgehen und ihre Vorfahren damals in den oberflächennahen Bodenschichten und den Abfallhaufen palaeolithischer Jäger und Nomaden lebten. Da die Schichten in dem fraglichen Bereich unter dem Grundwasserspiegel lagen, käme als zweite Möglichkeit eine Ansiedelung aus dem Grundwasserstrom in Frage, die wiederholt erfolgt und wesentlich jüngeren Datums sein könnte. Eine örtliche Sonderung je nach den angebotenen Lebensbedingungen, wie wir sie bei den Desulfurizierern beobachtet haben, wäre auch in diesem Fall ohne weiteres möglich. Tatsächlich können reine Grundwässer, in denen sich je ccm nur vereinzelte, auf den gewöhnlichen Nährböden wachsende Keime nachweisen lassen, eine verhältnismäßig hohe Zahl äußerst anspruchsloser Bakterien, offenbar autochthone Formen, mitführen ${ }^{2}$ ), die auf nährstoffreichen Nährböden entweder garnicht oder wesentlich schlechter als auf armen Substraten wachsen. Die für eine Bodenbedeckung von etwa $6 \mathrm{~m}$ auffällig hohen Keimzahlen in den sandig-kiesigen Ablagerungen der Proben (2) scheinen uns eher für die Herkunft der Keime aus dem Grundwasser $\mathrm{zu}$ sprechen.

$\mathrm{Z} u \mathrm{~s}$ a m m e $\mathrm{n}$ a s s u $\mathrm{g}$. Die Untersuchungen haben gezeigt, daß innerhalb der sandig-kiesigen glazialen Sedimente von Lebenstedt die Gehalte an aerob und anaerob kultivierbaren Bakterien Unterschiede aufweisen; sie sind höher, wenn die Proben von Stellen stammen, die palaeoltihische Reste enthalten. Desulfurizierende Bakterien waren nur an diesen Stellen nachweisbar. Noch heute können also an vorgeschichtlichen Fundstellen feine Unterschiede in der chemischen Beschaffenheit in Bezug auf die Anwesenheit organischer oder anorganischer Bestandteile vorhanden sein, die sich in den bakteriologischen Verhältnissen zu erkennen geben, gleichviel, ob es sich dabei um Bakterien handelt, die aus der vorgeschichtlichen Periode selbst, hier aus dem Palaeolithikum, stammen oder um Arten, die sich, z. B. aus dem Grundwasser stammend, an derartigen Stellen bevorzugt angesiedelt haben. Erweiterung und Ausdehnung derartiger Untersuchungen auf andere Fundstellen wäre wünschenswert, um festzustellen, ob allgemein gültige Gesetzmäßigkeiten zugrunde liegen.

2) Nach noch unveröffentlichten Untersuchungen von N. WoLlers im Laboratorium Börssum der Reichswerke Salzgitter. 


\section{Literatur}

Müller, Adelheid \& W. Schwartz: Geomikrobiologische Untersuchungen I. Die mikrobiologischen Verhältnisse in der spät- und postglazialen Sedimentfolge von Wallensen. - Geol. Jahrb. 67, S. 195-208. Hannover 1952.

StARKEY, R. L.: A study of spore formation and other morphological characteristics of Vibrio desulfuricans. - Arch. f. Mikrobiol. 9, S. 268-304. 1938.

Ms. eingeg.: 3. 11. 1952.

Anschr. der Verf.: Dr. Adelheid Müller und Prof. Dr. W. Schwartz, Institut für Mikrobiologie, (20a) Mahlum über Derneburg 